Linköping University Medical Dissertations

No. 1616

\title{
Impact of Pain and Evaluation of Education and Self-Care in Patients with Head and Neck Cancer
}

\author{
Anne Söderlund Schaller
}

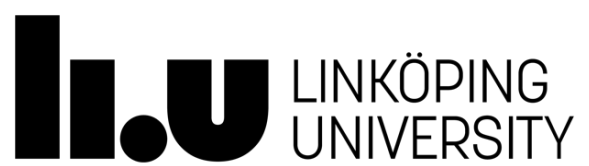

Department of Medical and Health Sciences

Faculty of Health Sciences, Linköping University

SE-581 83 Linköping, Sweden

Linköping 2018 
The cover illustration was created in http://www.tagxedo.com and designed by Anne Söderlund Schaller.

Printed in Sweden by LiU-Tryck, Linköping, Sweden, 2018

ISBN 978-91-7685-331-3

ISSN 0345-0082

Copyright $\odot$ Anne Söderlund Schaller 
To the memory of my loving grandma, Kerstin Söderlund I take your dreams seriously 

"It burns on the tongue and it stings in the throat and ... yes, burns in the whole mouth. It's like a sea of fire in the mouth"

Quoted from one of the interviewed participants 



\section{CONTENTS}

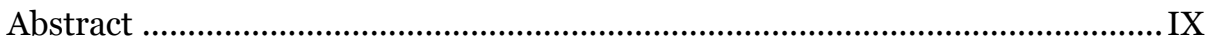

Svensk Sammanfattning ............................................................................

List of Papers .................................................................................................. XIII

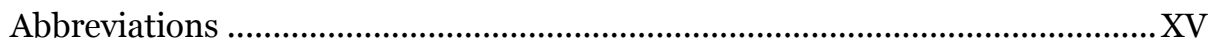

Part I: Comprehensive Thesis Summary ……………………………….... 1

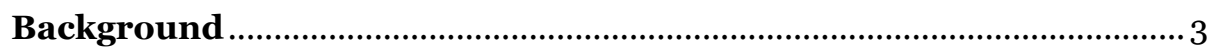

Patients with Head and Neck Cancer ............................................................ 3

Prevalence, Prognosis and Gender Distribution of Patients with Head and

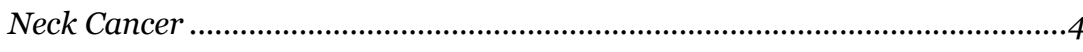

Overall Situation for Patients with Head and Neck Cancer ............................. 5

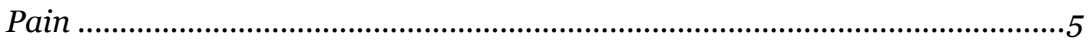

The Biopsychosocial Model and the Concept of Total Pain .............................. 8

Psychological Symptoms in Patients with Head and Neck Cancer ..................10

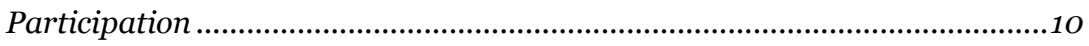

Quality of Life, Health Related Quality of Life and Health ............................12

Patient Education and Self-Care ....................................................................14

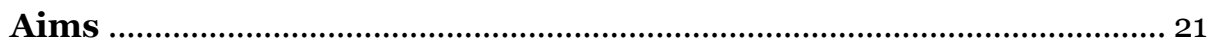

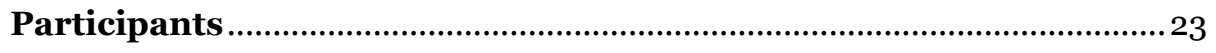

Paper I ...................................................................................... 23

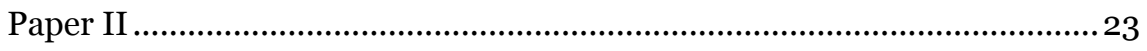

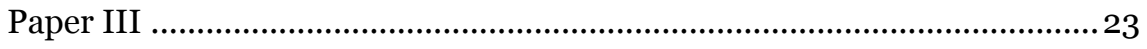

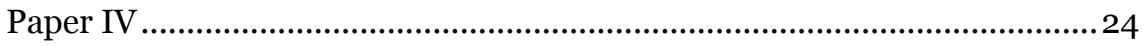

Methods

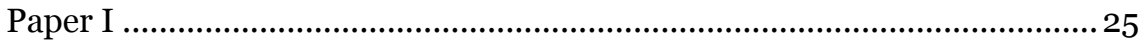

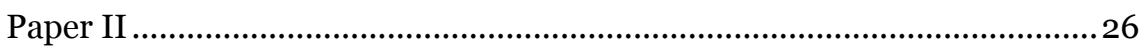

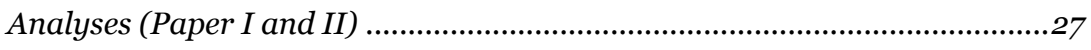

Paper III ........................................................................................... 28

Questionnaires ................................................................................... 28

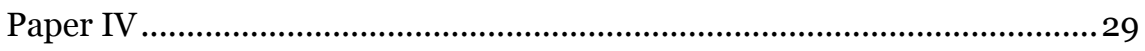




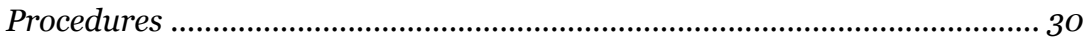

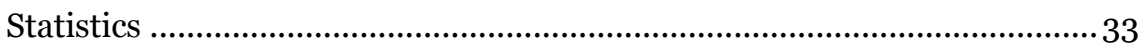

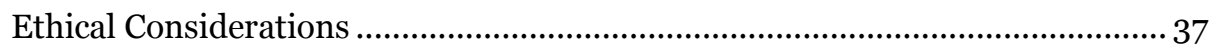

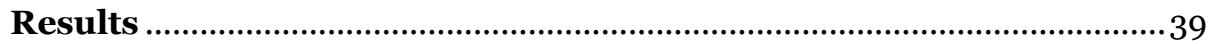

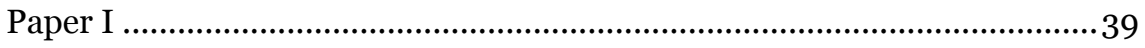

Description of the Categories ....................................................................... 40

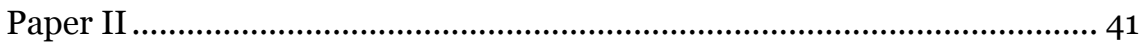

Description of the Categories .......................................................................42

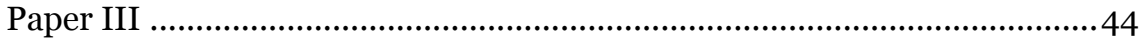

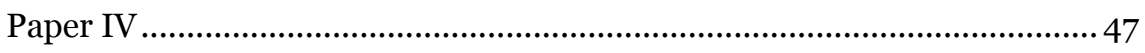

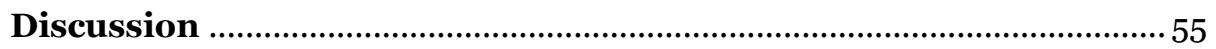

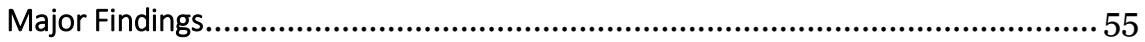

Meaning and Importance of Findings .....................................................56

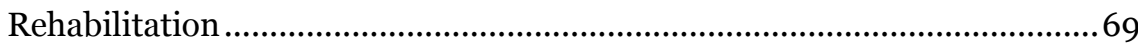

Methodological Considerations ..................................................................71

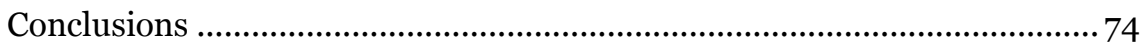

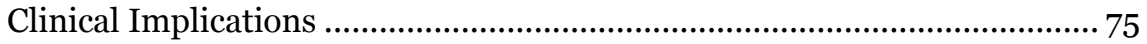

Future Research ....................................................................... 75

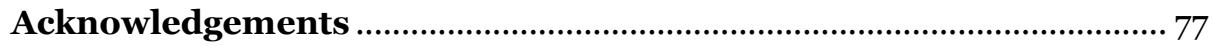

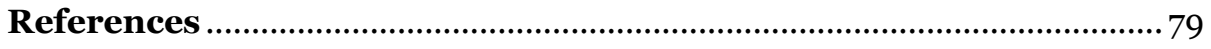

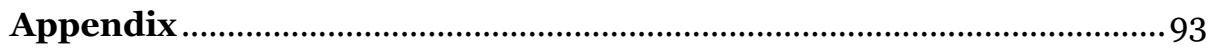

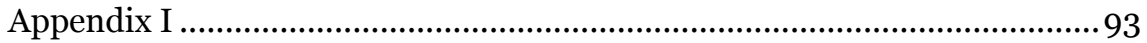

Text 1: Translation procedure of the questionnaire $B Q-I I$.............................93

Text 2: Policies of pharmacological treatment ...............................................93

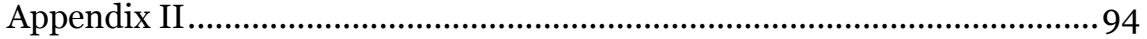

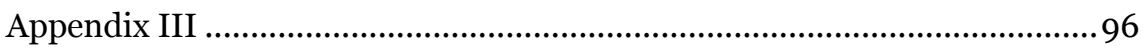

Written information on SC measures for the intervention group.................. 96

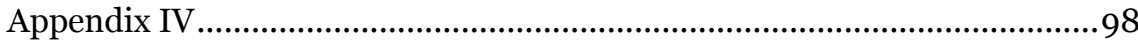

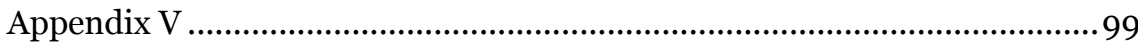

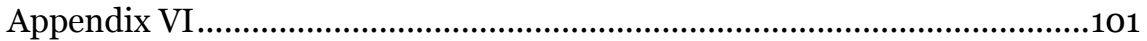

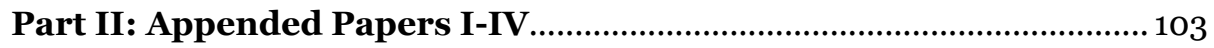




\section{ABSTRACT}

It is not unusual for patients with head and neck cancer (HNC) to suffer from both tumor and treatment-related pain that is difficult to alleviate despite individualized pharmacological treatment.

The presence of concomitant various dimensions of pain in patients during the often difficult period following radiotherapy (RT) has not been elucidated. Several aspects concerning the importance of relatives for $\mathrm{HNC}$ patients have been addressed. However, little attention has been given to how relatives perceive patients with HNC pain and it is important to further elucidate this sparsely studied topic. Knowledge about health-related quality of life (HR-QoL) in this patient group during early RT is limited and needs to be assessed in relation to diagnosis and treatment. Self-care (SC) refers to what patients do on their own to achieve, maintain, and promote optimal health and may help reduce pain for several pain conditions. The impact of patient education and SC on pain and other common HNC symptoms need further clarification.

The aims of this thesis were:

1) to describe experiences and perceptions of pain in patients with $\mathrm{HNC}$ shortly after RT

2) to describe how relatives perceived the patient's situation, especially concerning pain, and how they experienced their own situation

3) to identify factors that impact HR-QoL during early RT

4) to develop effective pain management strategies, maintain activities of daily living, and promote HR-QoL in patients with HNC undergoing RT using patient education and $\mathrm{SC}$ instruction.

In paper I patients with HNC described existential pain - expressed as fear of death, meaninglessness and guilt - already during and shortly after RT. Physical pain, psychological distress and social withdrawal played a significant role. Patients with HNC who were treated with RT should also proactively be offered treatment for the various dimensions of pain.

In paper II relatives described their mental stress in response to a challenging situation that required their active support to help ease the patient's difficult condition. The interviews with relatives also revealed a lack of personal knowledge and frustration over the inability to participate in patient care, as well as inadequate support from the healthcare system. Early interventions from the healthcare system on behalf of the relatives may be necessary to meet these needs. 
In Paper III regression models revealed that pain intensity and symptoms of depression adversely affected HR-QoL in patients with HNC during early RT. Customized prehabilitation programs aimed at preventing pain and symptoms of depression could help preserve good HR-QoL.

Paper IV assessed individual patient education and SC initiatives that resulted in a tendency for lower pain intensity during a portion of RT. One way to potentially enhance the benefits of education and SC could be to improve for example patient motivation and self-efficacy, as well as to optimize supportive efforts from caregivers.

In conclusion, by identifying factors that can impact HR-QoL and evaluating the effect of patient education and SC, this thesis contributes to knowledge on perceived pain and the patient's situation during and shortly after RT in patients with $\mathrm{HNC}$ and their relatives. This thesis points to the need for evaluation and further development of patient education and effective SC strategies for pain in patients with HNC undergoing RT, as well as for development and evaluation of support strategies for patients with pain and their families during and after RT.

Keywords: cancer pain; education; head and neck cancer; health related quality of life; pain; patient education; quality of life; relatives; self-care 


\section{SVENSK SAMMANFATTNING}

Det är inte ovanligt att patienter med öron-, näs- och halscancer (ÖNHC) drabbas av både tumör- och behandlingsrelaterad smärta som är svår att lindra trots individualiserad farmakologisk behandling. Förekomst av samtidiga olika dimensioner av smärta hos patienter under den ofta svåra tidsperioden efter strålbehandling har inte klarlagts. Flera viktiga aspekter av närståendes betydelse för patienter med ÖNHC är kända från tidigare forskning. Närståendes erfarenhet av patientens smärta är sparsamt studerad och viktig att belysa. Även kunskap om hälsorelaterad livskvalitet (HR-QoL) under initial fas av strålbehandling hos denna grupp av patienter är begränsad och bör utvärderas. Egenvård innebär de aktiviteter som patienter självständigt eller med stöd utför för att uppnå, upprätthålla och främja optimal hälsa och som eventuellt kan minska till exempel smärta. Effekten av patientutbildning och egenvård vid smärta och andra vanligt förekommande symtom hos patienter med ÖNHC behöver klarläggas.

Syftet med avhandlingen var:

1. Att beskriva upplevelser av smärta och hur smärta påverkar patienter med ÖNHC under och kort efter strålbehandling.

2. Att för närstående till patienter med ÖNHC beskriva patientens situation, särskilt avseende smärta och hur de närstående upplevde sin situation.

3. Att identifiera faktorer som påverkar HR-QoL i den initiala fasen av strålbehandling.

4. Att utveckla effektiva strategier för smärtlindring och bibehålla dagliga funktioner och HR-QoL hos patienter med ÖNHC vilka genomgår strålbehandling genom att införa och utvärdera patientutbildning och egenvård.

I studie I beskrev patienter med ÖNHC existentiell smärta i form av fruktan för döden, meningslöshet och skuld redan under och kort efter genomförd strålbehandling. Fysisk smärta, psykisk ohälsa och socialt undandragande var också betydande. Patienter med ÖNHC som genomgått strålbehandling bör aktivt erbjudas behandling mot olika dimensioner av smärta.

I studie II beskrev närstående upplevelse av psykiskt illabefinnande relaterat till en krävande situation i att stödja och lindra patientens svåra tillstånd. Även brist på 
egen kunskap och delaktighet i vården av patienten och brist på stöd från sjukvården framkom under intervjuerna med närstående. Tidiga insatser från sjukvården i syfte att möta dessa behov är nödvändiga.

I studie III framkom av regressionsmodeller att smärtintensitet och depressiva symptom påverkade HR-QoL negativt i initial fas av strålbehandling hos patienter med ÖNHC. Ett individuellt prehabiliteringsprogram i syfte att förhindra smärta och depressiva symptom, skulle kunna bibehålla god HR-QoL.

Resultatet i studie IV visar en tendens av lägre smärtintensitet i den grupp som fick individuell patientutbildning och individuell egenvård, dock fanns inga signifikanta skillnader mellan grupperna. En möjlighet att öka effekten av patientutbildning och egenvård skulle kunna vara att förbättra patienternas motivation, förbättra tillit till egen förmåga och att optimera vårdgivarnas stödjande insatser.

Sammanfattningsvis, avhandlingen ökar kunskapen om upplevd smärta och situationen under och kort efter strålbehandling för patienter med ÖNHC och deras närstående. Faktorer som kan påverka HR-QoL identifierades och effekten av patientutbildning och egenvård under strålbehandling utvärderades. Avhandlingen belyser vikten av fortsatt utveckling och utvärdering av effekt av patientutbildning och egenvård mot smärta samt av stöd till patienter med ÖNHC och smärta och deras närstående under och efter strålbehandling. 


\section{LIST OF PAPERS}

The present thesis is based on the following studies, which will be referred to in the text by their numerals:

Paper I: $\quad$ Schaller, A., Larsson, B., Lindblad M. and Liedberg G. M. Experiences of pain: a longitudinal, qualitative study of patients with head and neck cancer recently treated with radiotherapy. Pain Manag Nurs, 2015. 16 (3): $336-345$.

Paper II: Schaller, A., Liedberg G. M. and Larsson B. How relatives of patients with head and neck cancer experience pain, disease progression and treatment: a qualitative interview study. Eur J Oncol Nurs, 2014. 18 (4): 405-410.

Paper III: Schaller A, Dragioti E, Liedberg GM, Larsson B. Quality of life during early radiotherapy in patients with head and neck cancer and pain. Journal of pain research, 2017. 10: 1697-1704.

Paper IV: Schaller A, Dragioti E, Liedberg GM, Larsson B. Are patient education and self-care advantageous for patients with head and neck cancer? A feasibility study. Submitted.

Published articles have been reprinted with the permission of the copyright holders. 



\section{ABBREVIATIONS}

\begin{tabular}{|c|c|}
\hline ANOVA & Analysis of Variance \\
\hline BPI & Brief Pain Inventory \\
\hline BPS & The Biopsychosocial Model \\
\hline BQ-II & Barriers Questionnaire II \\
\hline $\mathrm{CS}$ & Cicely Saunders \\
\hline $\mathrm{DO}$ & Dorothea Orem \\
\hline ES & Education session \\
\hline EQ-5D & Euro QoL-5 Dimension Questionnaire \\
\hline EQ VAS & Euro Quality of Life Vertical Visual Analogue Scale \\
\hline GEE & Generalized Estimating Equations \\
\hline HAD & Hospital Anxiety and Depression scale \\
\hline $\mathrm{HNC}$ & Head and Neck Cancer \\
\hline HR-QoL & Health Related Quality of Life \\
\hline IASP & International Association for the Study of Pain \\
\hline ICC & Intra-Class Correlation \\
\hline NRS & Numeric Rating Scale \\
\hline $\mathrm{OM}$ & Oral Mucositis \\
\hline PCS & Pain Catastrophizing Scale \\
\hline $\mathrm{PRC}$ & Pain and Rehabilitation Centre \\
\hline QoL & Qulatiy of Life \\
\hline RT & Radiation Therapy \\
\hline $\mathrm{SC}$ & Self-Care \\
\hline $\mathrm{TP}$ & Total Pain \\
\hline TRN & Trained Research Nurse \\
\hline WF & Weekly Follow-up \\
\hline WHO & World Health Organization \\
\hline ÖNHC & Öron-, Näs- och Halscancer \\
\hline
\end{tabular}



Part I

Comprehensive Thesis Summary 



\section{BACKGROUND}

\section{Patients with Head and Neck Cancer}

Head and neck cancer (HNC) is an umbrella term for various types of cancers involving the lip, oral cavity, pharynx (including the oropharynx, nasopharynx and hypopharynx), larynx, paranasal sinuses, nasal cavity and salivary glands, as well as lymph node metastases of the neck from an unknown primary tumour sites [2]. The diagnoses of these various cancers differ greatly concerning incidence, treatment and prognosis [3]. Squamous cell carcinoma is the most common histological type of $\mathrm{HNC}$ and may originate from the mucous membranes of the oral cavity, pharynx, larynx, nose and sinuses. Also included in the HNC group are salivary gland malignancies, the most common histology being adenocarcinoma, and thyroid cancers, generally characterised by histology showing papillary cancer [4, 5].

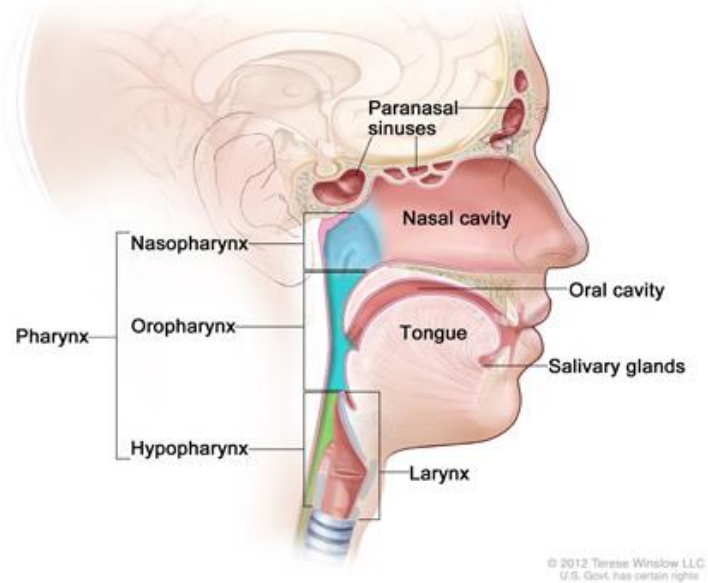

Figure 1. Head and neck cancer regions.

For the National Cancer Institute (C) 2012 Terese Winslow LLC, U.S. Govt. has certain rights. 


\section{THE MOST COMMON RISK FACTORS FOR HEAD AND NECK CANCER}

Tobacco, including smokeless tobacco and betel quid chewing, are important risk factors that underlie the majority of $\mathrm{HNC}$; 50-80\% of $\mathrm{HNC}$ are associated with tobacco exposure $[5,6]$. Smokers are at ten times the risk of HNC compared with non-smokers [5]. Alcohol consumption is yet another risk factor for HNC and may act synergistically with tobacco [5]. Daily alcohol consumption increases the risk of HNC compared with low alcohol consumption [7].

Human papilloma virus (HPV) is a risk factor for oropharyngeal cancer, especially tonsil cancer, and more than $50 \%$ of oropharyngeal cancers are associated with HPV $[4,5,8]$. Human papilloma virus is spread through sexual contact and infection is primarily associated with sexual behaviour, including many sex partners and oral sex $[5,9]$.

\section{TREATMENT OF HEAD AND NECK CANCER}

Treatment of HNC depends on location, type of tumour and tumour stage, as well as the patient's state of health. Treatment may include surgery, chemotherapy and radiotherapy (RT) in various combinations. Surgery combined with RT is the basic treatment for these tumours [10]. Radical surgery of HNC is often limited by the anatomical extent and location of the tumour $[4,10]$. Chemotherapy is used for both curative and palliative treatment of $\mathrm{HNC}$ and the goal is to achieve tumour control and to reduce its spread $[4,10]$. Radiotherapy is also aimed at controlling the tumour and reducing its spread [4]. A common RT fractionation is two gray per day, five days per week, for a total cumulative dose of 60-70 gray, resulting in five to seven weeks of treatment [10].

\section{Prevalence, Prognosis and Gender Distribution of Patients with Head and Neck Cancer}

Head and neck cancer is relatively common and affects more than 500,000 people, comprises about six per cent of all cancer diagnoses and causes 350,000 deaths annually worldwide [4, 11]. Five-year survival of patients with HNC varies between $23 \%$ and $88 \%$, depending on specific type [4].

Cancer of the oral cavity and oropharynx are the most common types of HNC, with more than 260,000 new cases and 128,000 deaths worldwide in 2008 [12]. In Sweden, about $60 \%$ of patients with HNC survive the disease [3]. Head and neck cancer is rare in Sweden and accounts for $2.3 \%$ of all cancer cases with more than 1400 reported cases in 2015. The two most common tumours seen in HNC are oral cancer and oropharyngeal cancer [3]. Head and neck cancer mainly affects males and the gender difference is most pronounced for larynx cancer, with $83 \%$ of cases in males and $17 \%$ in females. Oral cancer and salivary gland cancer occur almost equally among males (52\%) and females (48\%) [3]. The median age of onset for HNC in Sweden is 65 years for men and 68 years for women [3]. 


\section{Overall Situation for Patients with Head and Neck}

\section{Cancer}

It is well-known that patients with HNC suffer from impaired health related quality of life (HR-QoL) due to physical and mental signs and symptoms [13, 14]. Common disease and treatment-related symptoms include pain, swallowing difficulties, changes in appetite and taste, fatigue, decreased sense of well-being and depression. Symptoms related to RT may sometimes be so severe that hospitalisation may become necessary for problems such as severe pain that causes swallowing difficulties and leads to weight loss $[13,15,16]$.

\section{Pain}

The International Association for the Study of Pain (IASP) is a leading worldwide organisation for science, practice and education in the field of pain.

The widely used IASP definition of pain is:

'An unpleasant sensory and emotional experience associated with actual or potential tissue damage, or described in terms of such damage' [17].

Pain is a unique experience that is associated with actual or potential tissue damage. In this thesis, we acceded to the IASP definition of pain.

\section{PAIN PHYSIOLOGY}

When painful stimuli occur, the body receives signals through special pain receptors known as nociceptors [18-20]. Nociceptors are free nerve endings found in all somatic tissues and in many visceral tissues. Peripheral pain signals from the nociceptors are conducted through groups of fibres to the spinal cord [18, 20, 21]. These fibres include myelinated $\mathrm{A} \delta$ fibres that conduct the signals more rapidly than the unmyelinated $\mathrm{C}$ fibres. A $\delta$ fibres convey the initial sensation of pain, which is sharp, distinct and well-localised, while the $\mathrm{C}$ fibres convey pain signals with a diffuse, dull and burning sensation [18, 20, 21]. The nerve impulses ascend through the spinothalamic, spinoreticular and spinomesencephalic tracts of the spinal cord on their way to the thalamus. These nociceptive signals then activate areas within the brain such as the somatosensory cortex and pre-frontal cortex that process the sensory/discriminatory components of pain perception, and also activate the insula and anterior cingulate cortex, which process the affective and motivational components $[18,20,22]$.

The physiological mechanisms of pain also include the descending pain-inhibiting pathways, which have a supraspinal origin within the brain stem. As pain impulses are conducted, mainly via the spinothalamic tract on their way to the brain, areas such as the periaqueductal gray substance (PAG) and rostral ventromedial 
medulla (RVM) also become activated. The PAG and RVM belong to the descending pain-inhibiting pathways and play a key role in pain inhibition where they modulate endogenous opioids [23].

\section{NOCICEPTIVE AND NEUROPATHIC PAIN}

Nociceptive pain is a reaction to threatening or actual tissue damage and does not include nerve tissue. Nociceptive pain is often described as aching, tingling, cutting, pressing, throbbing, or pulsating. This pain arises through mechanical, chemical or thermal activation of nociceptors [20, 21].

Neuropathic pain involves damage to afferent fibers or to central pathways, or may entail diseases of the somatosensory nervous system. Neuropathic pain may be spontaneous and/or dependent on stimuli. The distribution of pain should correspond neuroanatomically to the affected nerve tissues. Both peripheral and central neuropathic pain are usually associated with sensory disturbances, such as a change in skin sensation. Typically, neuropathic pain has a burning or cutting character and may be experienced as lightening-like or occurring in sudden attacks [19].

\section{PERIPHERAL AND CENTRAL SENSITISATION}

According to the IASP, peripheral sensitisation entails an increased responsiveness and reduced threshold in peripheral nociceptive neurons in response to stimulation of their receptive fields [17]. Central sensitisation entails increased responsiveness of nociceptive neurons within the central nervous system to their normal or subthreshold afferent input [17, 20, 21].

The final perception of pain at any given moment is processed by various structures within the brain, sometimes referred to as the pain matrix. The peripheral situation and its associated nociceptive input must always be carefully considered, especially in patients with $\mathrm{HNC}$ whose nerve tissues and other tissues are in an activated state, as are peripheral and central sensitisation.

\section{PAIN IN PATIENTS WITH HEAD AND NECK CANCER}

Prevalence of pain among patients with $\mathrm{HNC}$ is high compared with patients with other types of cancer [24-26]. Pain prevalence, on active anticancer treatment, is about 50\% among patients with cancer in general and 70\% specifically among patients with HNC [24, 26]. Oral cancer and oropharyngeal cancer are the tumours most commonly associated with pain [27, Chapter 9]. Patients with HNC may experience both tumour-related pain and treatment-related pain [28].

\section{TUMOUR-RELATED PAIN}

Tumour-related pain may include both nociceptive and neuropathic mechanisms and is often a combination of both [29]. Nociceptive pain in cancer is usually the result of tissue damage due to tumour growth or to inflammation caused by the 
release of algogenic substances from the tumour [29]. Nociceptive pain is common and occurs in $70 \%$ of patients with advanced cancer [30]. Neuropathic pain can be caused by tumour infiltration resulting in injury or dysfunction in the nervous system and is common in cancer [29]. The occurrence of combined neuropathic and nociceptive pain in patients with cancer has been reported at 39\% [31]. Tumour-related pain in patients with HNC is common, since the affected tissues have a rich vascular and neural supply [32]. Injury caused by compression or infiltration of soft tissues such as mucosa, musculature and nerve tissue, as well as bone tissue, can cause pain via nociceptive, inflammatory and neuropathic pain mechanisms [33]. Tumour-related pain has been reported in approximately $70 \%$ of patients with $\mathrm{HNC}$ at the time of diagnosis, although less than four on a numeric scale of zero to ten [26, 33-35].

Basic analgesic treatment for tumour-related pain includes paracetamol, non-steroidal anti-inflammatories drug (NSAID) and opioids according to the World Health Organization (WHO) analgesic ladder [36]. Analgesics provide little or no pain relief for neuropathic pain. Instead, such pain can be treated with tricyclic antidepressants, the gabapentinoids (gabapentin or pregabalin) or other analgesic antidepressants (serotonin and noradrenaline reuptake inhibitors) [36].

\section{TREATMENT-RELATED PAIN IN PATIENTS WITH HEAD AND NECK CANCER; ORAL MUCOSITIS}

Patients with HNC who undergo RT and sometimes in combination with chemotherapy may, in addition to possible pain from the tumour area, experience pain due to radiation-induced mucositis $[10,37,38]$. Oral mucositis $(\mathrm{OM})$ is an inflammation of the oral and oropharyngeal mucous membrane resulting from the toxicity associated with RT and chemotherapy [39]. The pathophysiology has been elucidated in part as an inflammatory process in which both the mucosa and submucosa of the oral mucous membrane are affected [28, 39]. The pain mechanisms in mucositis entail both nociceptive and neuropathic pain components [33]. Up to $80 \%$ of patients with $\mathrm{HNC}$ report OM pain during their cancer treatment $[10,26,38,39]$. The onset of RT-induced mucositis is two to three weeks after treatment start. Initial symptoms are usually mild with erythema of the mucous membrane (mucositis grade 1), followed by areas of mucosal ulceration (mucositis grade 2) that continue to spread and penetrate deeper (mucositis grades 3 och 4) [40].

Previous studies have shown that adequate pain relief for patients with $\mathrm{HNC}$ who suffer from mucositis is difficult to achieve [26, 41]. Despite individualised pain management primarily with opioids, combined with anti-inflammatory analgesics with a local effect on mucositis and tumour pain, many patients continue to experience moderate to severe pain [33, 41, 42]. In addition to pain management using analgesics according to the WHO analgesic ladder and treatment for neuropathic pain [36], frequent oral hygiene entailing brushing teeth with an extra 
soft toothbrush as well as use of saliva substitutes with local anesthetics are recommended $[43,44]$.

\section{The Biopsychosocial Model and the Concept of Total Pain}

In this thesis we discuss two concepts of pain: the biopsychosocial model and the concept of total pain.

\section{BIOPSYCHOSOCIAL MODEL}

The biopsychosocial (BPS) model is a modern, scientifically formulated model that is commonly used in the assessment and treatment of pain. A biopsychosocial approach entails a multifaceted view of pain in which the perception of pain depends on peripheral signals, the emotional state of the individual and the general context. The BPS model stresses the complex interactions between the biological state and the psychosocial factors in relation to the patient's perception of pain and its consequences [45]. According to the BPS model, the experience of pain does not always correspond to nociception (activation of nociceptors in the nervous system), but is also influenced by psychosocial factors. These factors may include prior pain experiences, mood, expectations, beliefs, reinforcement, predicted consequences and sociocultural aspects $[45,46]$.

\section{THE CONCEPT OF TOTAL PAIN}

Cicely Saunders (CS) - physician, nurse and founder of the hospice movement introduced the concept of total pain (TP), which even today is of great significance to palliative care. The background underlying the TP and what it entails emerges from a compilation presenting some of CS' publications [47]. The compilation reveals how CS reviewed patient charts, conversed with patients and documented the results. With this approach, CS found that patients who described the perception of pain went beyond the usual physiological descriptors such as pain intensity, localisation, nociceptive or neuropathic pain. Based on these observations, CS hypothesised that the existential, physical, psychological and social perceptions of pain are inseparable. In other words, the various dimensions of perceived pain influence one another and generate the entirety of the patients' total pain experience (Figure 2) [47]. To understand CS' TP an understanding of the dimensions of the existential, physical, psychological and social pain experience is needed.

Cicely Saunders observed that the patient's anxiety, depression, fear, concern over losing one's family and the need to find meaning in life influenced the pain experience at the end of life [47]. According to CS, psychological discomfort and suffering were often partially misunderstood in clinical assessments and were therefore often difficult to treat [48]. When patients discussed their pain they may actually be referring to an existential perception of pain involving wrath or anger over religious beliefs, loss of faith, the meaning of life and fear of dying, as well as fear of the unknown [48]. The concept of existential pain is in common 
current use, but poorly defined. Consequently Swedish hospital chaplains, physicians in palliative care and pain specialists answered the question of how to define existential pain. The solution that emerged was that existential pain is used as a metaphor for suffering and focuses on problems concerning the meaning of life and fear of death, which can intensify the pain experience and decrease quality of life (QoL) regardless of whether or not physical pain is present [49]. Patients with existential perception of pain need support which should be provided by healthcare professionals who are able to listen and contribute to a dialogue on existential issues [50].

Psychological pain causes and is influenced by fear, anxiety and depression, while social pain is related to the patient's standing in the community and the cultural environment, as well as financial problems and impact on the family [47]. Painful experiences that follow after social exclusion or loss, loneliness and moral wounds may create social pain [51]. The alleviation of pain that does not arise as a consequence of harmful stimuli may require measures such as social cognitive therapy [52].

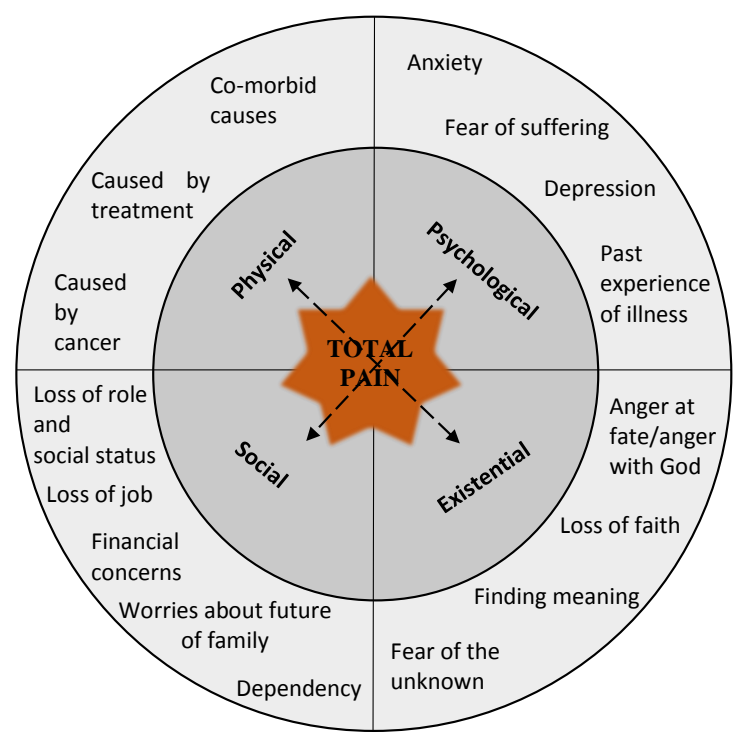

Figure 2. The concept of total pain is a composite of existential, physical, psychological and social perception of pain and strives to achieve a holistic view of the concept of pain. Modified and reproduced from [53] with permission.

How existential, physical, psychological and socially perceived pain affects patients with $\mathrm{HNC}$ has not previously been studied. A partial goal of this thesis is to increase knowledge regarding experiences and perceptions of pain in patients with HNC. 


\section{Psychological Symptoms in Patients with Head and Neck Can- cer}

Symptoms of anxiety and depression are commonly reported psychological factors that may adversely affect patients with HNC [54-56]. When combined with pain, symptoms of anxiety and depression have been shown to increase the severity of the pain experience $[57,58]$. Depressive symptoms in patients with HNC may be associated with advanced cancer, lifestyle factors such as loneliness, male gender, youth, low level of education and smoking [59]. In addition, patients with cancer commonly experience sleep disorders, which can further intensify psychological symptoms [60, 61].

Anxiety and depression have been reported to increase pain catastrophizing thinking such as obsessions and ruminations, leading to increased mental stress that influences the clinical picture. Another important aspect that has emerged is that catastrophic thinking can amplify the severity of the pain experience [57, 62]. Further, pain catastrophising thinking has been shown to contribute to increased fear of treatment failure, as well as to increased pain and depression in patients with HNC undergoing RT [57]. Anxiety and stress over possible recurrence of cancer have been shown to be common among patients with $\mathrm{HNC}$ who have recently been declared cancer-free following completion of treatment [63].

Insufficiently treated cancer pain may lead to negative perceptions of pain and may entail pain catastrophising experiences. Patients with HNC have potentially serious disease where catastrophising thoughts could conceivably affect psychological factors and pain already during early RT. Few studies have addressed the extent to which HNC patients undergoing cancer treatment may experience catastrophising thoughts [57]. Knowledge about catastrophising thoughts with an impact on psychological factors and pain needs to be expanded and systematically described for patients with HNC, which is the topic under study in this thesis.

\section{Participation}

Participation in the community through work and a social life is an important part of every person's existence and should be a central part of rehabilitation and a sign of normalcy and the feeling of being re-integrated into daily life. The inability to return to work following cancer treatment may lead to financial loss, lack of self-esteem and social isolation [64], also referred to as social pain [51].

\section{WORK AND SICK LEAVE}

Cancer diagnoses among working age individuals are on the rise in Sweden; more than 65,000 new cases of cancer were diagnosed in 2015, including about 20,000 patients aged 15-64 years [65]. A study of 598 patients with various cancer diagnoses who were gainfully employed at the time of diagnosis showed that $63 \% \mathrm{had}$ returned to work about 3 years later [66]. Considering the need for aggressive treatment and related severe symptoms, patients with $\mathrm{HNC}$ and lung cancer had 
the lowest probability of returning to work approximately 3 years after diagnosis [66]. At the time of diagnosis of $\mathrm{HNC}, 62 \%$ and $86 \%$, respectively, were of working age $[67,68]$. Psychosocial factors and physical symptoms were the most common underlying reasons for sick leave among patients with HNC [67-69]. The time required for return to work following treatment varied significantly depending on tumour stage and symptoms $[67,69]$. Median duration of sick leave for patients with HNC was 22 weeks $[67,69]$. One Swedish study reported that 32 of 66 participating patients with $\mathrm{HNC}$ had returned to work 12 months after diagnosis [68].

The healthcare system faces major challenges in meeting the rehabilitation needs of patients with cancer who suffer from multiple symptoms to be able to return them to work. Both physical and psychological factors appear to be important in order for HNC patients to be considered fit to return to work. The treatment process should therefore prepare patients of working age for their return to work.

\section{SOCIAL LIFE}

Access to an active social life has a positive influence on the ability to cope with cancer. The importance of being surrounded by family and the social support that family entails, has proven to be important for health, especially when suffering from severe illness [70]. Social support has also been shown to have a positive effect on QoL among patients with HNC [71].

\section{RELATIVES OF PATIENTS WITH HNC}

Social support and the impact of living with a partner have been shown to reduce the risk of negative changes in QoL among patients with HNC [72, 73]. The Swedish National Board of Health and Welfare defines close relatives as people with whom the patient has a close relationship, regardless of whether they are family members or close friends [74]. A family member is a person within the patient's immediate family or among the closest relatives [74].

When a patient is diagnosed with cancer there is a risk of negative impact on QoL for the patient, family members and relatives [75, 76]. Patients with $\mathrm{HNC}$ require extensive care and support and it can be difficult for relatives to fully meet this need [77]. An overview article of eleven observational studies showed that relatives often experience anxiety and depression when a patient (family member) suffers from HNC [78]. In addition, it has been reported that relatives may have to deal with an increased burden including lack of support from the family, financial problems and worsened QoL when a family member undergoes RT [79] and suffers from pain [8o]. Compared with the general population, it has been reported that relatives of patients with HNC experience higher levels of mental distress and lower levels of a sense of well-being [81].

A better understanding of the situation and needs of relatives may improve the situation for both relatives and the patient with HNC during RT. How relatives 
perceive and describe the patient's condition can supplement assessment of patient pain. Moreover, knowledge and experience of pain and pain management among relatives are crucial for treatment outcome in patients with HNC [70].

\section{Quality of Life, Health Related Quality of Life and Health}

Quality of life and health is a broad concept with several different definitions, though there are no generally accepted definitions.

The WHO describes QoL as: "individuals' perceptions of their position in life in the context of the culture and value systems in which they live and in relation to their goals, expectations, standards and concerns" [82]. According to another definition, QoL is different for different people and has different meanings depending on the area studied [83]. Quality of life includes a person's physical health, mental health, independence, and social relationships in interaction with the environment. According to this definition, one person might report a good QoL despite illness and symptoms, while another may experience poor QoL, despite absence of disease [83].

In health and medical services, QoL commonly refers to how physical and psychological symptoms affect the patient's life [83]. A consensus meeting in 1992 that addressed measurement of QoL in medicine determined that studies should report those elements of QoL that directly affect an individual's health. Such aspects, physical, psychological, social, emotional and role functioning, as well as general well-being, together comprise health-related quality of life (HR-QoL) [84]. Specific and detailed definition of HR-QoL vary from study to study [83]. However, according to the US Food and Drug Administration HR-QoL is "a multidomain concept that represents the patient's general perception of the effect of illness and treatment on physical, psychological, and social aspects of life" [85].

The WHO formulated a well-known definition of health: "a state of complete physical, mental and social well-being and not merely the absence of disease or infirmity". This definition has been revised several times and currently health is often described as a resource in daily life - not as the goal of life, but rather as a means to a good life [86]. Health is not necessarily essential to a good QoL, though subjectively perceived well-being is considered to contribute to a good QoL [87]. The author suggests that QoL is linked to the degree of happiness or unhappiness at a certain point in time. Factors affecting happiness are primarily hope, expectation and whether the individual has achieved balance between desire and reality [87].

\section{HEALTH RELATED QUALITY OF LIFE FOR PATIENTS WITH HEAD AND NECK CANCER}

It is well known that impaired HR-QoL often affected patients with HNC [55, 88]. Both the disease and the treatment impaired HR-QoL in patients with HNC during treatment, although most returned to baseline (BL) levels, usually within 12 months $[14,71]$. Pain and fatigue in particular were significant symptoms that 
negatively affected HR-QoL in patients with HNC, as does social withdrawal due to emotional distress $[13,55,89]$. One study has shown that HR-QoL in patients with $\mathrm{HNC}$ may be negatively impact during an early stage by RT due to conditions such as pain and difficulties eating [90].

This thesis will further explore whether pain and psychological factors such as catastrophising thoughts affect HR-QoL in patients with HNC.

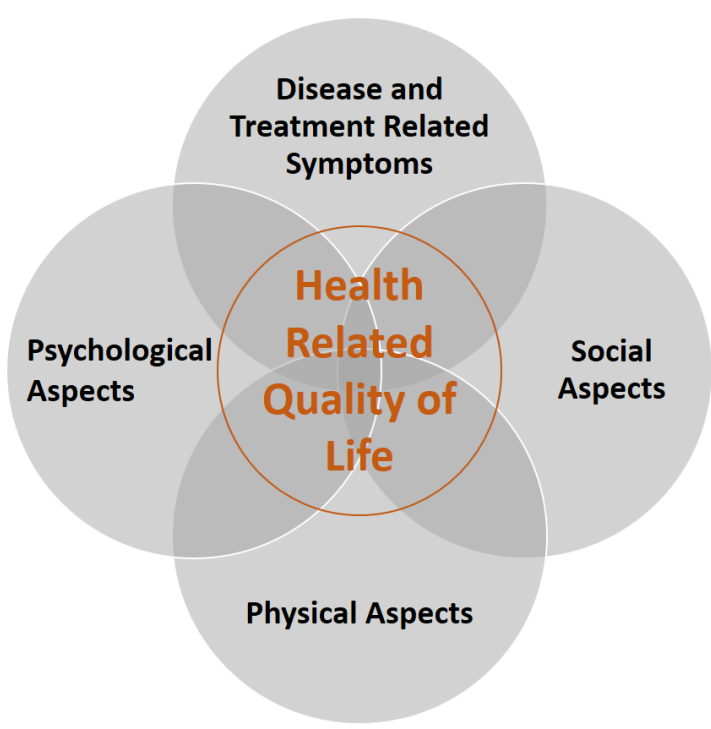

Figure 3. Overview of the Health Related Quality of Life in this thesis. 


\section{Patient Education and Self-Care}

\section{PATIENT EDUCATION}

Pain is often undertreated in cancer patients and one reason may be "barriers" that arise among patients and healthcare personnel resulting from inadequate knowledge about cancer-related pain and treatment [91, 92]. Such barriers may lead to nonadherence among cancer patients in taking prescribed pain medications due to fear of abuse, misunderstanding of doses, concerns about side effects and lack of knowledge about how the drug should be administered, any of which may result in insufficient pain relief [91, 93]. Another potential barrier arising in patients with cancer might be exercise-related depression and fatigue. Current reports conclude that the introduction of structured and repetitive exercise effectively reduces cancer-related fatigue [94, 95]. For patients with cancer, fatigue might be impacted through education concerning the potential benefits of physical activity and by encouraging exercise participation.

Several systematic review articles conclude that educating cancer patients about pain has been proven effective in helping to reduce pain intensity and pain interference [96-103]. However, other studies have found that educational initiatives for patients with cancer have not been effective for pain management [104, 105]. Similarly, a systematic review that included four studies found that patient education had no effect on QoL [101].

The scientific literature contains extensive suggestions on what to include in patient education regarding cancer pain and pain management $[97,106]$. Because of the heterogeneity of the studies, however, it is currently difficult to understand what interventions have an adequate effect on cancer patients regarding pain, psychological mood and QoL [96, 97, 99]. The educational principles may include customised education, coaching including communication between healthcare professionals and patients, coaching regarding patient empowerment and advice regarding on SC [96, 107].

Patient education has been shown to reduce symptoms of depression and anxiety and to improve QoL among cancer patients [99, 108]. Moreover, patient education that underscores the importance of exercise and relaxation has been shown to improve sleep disturbances among patients with cancer [109].

Patients with HNC are usually affected by a variety of physical and psychological symptoms, including pain that is often present before and during cancer treatment $[25,26,110]$. Pharmacological strategies were developed long ago to treat cancer-related pain $[36,111,112]$; despite such strategies, most patients with HNC experience limited pain relief [42]. 


\section{SELF-CARE}

Self-care (SC) is usually used synonymously in the literature with self-management, self-monitoring and symptom management [113]. Self-care can also be used as an umbrella concept for self-management, self-monitoring and symptom management [113, 114].

\section{The Self-Care Deficit Nursing Theory}

Dorothea Orem (DO) was active as a nurse in the 1950s and developed the selfcare deficit nursing theory, usually considered to be a grand nursing theory. A grand nursing theory is a comprehensive framework that prioritises perspectives on nursing and serves as a frame of reference [115]. The following description of DO's nursing theory is based on the sixth edition of her book Nursing: Concepts of Practice [1] with chapters contributed by Susan G. Taylor and Kathie McLaughlin Renpenning.

Dorothea Orem noted that healthy people usually take care of themselves and their daily needs and that it would be wrong to help healthy individuals with activities of daily living.

Moreover, to maintain health and well-being individuals affected by disease need to develop behavioural patterns through emotional and mental processing of their current situation. Dorothea Orem also observed that individuals who are encouraged to do SC developed high self-esteem and self-sufficiency. Self-care include observation and assessment of state of health, as well as seeking medical care, following prescribed medical treatment, handling potential adverse effects and taking decisions to carry out SC. Individuals also need to have help from the healthcare system (Orem et al., 2001).

The self-care deficit nursing theory includes sub-theories: theory of self-care, theory of self-care deficit and theory of nursing system (Figure 4).

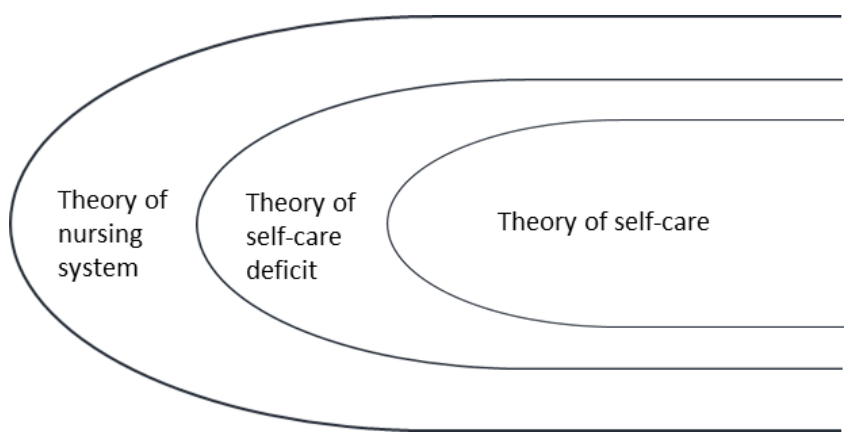

Figure 4. Sub-theories in the self-care deficit nursing theory. Modified and reproduced from [1] with permission. 


\section{Theory of Self-Care}

Dorothea Orem's theory on SC was first published in 1971 and defined SC as follows: "the practice of activities that individuals initiate and perform on their own behalf in maintaining life, health and well-being" [1]. Consequently, SC entails personal care aimed at achieving the best possible health and well-being.

The theory is based on the idea that physical, psychological, social and interpersonal interactions are components of individual health. The exercise of SC requires individuals to possess knowledge and understanding of the significance of the measures. Self-care can be viewed as goal-oriented actions carried out by the individual. Self-care is deliberately learned and exercised in order to continually meet the needs of the individual.

\section{Theory of Self-Care Deficit}

A self-care deficit occurs when individuals encounter a life situation in which they are unable to meet their SC needs. Self-care deficit may be due to lack of knowledge, inadequate self-awareness or impaired functional and cognitive ability.

Concepts underlying DO's theory on SC deficit include SC requisites, therapeutic $\mathrm{SC}$ demands, $\mathrm{SC}$ agency, and nursing agency. Individuals must recognise the SC requisites that are meaningful and necessary for their own function, developments and well-being. Therapeutic SC demands refer to the quantity and quality of individual SC needs. Self-care requisites must be met to promote normal life processes, normal function, development and wellness [1]. Self-care agency refers to the ability that meet SC demands. Self-care agency develops throughout life and such agency is dependent on state of health, education, life experiences, cultural factors and resources. Nursing agency refers to the knowledge and skills needed to exercise nursing care in cases where the individual's SC agency is limited. The mission of the nurse is to compensate for the inadequate resources of the patient by initiating and carrying out actions to help patients to meet their therapeutic SC demands.

Meanings of terms used to express the conceptual model of Orem's nursing system are summarized in Figure 5. 


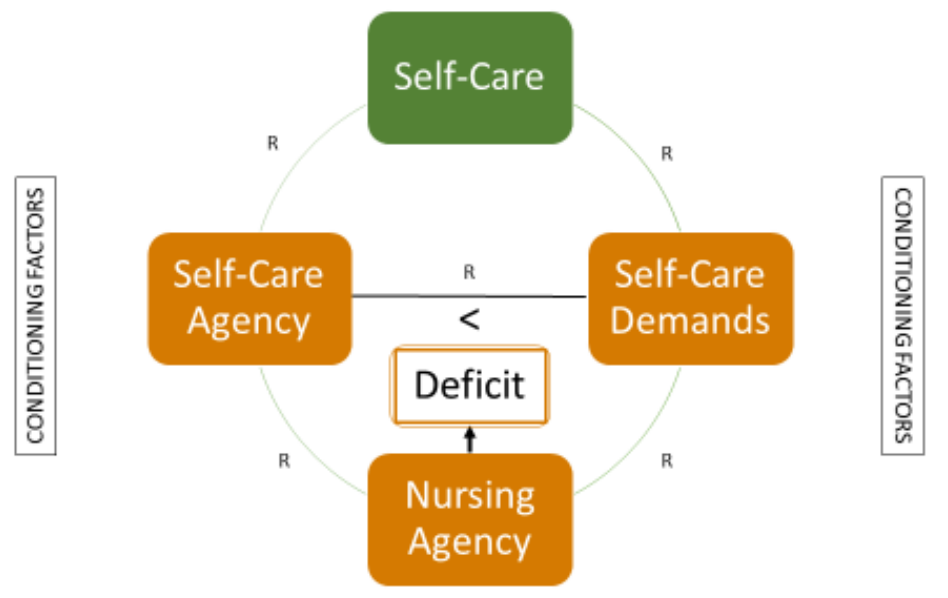

Figure 5. A conceptual framework for nursing. R, relationships; <, deficit relationship. Modified and reproduced from [1] with permission.

\section{Theory of Nursing System}

The theory of nursing system is based on three levels: wholly compensatory, partly compensatory, and supportive-educative nursing.

In the wholly compensatory nursing system the individual is unable to carry out the actions required for $\mathrm{SC}$ demands. In the partly compensatory nursing system, the nurse carries out those portions of SC that patients are unable to manage on their own. In the supportive-educative nursing system, the nurse plays a supportive and educative role. More specifically, the nurse supports patients in developing their ability to exercise SC.

The nurse chooses the nursing care option based on the extent of the patient's SC deficit and what is most likely to support the individual's SC agency and SC requisites. By providing support and advice, the nurse can encourage the individual to identify and practise SC based on personal needs [1].

Taken together, the sub-theories theory of self-care, theory of self-care deficit and theory of nursing system (Figure 4) form a whole and clarify that the individual's $\mathrm{SC}$ is a balance between the ability to practise $\mathrm{SC}$ and the requisites of SC. A selfcare deficit arises when there is an imbalance between $\mathrm{SC}$ requisites and when SC agency is insufficient to meet the requirements that the situation demands. The nurse adapts nursing care to the SC requisites and SC agency of the patient in order to achieve SC balance. 


\section{DEVELOPMENT OF THE CONCEPT OF SELF-CARE}

Dorothea Orem's theory of SC has been further developed and a number of definitions that have been modified to varying degrees are described in the literature. Although attempts have been made to reach a consensus definition of SC, to date none has been achieved [116].

One of the earliest definitions of SC is described by Levin, who introduced the concept of health promotion and explained the role of the individual in health care [117]. According to experts from six academic fields including medicine, nursing and psychology, SC is situation-specific, culturally influenced and involves the ability to take decisions and perform individual actions [118]. These actions are influenced by a variety of individual factors, including self-efficacy, control, knowledge, skills and values, that are individually addressed by the healthcare system [118]. In other words, the premise is that SC should be undertaken in cooperation with the healthcare system. Furthermore, SC on the individual level has been described as a continuum that ranges from complete independence in managing health to complete dependence on the healthcare system. Shared responsibility for SC means that healthcare personnel work together with the individual to cope with acute and chronic health conditions. Self-care in connection with major trauma and care that the patient is unable to manage independently is provided by the healthcare system $[114,119]$.

Self-care has been proposed as a broad concept based on nursing interventions such as supportive and educative activities aimed at promoting personal development and the ability to take responsibility for self-care requisites [113]. Selfcare could also be considered to result in beneficial health effects, reducing the risk of complications and consumption of health and medical services, while improving well-being, QoL and control of symptoms among chronically ill patients [113].

Riegel et.al presented SC within the framework of a middle-range theory [120]. A middle-range theory describes nursing concepts more specifically and fills the gap between grand nursing theory and practical nursing care. Riegel et. al define $\mathrm{SC}$ as a process of maintaining health through health-promoting methods and disease management [121]. The theory includes concepts such as SC maintenance, with the aim of improving well-being and preserving health. Self-care monitoring refers to surveillance and intervention in response to symptoms, while SC management is the process of assessment of changes in signs and symptoms. To achieve the best results, it is important for the individual to be motivated and reflect on deliberately chosen SC. In addition, the authors point out the importance of providing meaning to $\mathrm{SC}$ that is based on a firm foundation of knowledge (Riegel et al., 2012). 


\section{SELF-CARE FOR PATIENTS WITH CHRONIC DISEASES AND CANCER}

Chronic obstructive pulmonary disease, diabetes and heart failure are examples of chronic diseases for which SC is commonly practised and has been found to be effective [122-124]. The aim of SC has been to improve treatment outcomes and health conditions, to increase perceived patient control over the disease and to reduce anxiety and depression [120, 125].

Cancer is now increasingly recognised as a chronic illness [126]. The concept of SC among patients with cancer has been described as a process that includes education, interaction, self-control and self-reliance [127]. Healthcare personnel play an important role for patients with cancer by enabling and maximising their ability for SC through provision of the necessary information, resources and support [107]. Cancer patients have shown a willingness to embrace SC [128] and where patients collaborate with care providers to achieve SC, patients felt supported and proactively practised SC [126].

Since important SC principles include patient participation and responsibility, it is highly desirable to motivate patients to exercise SC [129]. By educating cancer patients about SC, a common language can be achieved that helps to optimise patient care. Self-care also provides an opportunity for change and improvement in health-promoting behaviour among patients with cancer [126].

\section{SELF-CARE FOR PATIENTS WITH PAIN}

Self-care reportedly has a moderate pain-relieving effect among patients with chronic pain [130-132]. Self-care has even proven to be effective for cancer-related pain $[97,108]$. For patients with cancer and pain, SC may entail the correct use of analgesics, social support, rest, and keeping busy, all of which can contribute to an increased sense of well-being [133, 134].

Self-care may be of benefit to patients with $\mathrm{HNC}$ and pain, but has not previously been adequately studied. We have found only one study that addressed SC in HNC. The study evaluated SC behaviours in relation to RT-induced mucositis pain and showed positive involvement with SC among patients with HNC [134].

\section{CONCLUSIONS REGARDING SELF-CARE}

A common denominator for the various definitions of SC includes prevention and promotion of health and well-being. Self-care has developed into a process-oriented activity in which patient participation is extremely important, which also requires patient education provided by medical personnel. Self-care can influence the ability of individuals to manage their situation and gain greater control over their disease by making necessary choices. Successful promotion of individual responsibility and opportunities to take care of personal health requires involvement by the healthcare system. The benefits of SC include improved QoL, as well as physical and mental health, with a reduction in the need for healthcare services and related costs [113]. 
Self-care has received increased attention in recent decades, likely due to the worldwide increase in chronic diseases, including cancer, with associated social and financial burdens on both the individual and the healthcare system [114].

To improve SC, patient needs knowledge, and health-care professionals provides education to improve SC (Figure 6).

According to the scientific literature on SC for patients with cancer [44, 133, 134], $\mathrm{SC}$ has been identified as patient activities educated by medical personnel.

\section{Patient education and Self-Care In THIS THesis}

Self-care in this thesis is based on theories about SC, with an emphasis on the theories of Dorothea Orems and Barbara Riegel.

We view SC as a process which can be improved with education about pain, pain management and other symptoms related to their disease. Integrated support from nurses helps patients with $\mathrm{HNC}$ to assess and monitor pain symptoms and their attitudes towards pain management. We consider patient education to be an opportunity to nurture the attitude of the patients and their ability to assess, cope with and manage their own symptoms. Self-care should be viewed as a complement to pharmacological treatment in the field of pain and pain management. A part of this thesis was to explore pain education and $\mathrm{SC}$ in relation to pain and other symptoms.

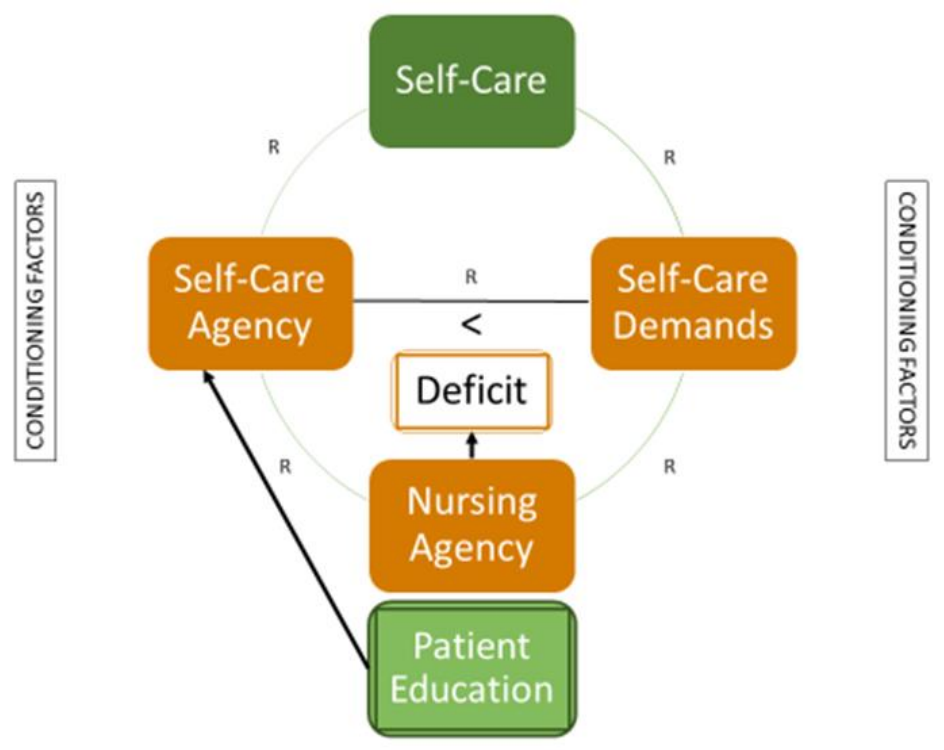

Figure 6. To improve SC, patient needs knowledge, and health-care professionals provides patient education to improve SC agency. $\mathrm{R}$, relationships; <, deficit relationship. Modified and reproduced from [1] with permission. 


\section{AIMS}

The overall aim of this doctoral thesis including of four papers was:

- to describe experiences and perceptions of pain and HR-QoL in patients with $\mathrm{HNC}$ undergoing and after RT

- to develop pain management strategies in order to maintain QoL and activities of daily living among patients with $\mathrm{HNC}$.

The specific aims of the studies were as follows:

Paper I: To describe how pain is experienced and perceived in patients with HNC undergoing RT.

Paper II: To describe how relatives of patients with HNC undergoing RT experienced the situation of the patient, especially with respect to pain, and how the relatives felt about their own experiences.

Paper III: To identify potential factors that may influence HR-QoL in patients with HNC during the early stage of RT.

Paper IV: To determine whether individually tailored patient education and SC can help reduce pain intensity and maintain HR-QoL, stabilise mood, and improve sleep during and after RT. 



\section{PARTICIPANTS}

The participants in this thesis are patients with HNC treated with RT (Paper I, III, IV) and their closest relatives (Paper II). For an overview of the participants' sex, age and cancer site, Table 1.

\section{Paper I}

All patients with $\mathrm{HNC}$ referred to the Pain and Rehabilitation Centre (PRC) at Linköping University Hospital were asked to participate in the study. The recruitment consecutively followed the ordinary patient flow between spring 2010 and summer 2011. Inclusion critera were completed RT for HNC and of the 46 patients asked to participate, 26 agreed. Written and verbal information was provided to all patients, and they signed a written consent before inclusion in the study.

Of those who did not give consent to participate $(\mathrm{n}=20)$ in this study, the most common reason for decline was poor general health condition.

\section{Paper II}

Relatives of patients with HNC who had been treated with RT (included in Paper I) participated. To be included, the relative had to be identified by the patient as their closest relative. The patients defined what was meant by closest relative and these individuals are continuously labelled as relatives, and the patients are labelled as a family member in Paper II.

The data were collected between autumn 2010 and summer 2011 after the family member had completed the RT. Of the 26 relatives asked to participate in the study, 21 agreed. Verbal and written information about the study was delivered to all relatives and they signed a written consent before they were included in the study.

For the five individuals that declined to participate; no information is available to their reasons for not participate.

\section{Paper III}

All patients with $\mathrm{HNC}$ referred to the PRC were invited to participate in the study and the recruitment consecutively followed the ordinary patient flow. Our sample was restricted to patients during their early stage of treatment that was defined no later than two weeks of ongoing RT in this paper. The data were collected from January 2015 to August 2016. 
Inclusion criteria were 18 years of age or older, enrollment for RT with curative intent, and ability to read, write, and understand Swedish. Of the 102 patients with HNC who were invited to participate, 54 were finally included in the study. The only reason reported for declining to participate in the study was poor general health condition.

Verbal and written information about the study was delivered to all included patients and they signed a written consent before the study started.

\section{Paper IV}

All patients with $\mathrm{HNC}$ referred to the PRC were invited to participate in the study and the recruitment consecutively followed the ordinary patient flow. Our sample was restricted to patients during their early stage of treatment that was defined no later than two weeks of ongoing RT in this study. The data were collected from January 2015 to December 2016.

Inclusion criteria were 18 years of age or older, enrollment for RT with curative intent, and ability to read, write, and understand Swedish. Of the 119 eligible patients, 64 were included in the study ( 54 also was included in Paper III). The only reason reported for declining to participate in the study was poor general health condition.

Verbal and written information about the study was delivered to all included patients and they signed a written consent before the study started.

Table 1. An overview of the participants, sex, age and cancer site in Paper I-IV

\begin{tabular}{lllll}
\hline & Paper I & Paper II & Paper III & Paper IV \\
\hline $\begin{array}{l}\text { Participants (n) } \\
\text { Eligible patients }\end{array}$ & 46 & 26 & 102 & 119 \\
$\begin{array}{l}\text { Denied participation } \\
\text { Included }\end{array}$ & 20 & 5 & 48 & 55 \\
$\begin{array}{l}\text { Sex, } \mathbf{n} \text { (\%) } \\
\text { Female }\end{array}$ & 26 & 21 & 54 & 64 \\
Male & $7(26.9)$ & $18(85.7)$ & $18(33.3)$ & $25(39.1)$ \\
$\begin{array}{l}\text { Age in years } \\
\text { Mean ( } \pm \text { SD) }\end{array}$ & $19(73.1)$ & $3(14.3)$ & $36(66.7)$ & $39(60.9)$ \\
Cancer site, $\mathbf{n}(\%)$ & $64( \pm 10)$ & $55( \pm 19)$ & $65( \pm 11)$ & $65( \pm 10)$ \\
Oral cavity & & & & \\
$\begin{array}{l}\text { Pharynx } \\
\text { Larynx }\end{array}$ & $9(34.6)$ & NA & $14(25.9)$ & $14(21.9)$ \\
Others & $9(34.6)$ & NA & $19(35.2)$ & $26(40.6)$ \\
\hline
\end{tabular}

Abbreviations: $n$, total number of participants; SD, Standard Deviation; NA, Not Applicable. 


\section{METHODS}

This thesis is based on four papers (Table 2). Qualitative design was undertaken in Paper I and II to gain understanding of patients with HNC and their relatives experiences of pain and other symptoms during and after RT. Paper III was a cross-sectional study to identify factors that may influence HR-QoL during early RT in patients with HNC and pain. Paper IV had a longitudinal study design to evaluate whether tailored patient education and tailored SC were advantageous for patients with HNC.

Table 2. Design, participants and inclusion, data collection and data analyses (Papers I-V)

\begin{tabular}{|c|c|c|c|c|}
\hline Paper & I & II & III & IV \\
\hline Design & $\begin{array}{l}\text { Qualitative, longitu- } \\
\text { dinal }\end{array}$ & $\begin{array}{l}\text { Qualitative, cross- } \\
\text { sectional }\end{array}$ & $\begin{array}{l}\text { Quantitative, cross- } \\
\text { sectional }\end{array}$ & $\begin{array}{l}\text { Quantitative, longitu- } \\
\text { dinal, two-armed } \\
\text { feasibility study }\end{array}$ \\
\hline $\begin{array}{l}\text { Inclusion and } \\
\text { participants }\end{array}$ & $\begin{array}{l}\text { Consecutive inclusion } \\
\text { of patients with HNC, } \\
n=26\end{array}$ & $\begin{array}{l}\text { Consecutive inclusion } \\
\text { of relatives to pa- } \\
\text { tients with HNC ( } \mathrm{Pa} \text { - } \\
\text { per I), } n=21\end{array}$ & $\begin{array}{l}\text { Consecutive inclusion } \\
\text { of patients with HNC, } \\
n=54\end{array}$ & $\begin{array}{l}\text { Consecutive inclusion } \\
\text { of patients with HNC, } \\
n=64 \text { ( } 54 \text { of those } \\
\text { also participated in } \\
\text { Paper III) }\end{array}$ \\
\hline Data colletion & $\begin{array}{l}\text { Semistructured inter- } \\
\text { views }\end{array}$ & $\begin{array}{l}\text { Semistructured inter- } \\
\text { views }\end{array}$ & $\begin{array}{l}\text { Self-reported } \\
\text { questionnaires }\end{array}$ & $\begin{array}{l}\text { Self-reported } \\
\text { questionnaires and } \\
\text { items by text mes- } \\
\text { sage }\end{array}$ \\
\hline Data analyses & $\begin{array}{l}\text { Qualitative content } \\
\text { analysis }\end{array}$ & $\begin{array}{l}\text { Qualitative content } \\
\text { analysis }\end{array}$ & $\begin{array}{l}\text { Quantitative analyses } \\
\text { using descriptive sta- } \\
\text { tistics and regression } \\
\text { analysis }\end{array}$ & $\begin{array}{l}\text { Quantitative analyses } \\
\text { using descriptive } \\
\text { statstics, repeated } \\
\text { measures and regres- } \\
\text { sion analysis }\end{array}$ \\
\hline
\end{tabular}

Abbrevations: HNC, Head and Neck Cancer; n, total number of participants.

\section{Paper I}

Paper I, describes how patients with HNC experienced pain and disease burden and how pain influenced those who were treated with RT. The patients were invited for two interviews and the first interview (26 participants) was conducted one month after completed RT. The second interview was conducted four to six months after the first interview (23 participants). This study design made it possible to capture comprehensive experiences of patients' pain and disease burden over time. 
An interview guide was prepared to ensure that certain topics were discussed during the interviews. The same questions were posed to all patients and the interviews were conversation-like in nature, that is to say, follow-up questions were asked after the main questions as the conversation progressed.

The interview guide, included predetermined areas, developed to explore the patients experience with pain. The opening question "Can you describe your experiences since the start of the RT?" provided rich information and often covered or initiated a discussion about many of the areas that were elicited using several follow-up questions when more elaborations were needed. The follow-up questions included for example: "What are your thoughts about what has happened to you?"; "In what way has the pain impacted on your life?"; "How do you feel emotionally?"; "What are your thoughts about the future?"; and "What does an ideal treatment look like?".

The formulation of the questions and when they were posed during the interview varied, depending on how the conversation developed. At the end of the session, the interview guide was used as a checklist to guarantee that all of the areas had been discussed.

The interviews were audio recorded and transcribed verbatim and varied in length from eleven to 61 minutes. Mean duration for the interviews was 28 minutes $(\mathrm{SD}=12)$ at the first interview and 31 minutes $(\mathrm{SD}=11)$ at the second. One initial interview was conducted by telephone because of problematic weather conditions with transportation difficulties.

\section{Paper II}

Paper II, describes how relatives to family member's with HNC perceived the experiences of the family member's situation, especially with respect to pain, and how the relative themselves experienced the situation. Relatives were invited for one interview (21 participants) and the interview was conducted in median 3.5 months (range 0.25 - 9.75) after the family members had completed RT (Paper II, Table 1).

An interview guide was prepared by using the same methodology approach for interviews as reported in Paper I.

The interview guide, included predetermined areas, developed to explore the relative's perspective of the family member's pain and of the relative's own situation. The opening question "Can you describe your experiences during the period your family member underwent the RT treatment?" gave rich information and often covered or initiated many of the areas. Follow-up questions included for example: How is the relationship between you and your family member?; Can you describe if the relationship has been affected since the treatment or diagnosis?; What do you feel have helped your family member during the treatment? 
The formulation of the questions and when they were posed during the interview varied, depending on how the conversation developed. At the end of the session, the interview guide was used as a checklist to guarantee that all of the areas had been discussed.

The interviews were audio recorded and transcribed verbatim and varied in length from twelve to 34 minutes. Mean duration for the interviews was 23 minutes $(\mathrm{SD}=7)$.

\section{Analyses (Paper I and II)}

Paper I and II were analysed with qualitative content analysis as described by Elo and Kyngäs [135] and Krippendorff [136]. Thus, the interview material was read by all authors (Paper I: AS, ML, BL, GL; Paper II: AS, GL, BL) systematically, line by line, to identify meaning units relevant to the study's purpose and to gain a general understanding of the material as a whole with an inductive approach. The meaning units may consist of a sentence, several sentences, or a paragraph. Descriptive notes were written in the paper margin while reading the interviews and these then formed the beginning of the codes. After that, the codes were organized into subcategories and categories. As a first step, coding was undertaken by each of the authors independently of one another. As a second step, the authors held repeated discussions about the codes, alternative subcategories and categories based on quotes taken from the interview transcripts. Based on the categories, a main category was created. This process was conducted by the first author (AS), who frequently consulted the other (BL, GL) regarding excerpts of the primary transcript data and the clustering of the data into subcategories and categories. All interviews were organized in a computer program for qualitative methodology - Nvivo 9 [137], which facilitate the handling of large quantities of text and the sorting of data.

The process, from meaning units to categories constituted a manifest content analysis, in order to maintain the participants' experiences and their view of reality.

A number of measures were taken to increase the reliability and credibility of the results. To validate the meaning units and codes, these were compared and discussed by the authors until an agreement was reached. The results was validated by each author reading and analysing them separately before comparing and confirming the categories that appeared. Finally, the category system was tested by all authors for its consistency within categories and the categories comprising the complete picture and to ensure that codes only occurred in one subcategory (Malterud, 2001). 


\section{Paper III}

Paper III, a cross-sectional study aimed to identify factors that may influence HRQoL in patients with HNC. Data was collected by self-reported questionnaires on HR-QoL, pain intensity, pain interference, anxiety, depression and pain catastrophizing.

\section{Questionnaires}

Five validated patient-reported outcome measurements was used in the study:

\section{HEALTH RELATED QUALITY OF LIFE}

The Euro QoL-5 Dimension Questionnaire (EQ-5D) assesses health outcome and perceived state of health. The questionnaire comprises five items: mobility, selfcare, usual activities, pain and discomfort, anxiety and depression. Each item has three levels - no problems, some problems, and extreme problems - and the answers were coded (1-3). An algorithm developed for EQ-5 D was used to calculate the final individual score. The EQ-5D score has a range from -0.5 to 1 where negative values mean low HR-QoL and 1 means no reduction in HR-QoL. The EQ$5 \mathrm{D}$ scores were determined by applying scores from standard population values [138].

The Euro Quality of Life Vertical Visual Analogue Scale (EQ VAS) measures the respondent's general health on a vertical visual analogue line with 100 scale steps with the endpoints labelled "Best imaginable health state" and "Worst imaginable health state" [83].

\section{PAIN INTENSITY AND PAIN INTERFERENCE}

The Brief Pain Inventory (BPI) measures how pain interferes with daily activities (seven items) and pain intensity (five items) rated on a o -10 Likert scale [139]. The scores were summed and mean values of the items of pain interference and pain intensity items were calculated. The Swedish version of BPI used in this study has been linguistically validated but has not yet been psychometrically validated.

\section{ANXIETY AND DEPRESSION}

The Hospital Anxiety and Depression Scale (HADS) assesses anxiety (seven items) and depression (seven items), both with a score range of o to 21 [140]. Each item uses a four-point Likert scale (ranging from 0-3) and the answers were summed. Higher scores indicate likelihood of anxiety or depressive symptoms. A score of 7 or less indicates a non-case, a score of 8-10 a doubtful case, and a score of 11 or more a definite case. 


\section{PAIN CATASTROPHIZING}

The Pain Catastrophizing Scale (PCS) comprises 13 items assessing the incidence of catastrophizing in relation to how individuals experience pain [141]. Each item is rated on a five-point scale ( $\mathrm{o}=$ not at all; $4=$ all the time). The maximum score is 52 ; a high score represents a worse situation.

\section{Paper IV}

Paper IV, a two-armed feasibility study design was performed, with randomization (randomization details, see below) of patients with $\mathrm{HNC}$, either to a control group or to a intervention group. Patient education on management of cancer pain in combination with advice on SC were compared with usual care.

\section{PRIMARY OUTCOMES}

The primary outcome measurements were items about pain intensity and pain interference the previous 24 hours, reported by both groups of patients and collected by text message every Monday, Wednesday, and Friday during the ten study weeks.

\section{Pain Intensity and Pain Interference by Text Message}

Mouth pain intensity (two items from Oral Cancer Pain Questionnaire [142]) and pain interference (five items from Brief Pain Inventory, (BPI) [139]). The items on pain intensity included pain in connection with and without speaking, talking, and drinking. The items on pain interference included general activities, mood, relations, sleep, and enjoyment of life. The items were scored on a scale from $o$ (no pain, does not interfere) to 10 (the most intense pain sensation imaginable, interferes completely). For each item, the average score of the three weekly scores was calculated.

\section{SECONDARY OUTCOMES}

The secondary outcome measurements covered HR-QoL, pain intensity, pain interfence, psychological aspects, and barriers towards pain management and were answered by both groups at BL, at four weeks, and at ten weeks. The same questionnaires as in study III (EQ-5D, EQ VAS, BPI, HAD and PCS) were used. Additionally, one issue about sleep pattern, and a pain barrier questionnaire were added.

\section{Barriers towards Pain}

The Barriers Questionnaire II (BQ-II) comprises 27 items on patient reported beliefs on pain and pain management [93]. Each item was measured on a six-point scale: o (do not agree at all) to 5 (agree very much). Before this study, BQ-II was translated into Swedish using a backward-forward procedure (appendix I, text 1). The Cronbach's alpha coefficient was 0.90 . 


\section{Current Sleep Pattern}

One issue about sleep from the Insomnia Severity Index [143] was added at the end of the BQ-II questionnaire and reads as follows: How satisfied are you with your current sleep? ( $0=$ very satisfied to $5=$ very dissatisfied).

\section{Procedures}

\section{THE INTERVENTION AND CONTROL GROUP}

All participants answered the text message with seven items on pain intensity and interference every Monday, Wednesday, and Friday during the ten study weeks. If the text message survey showed $\geq 3$ numeric rating scale steps increase on any items, a trained research nurse (TRN) phoned the patient the same day (if a weekend no later than three days) and a pharmacological treatment was promptly prescribed or adjusted. If the patient was displeased with the pain relief at the next day's phone contact with the TRN (or at next scheduled individual weekly followup if imminent), the pharmacological treatment was adjusted. Both groups were offered care as usual. Thus, they were encouraged to contact the TRNs by phone and had access to advice from the TRN. The pharmacological treatment was based on identical principles for both groups and prescribed by the physicians according on the ward's policies (appendix I, text 2).

\section{THE INTERVENTION GROUP}

\section{Two Tailored Patient Education Sessions}

The scientific literature $[97,107]$ on patient education on management of cancer pain was scrutinized. Six essential education areas were identified: pain and pain physiology, pain medication, side effects of medication and prevention of side effects, abuse of medications, and advice on anxiety and sleep. To make it possible to tailor education interventions for each patient, a procedure to match the 27 items barriers to pain management (BQ-II) to the six educational areas was undertaken. Thus, the BQ-II scoring of the items (several items could be assigned the same education area) coordinated by the majority of a group of nurses (two TRNs, eight nurses employed at PRC, and the first author (AS)) to each education area (appendix II) constituted the base for the individual tailoring of education. The inter-rater reliability of the item-to-education coordination process was assessed using a two-way mixed, consistency, average-measures intra-class correlation (ICC) to assess the degree that the 11 coders provided consistency in their ratings of education areas across the 27 items of the BQ-II. The ICC was 0.91. A minimum summed BQ-II score (appendix II) of the group of items assigned to each education area decided whether and which education should be delivered.

At week 1, BL, a TRN delivered a PowerPoint presentation covering the education areas. This presentation was labelled education session 1 (ES 1). To ensure that 
as many current needs as possible were addressed at week 4 (ES 2), the TRN initiated a structural discussion with the patient on the specific education areas presented at ES1. If needed, based on the second scoring of BQ-II one week before the ES 2, additional education areas were presented at ES 2.

\section{Individually Tailored Self-Care}

The scientific literature of SC for cancer patients were reviewed [44, 133, 134], which was supplemented with the two TRNs, the author (AS), and four nurses employed at PRC clinical experiences of pain care regarding patients with HNC. Fourteen SC measures were identified that covered maintaining wellbeing, prevention of symptoms, and pain relief of mouth and throat (appendix III). At weekly follow-ups, adjustments or initiations of SC were suggested depending on the previous three text message scores i.e. if the score on any of the text message items was $\geq 3$ ( $\geq 1$ on the item pain interferences on general activities). The intention was a preventive approach. Self-care measurement was systematically selected and suggested (appendix IV). In addition, the TRN verbally presented written information (appendix III).

\section{THE CONTROL GROUP}

The control group did not receive the individual tailored education sessions or the systematic adjustments of SC at weekly follow-up. However, the weekly follow-up of the control group was consistent with the usual care at the PRC. That is, if the patient asked for advice or if it was apparent to the TRN that one or more SCs would be beneficial, unstructured verbal advice regarding SC was provided by the TRN.

\section{RANDOMIZATION}

When patients agreed to participate in the study, their personal data were documented in consecutive order on a list in a confidential data file. All patients were assigned a code number and were consecutively distributed to the control group or to the intervention group - every second patient to the control group and every second patient to the intervention group.

\section{SAMPLE SIZE}

The sample size was assessed based on BPI, pain intensity (o - 10 scale). With an assumed clinically relevant average difference of four scale steps (SD 3), an alpha value of 0.05 , and a power of $80 \%$, each group was calculated to include approximately 30 patients. Sample size calculations were made using the computer program Power and Sample Size Calculations (v. 3.0.43, http://biostat.mc.vanderbilt.edu/wiki/Main/PowerSampleSize).

An overview of the procedure for the intervention and control group is illustrated in Figure 7. 


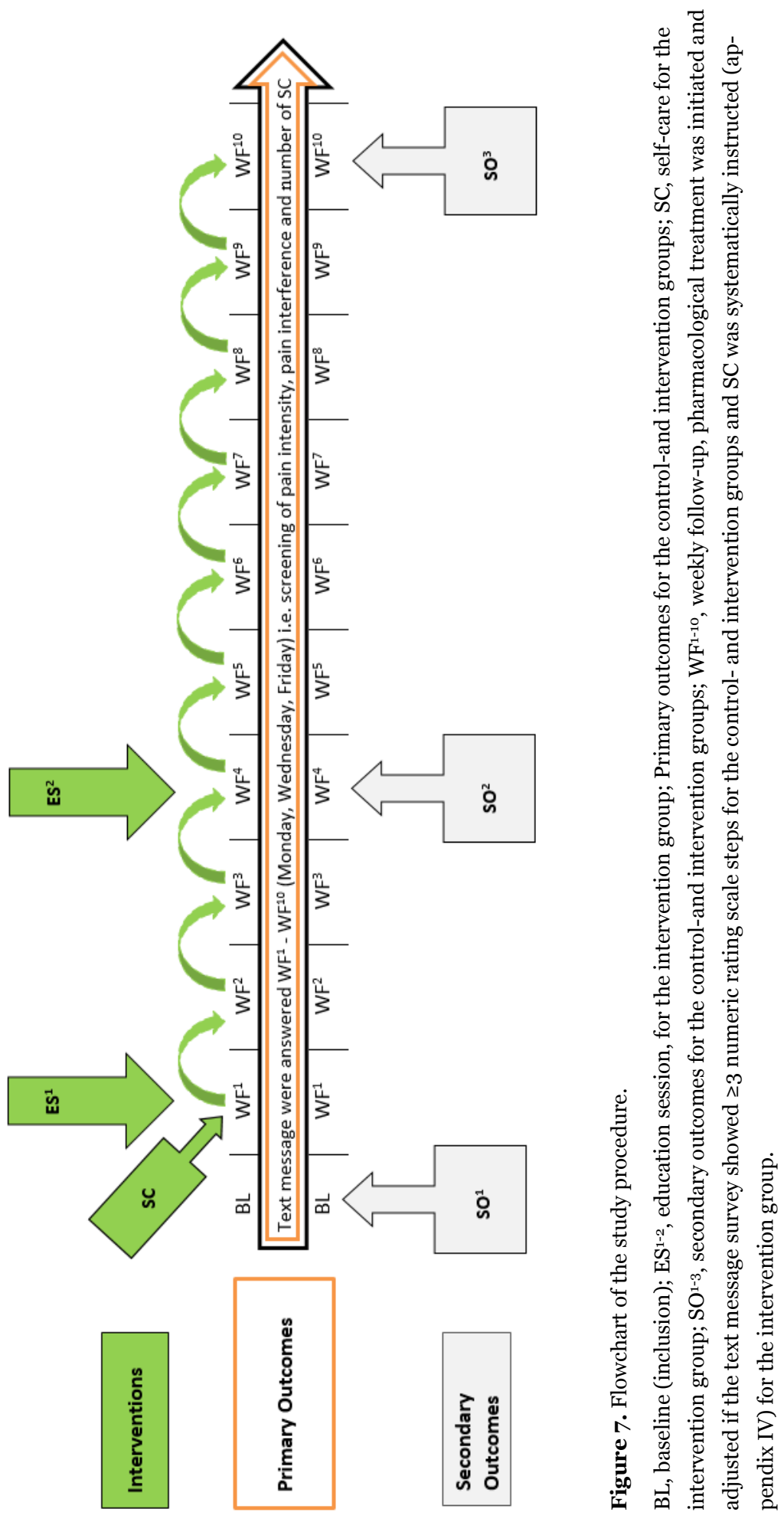




\section{Statistics}

All the statistical data were analysed using SPSS 23.0 for Windows (IBM Corp., Armonk, NY, USA). In all Papers (I-IV) descriptive statistics were used to present demographic data. Continuous data are presented as mean and standard deviation (SD). The categorical data are presented as minimum and maximum values and as percentages $n(\%)$. An overview of all statistical tests is presented in Table 3. For all statistical analyses, a p-value of <0.05 was accepted as significance.

In Paper I the Chi-Square test were used to test between-group differences for dichotomous variables and in both Paper I and II descriptive statistics were presented.

In Paper III, descriptive statistics were presented and for comparisons betweengroups, Student's t-tests and one-way analysis of variance (ANOVA) were performed for continuous variables.

Pearson correlation test was used for bivariate correlation between the dependent variables (EQ-5D and EQ VAS) and independent variables (BPI, PCS, and HADS). Multivariable linear regression models were used to investigate the possible associations between the dependent variables and independent variables. These results are presented as unstandardized (regression coefficients with 95\% confidence intervals) and standardized regression coefficients (with p-values). Multicollinearity was assessed by examining the Pearson correlation coefficients between the examined variables. Bivariate correlation coefficients $\geq 0.7$ indicate risk of collinearity.

In Paper IV, for comparisons between groups, Student's t-tests and ANOVA were performed for continuous variables and Chi-Square test for dichotomous variables.

For the primary outcomes, the average score were calculated for three time points every week to measure the primary outcomes for ten weeks. Then a linear repeated measures multilevel model (Generalized estimating equations (GEE) for continuous variables) was used to determine the effectiveness of the intervention compared to control conditions over time. The estimated impact (i.e. overall effect, Appendix V) of treatment on the outcome in the GEE model reflects the "combined" within- and between-subjects effects. The results are presented as regression coefficients (B) with 95\% confidence intervals (CI) and can be interpreted as the time effect for the groups at a certain follow-up compared with BL. In multilevel analysis, missing scores do not need an imputation strategy, as this analysis is flexible in handling missing data. A repeated measures ANOVA/mixed model (continuous variables) with Bonferroni post-hoc tests was used for the secondary outcomes. All analyses were conducted on an intention-to-treat basis. 
The inter-rater reliability of the item-to-education coordination process was assessed using a two-way mixed, consistency, average-measures intra-class correlation (ICC) to assess the degree that the 11 coders provided consistency in their ratings of education areas across the 27 items of the BQ-II. 


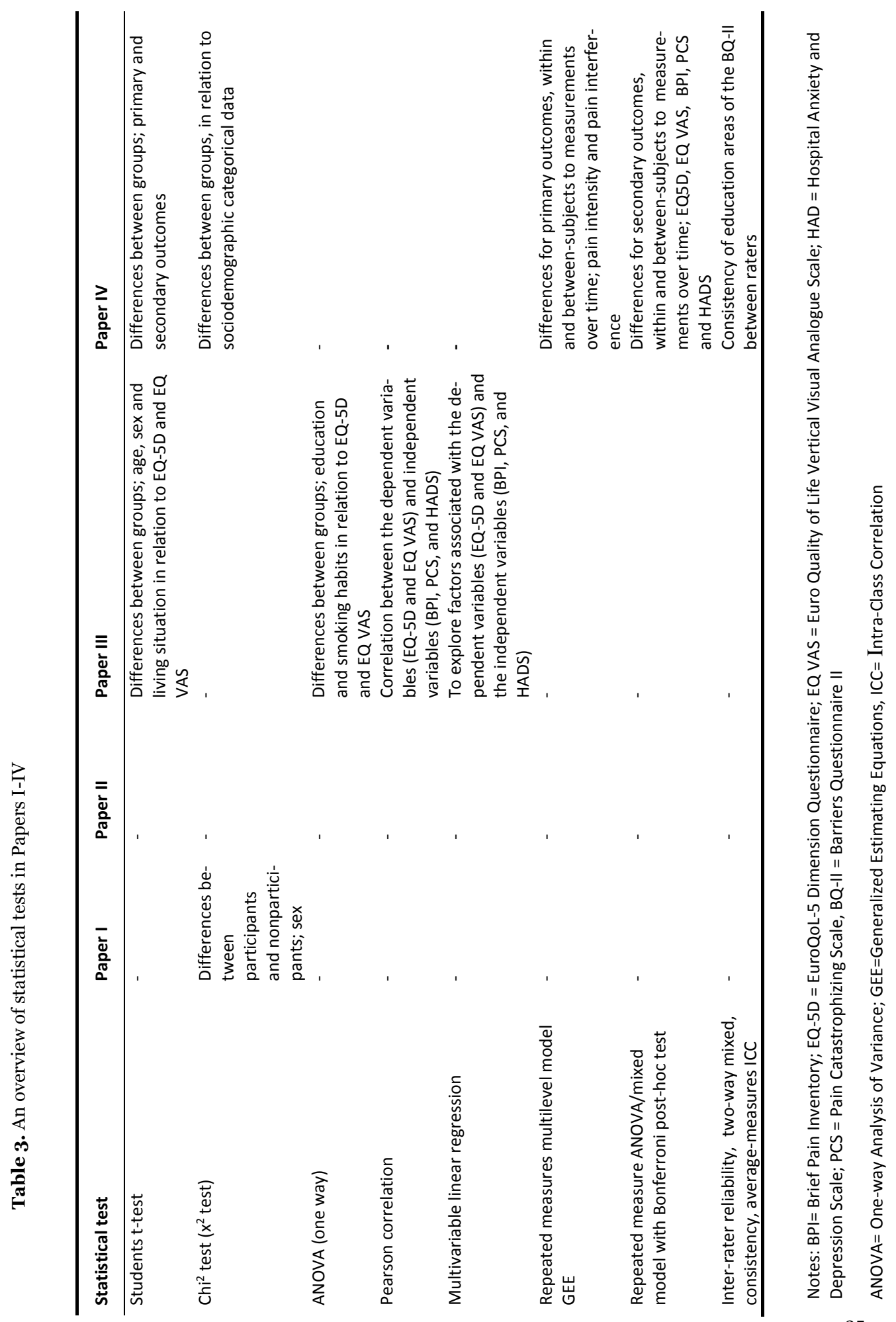





\section{ETHICAL CONSIDERATIONS}

The studies on which all papers were based (I - IV) were approved by the Regional Ethical Review Board in Linköping, reference number: 2010/154-31 (Papers I and II), 2014/356-31 (Papers III and IV). The Code of Ethics of the World Medical Associations (Declaration of Helsinki) was applied throughout the study.

All participants were provided with written and oral information and signed a written consent form prior to inclusion. They were informed that they could withdraw from the study at any time, without any explanation, and without negative effects on their care or their relationship with their healthcare provider.

Participation in the studies for Papers I and II is considered justifiable, since the studies could help medical personnel to better understand the situations that patients and their family members experience as difficult. By elucidating how family members experience difficult and positive situations during the patient's illness, lessons can be drawn regarding how to improve the healthcare system. It is not unusual for patients and relatives to experience an interview as positive since it provides an opportunity to talk about something that is likely important to them and they can reflect on the situation. In summary, we determined that the benefits of participating in this project far outweighed the risks.

Participation in the studies for Papers III and IV entailed repeated contact with nurses, thereby providing patients with the opportunity to discuss their situation, which possibly offset any discomfort or disruption that we caused for the individual. The studies entailed a more extensive investigation for patients than they would otherwise have been subjected to, which is usually appreciated by patients, as was the case in our study. In research studies on pain, it is not unusual for subjects to express satisfaction with the research that is focused on their condition.

One might think that the focus on pain symptoms associated with the studies could entail a risk of reinforcing physical symptoms. However, we considered the benefits of participation to be greater than this inconvenience, and that participation in the study did not find any ethical problems related to participation in the studies. 



\section{RESULTS}

Referring back to the specific aims of the studies the main findings of Papers I-IV will be summarized in the present chapter. For the complete results, see Papers I-IV.

\section{Paper I}

Paper I, describes the experiences of pain and how pain influences patients with HNC treated with RT.

The analysis of the interviews resulted in one main category, 'patients with HNC did not report that their severe physical pain influenced their psychological suffering, but it did influence their social lives'. This main category was based on the following four categories: pain in the head and neck region; overwhelming fatigue; altered mood and preoccupied mind; decreased participation and changed relationships.

Table 4. An overview of main category, categories and subcategories appearing in the interviews with patients with HNC.

The main category:

Patients with HNC did not report that their severe physical pain influenced their psychological suffering, but it did influence their social lives

\begin{tabular}{|c|c|c|c|c|}
\hline Categories & $\begin{array}{l}\text { Pain in the head } \\
\text { and neck region }\end{array}$ & $\begin{array}{l}\text { Overwhelming } \\
\text { fatigue }\end{array}$ & $\begin{array}{l}\text { Altered mood and } \\
\text { preoccupied mind }\end{array}$ & $\begin{array}{l}\text { Decreased partici- } \\
\text { pation and changed } \\
\text { relations }\end{array}$ \\
\hline \multirow[t]{7}{*}{ Subcategories } & $\begin{array}{l}\text { Oral cavity and phar- } \\
\text { ynx and its conse- } \\
\text { quences }\end{array}$ & $\begin{array}{l}\text { Sleep disturbance } \\
\text { Consequences in } \\
\text { daily activities }\end{array}$ & $\begin{array}{l}\text { Altered feelings } \\
\text { Feelings of mistrust }\end{array}$ & $\begin{array}{l}\text { Changed social life } \\
\text { Nutritional barriers }\end{array}$ \\
\hline & Pain medication & Debility and fatigue & Depressed mood & Withdrawal \\
\hline & & & Thoughts of death & $\begin{array}{l}\text { Changed relation- } \\
\text { ship }\end{array}$ \\
\hline & & & Conquer the illness & \\
\hline & & & Guilt and unfairness & \\
\hline & & & $\begin{array}{l}\text { Changed life per- } \\
\text { spectives and mean- } \\
\text { ing of life }\end{array}$ & \\
\hline & & & $\begin{array}{l}\text { Yearning for the fu- } \\
\text { ture }\end{array}$ & \\
\hline
\end{tabular}




\section{Description of the Categories}

\section{Pain in the HeAd and Neck Region}

Almost all patients reported physical pain, usually located in the oral cavity, pharynx and pain when swallowing. Four to six month later, about half of the patients still reported pain. Due to the painful situation, nearly all patients used pain medication regularly, whereof opioid medication was common, even four to six month later. However, a few patients experienced no pain relief no matter how much analgesic they were prescribed and some experienced side effects due to the opioid treatment.

\section{OVERWhelming FAtigue}

The category overwhelming fatigue, experienced by a majority of patients with $\mathrm{HNC}$ identified fatigue as affecting their lives and resting did not help. Physical activities were experienced as very strenuous and fatigue led to a passive lifestyle. Many of the patients still experienced the feeling of fatigue at the second interview. Sleep disturbance, impaired food intake, weight loss, pain and opioid treatment were commonly mentioned reasons for fatigue.

\section{Altered Mood and Preoccupied Mind}

Almost all patients reported alterations in moods that could be expressed as tearfulness, depression, anxiety, anger, and irritation and these moods still remained at the second interview. Patients' moods were affected by anxiety about survival and concern about risks associated with RT. Adequate medical information was perceived as positive and calming. According to some patients, easily accessible contact with caregivers would improve their situation.

During the first interview, more than half of the patients expressed that the diagnosis itself caused them thoughts about death. The patients were preoccupied with worries that the cancer could relapse or had not diminish as expected. During the second interview, almost all of the patients mentioned that they still were preoccupied with cancer, death, and treatment efficacy.

Feelings of unfairness were apparent as several patients expressed thoughts that this disease will affect others but not themselves; these concerns remained at the second interview. Furthermore, former smokers or those who continued to smoke reported a sense of guilt because of their habits. Additionally, several patients reported feelings of guilt when they complained as they often felt others might be in a worse situation.

Nearly all patients reflected about the meaning of life and the importance of being healthy during their first interview and even at the second interview. Their perspective of life were no longer taking for granted but they emphasized the importance of believing in a future. 
Many patients emphasized the importance of believing in a future, however uncertain, as necessary in order to manage the treatment. On the contrary, a few patients expressed that they did not think about the future. Several patients were more hopeful and expressed a yearning for the future at the second interview.

\section{DeCreased Participation And Changed Relationships}

More than half of the patients experienced changes in their social lives, in both intervews. Nutritional barriers as lack of appetite, eating difficulties and speech difficulties resulted in withdrawal from socializing with others.

During both interviews, patients noted that support from relatives helped them to overcome feelings of isolation and withdrawal. A few patients experienced improved contact with their relatives.

\section{SUMMARY PAPER I}

Paper I, showed that as early as in the treatment phase these patients experienced existential pain in the form of fear of death, feelings of guilt and unfairness. Physical pain, psychological suffering and social withdrawal were also prominent in the group.

\section{Paper II}

Paper II, describes how relatives to family members with HNC experienced the family members situation, especially with respect to pain, and how the relatives themselves experienced the situation.

A main category, 'relatives struggle with loves one's pains related to head and neck cancer treatment and with their own demanding situation'. This main category was based on the following four categories: inability to relieve and comprehend the physical suffering of the family members; overwhelming emotions were experienced that affect the family members and the relatives themselves; in need of support from the health care service; and altered daily activities and family roles due to illness and treatment. 
Table 5. An overview of main category, categories and subcategories appearing in the interviews with relatives of family members with $\mathrm{HNC}$

The main category:

Relatives struggle with loves one's pains related to head and neck cancer treatment and with their own demanding situation

\begin{tabular}{|c|c|c|c|c|}
\hline Categories & $\begin{array}{l}\text { Inability to relieve } \\
\text { and comprehend } \\
\text { the physical suffer- } \\
\text { ing of the family } \\
\text { members }\end{array}$ & $\begin{array}{l}\text { Overwhelming emo- } \\
\text { tions were experi- } \\
\text { enced that affect } \\
\text { the family members } \\
\text { and the relatives } \\
\text { themselves }\end{array}$ & $\begin{array}{l}\text { In need of support } \\
\text { from the health care } \\
\text { service }\end{array}$ & $\begin{array}{l}\text { Altered daily activi- } \\
\text { ties and family roles } \\
\text { due to the illness } \\
\text { and treatment }\end{array}$ \\
\hline Subcategories & $\begin{array}{l}{ }^{1} \text { Extensive physical } \\
\text { pain } \\
{ }^{1} \text { Fear of medication } \\
{ }^{1} \text { Tolerated much } \\
\text { pain } \\
{ }^{2} \text { Struggles to relieve } \\
\text { the pain } \\
{ }^{2} \text { Inadequate } \\
\text { knowledge about } \\
\text { pain and pain relief }\end{array}$ & $\begin{array}{l}{ }^{1} \text { Negative emotions } \\
\text { with feeling of fear, } \\
\text { anger and unfairness } \\
{ }^{1} \text { Psychological symp- } \\
\text { toms were difficult } \\
\text { to distinguish from } \\
\text { physical pain } \\
{ }^{3} \text { Great uncertainty of } \\
\text { the cancer diagnosis } \\
{ }^{3} \text { Affecting the psy- } \\
\text { chological mood } \\
{ }^{2} \text { A state of worries } \\
{ }^{2} \text { Loneliness and pow- } \\
\text { erlessness }\end{array}$ & $\begin{array}{l}{ }^{2} \text { The holistic ap- } \\
\text { proach was missing } \\
{ }^{2} \text { Challenges about in- } \\
\text { formation } \\
{ }^{2} \text { Lack of information }\end{array}$ & $\begin{array}{l}{ }^{1} \text { Decreased partici- } \\
\text { pation in social activ- } \\
\text { ities } \\
{ }^{2} \mathrm{~A} \text { feeling of embar- } \\
\text { rassment } \\
{ }^{2} \text { Emotional and prac- } \\
\text { tical support for the } \\
\text { family members } \\
{ }^{2} \mathrm{~A} \text { strenuous situa- } \\
\text { tion } \\
{ }^{2} \text { We came closer to } \\
\text { each other }\end{array}$ \\
\hline
\end{tabular}

${ }^{1}$ Relatives' experiences of the family members; ${ }^{2}$ Relatives' own experiences; ${ }^{3}$ Relatives' experiences of the family members as well as themselves

\section{Description of the Categories}

\section{INABILITY TO RELIEVE AND COMPREHEND THE PHYSICAL SUFFERING OF THE FAMILY MEMBERS}

Most relatives described an extensive physical pain in the family member's mouth and throat region. Despite this, pharmacological prescription were not followed in some cases and one reason was fear of medication. Some relatives, however, explained that their family member tolerated the severity of pain. To see their loved ones in severe pain was hard for them and includes struggles to relieve the pain. Some relatives were not aware of whether the family member had pain and thus experienced inability to understand the physical suffering of the family member.

The relatives' knowledge about adequate pain relief was sparse and sometimes they were uninformed about which medication patients used. A few relatives reported an impression of better wellbeing of their family members when pain medications were used. 
THE RELATIVES THEMSELVES

Many relatives described that their family member's had difficulties to express negative emotions such as feeling of fear, anger and worries and sometimes they provided difficulties to distinguish these feelings from physical pain.

The delivering of the cancer diagnosis experienced as an awkward situation with vulnerability and fear about the future and regarded as affecting the psychological mood of both the family members and relatives.

The relatives became worried, of not being able to help their family member, and some relatives experienced loneliness and powerlessness. A need to help manage the difficult emotions and support with psychological help was requested, both for themselves and for their family members.

\section{IN NEED OF SUPPORT FROM THE HEALTH CARE SERVICE}

The relatives described meetings with several health professionals as lacking a comprehensive view of the patient's situation. It was also difficult to know whom to contact and there was a lack of straight answers from the healthcare providers. Relatives wanted more support and information about the disease, treatment side effects, whether the treatment was effective, and a prognosis of the cancer.

\section{ALTERED DAILY ACTIVITIES AND FAMILY ROLES DUE TO ILLNESS AND TREATMENT}

More than half of the family members had to make changes in their daily activities due to the pain, illness, fatigue, and weakness, which led to decreased participation in social activities, reported by the relatives. The family members pain was mainly associated with eating problems and described as difficult, painful, and time consuming. In addition, the relatives had a feeling of embarrassment and guilt and were ashamed of their own ability to eat, and thus their appetite decreased as a result.

Almost all the relatives stated the importance of family members and friends support during the illness and treatment, expressed in terms of practical support and someone to talk to.

The relatives had to encourage the family members with their daily activities as eat and drink and to assist with personal hygiene, and sometimes to be responsibile for medication distribution. Furthermore, dealing with the everyday chores, and for some, at the same time managing a job, was perceived as strenuous. Although there had been temporary frictions in some relations, the relatives most often experienced that they had come closer to each other.

\section{SUMMARY PAPER II}

For relatives, supporting family members with HNC (who often suffered from several dimensions of pain) was a demanding task. The relatives described their 
own situation negatively, reporting psychological distress, lack of involvement and a lack of support and care from caregivers.

\section{Paper III}

Paper III, describes HR-QoL during early RT in patients with HNC and pain.

\section{DESCRIPTION OF THE PATIENTS}

Forty-five of the 54 patients were diagnosed with $\mathrm{HNC}$ and informed in mean 6.7 weeks before inclusion in the study on the curative intend. These 45 patients are continuously labelled as "newly diagnosed". Nine out of those 54 patients were diagnosed with HNC and informed in mean 160 weeks before inclusion in the study on the curative intent and are continuously labelled as "non-newly diagnosed". Of the nine non-newly diagnosed patients, seven patients had undergone surgery once between 2013 and 2015, one patient had undergone surgery in 2001, 2008, and 2015, and one patient had received RT in 2010.

\section{DESCRIPTION OF THE DEPENDENT AND INDEPENDENT VARIABLES}

The mean values for HR-QoL were high and the mean values for pain intensity and pain interference were low (Table 6). Likewise, low mean values were found for HAD-anxiety, HAD-depression, and pain catastrophizing. The only differences found in all examined variables with respect to sociodemographic characteristics were in HAD-depression. Thus, HAD-depression (HAD-D) differed significantly in relation to education level $(p<0.05)$ i.e lower HAD-D were reported by patients with higher education. All examined variables are summarized in Table 6 . 


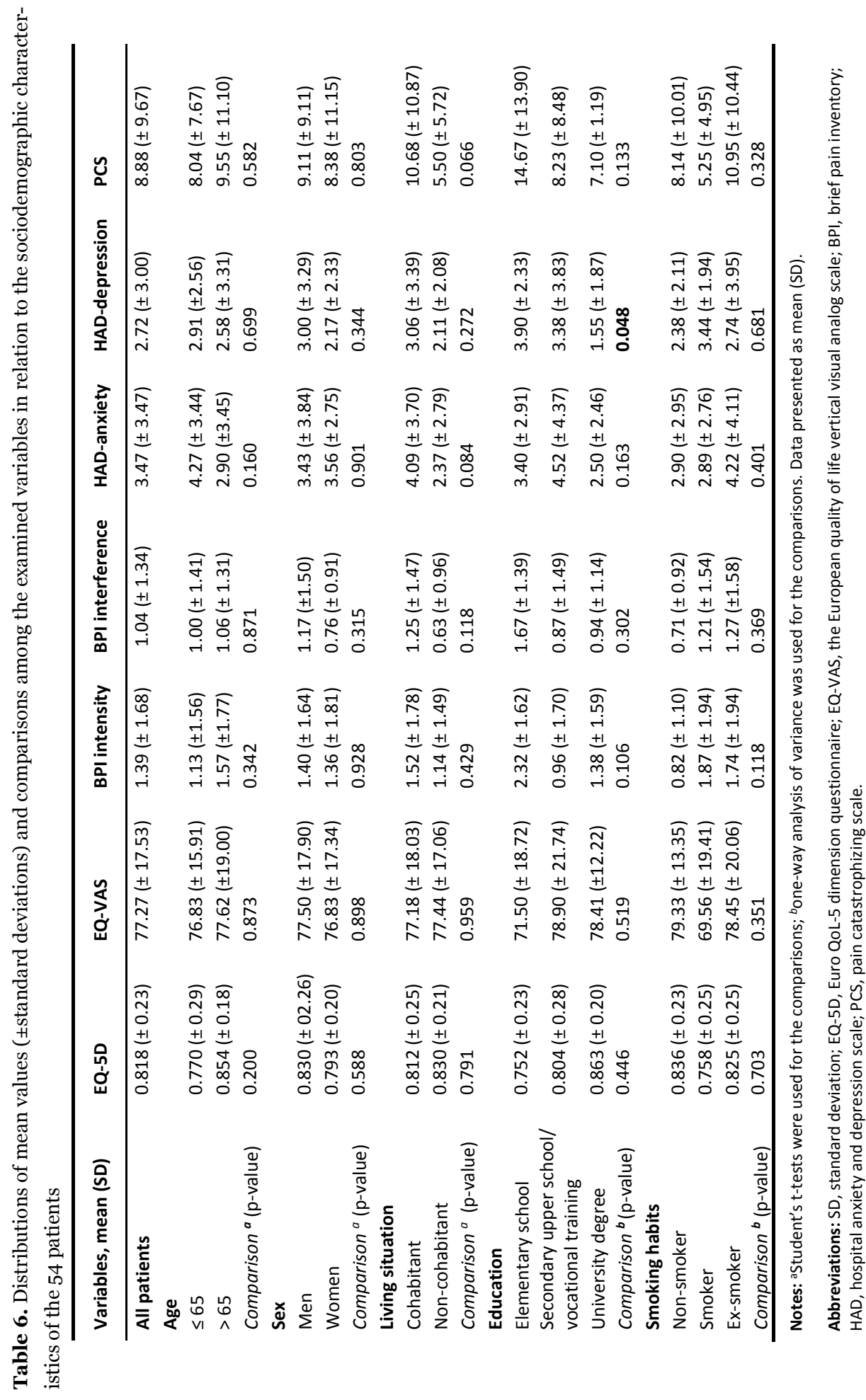




\section{REGRESSION ANALYSES}

Before the regression analysis, multicollinearity was observed for BPI interference and BPI intensity (i.e., bivariate correlation $>0.7$ ), and only pain intensity was entered into the regression models because it provides a stronger relationship with the dependent variables (EQ-5D and EQ VAS). In the regression model with EQ-5D as a dependent variable, pain intensity (BPI intensity) and depression (HAD-D) were significant regressors (Table 7). These associations remained significant after adjustments for age, gender, living status, education, smoking habits, and weeks from diagnosis to inclusion in the study (newly diagnosed and non-newly diagnosed). In the regression model with EQ VAS as dependent variable, pain intensity (BPI intensity) and depression (HAD-D) also were significant regressors (Table 8). Likewise, adjustments from the earlier variables did not alter the results.

Hence, the regression models showed that pain intensity and depression negatively influenced both dimensions of HR-QoL.

Table 7. Bivariate correlations and unadjusted and adjusted linear regression models of EQ-5D

\begin{tabular}{|c|c|c|c|c|c|c|}
\hline \multirow{2}{*}{ Variables } & \multirow{2}{*}{$\begin{array}{l}\text { Correlations } \\
\text { with EQ-5D (r) }\end{array}$} & \multirow{2}{*}{$p$-value } & \multicolumn{2}{|l|}{ Regression coefficients } & \multirow{2}{*}{$p$-value } & \multirow{2}{*}{$\mathbf{R}^{2}$} \\
\hline & & & Unstandardized (95\% Cl) & Standardized & & \\
\hline RLM1 & & & & & & $34.7 \%$ \\
\hline BPI intensity & -0.502 & $<0.001$ & $-0.050(-0.093,-0.008)$ & -0.341 & 0.022 & \\
\hline HAD anxiety & -0.319 & 0.020 & $0.000(-0.025,0.024)$ & -0.007 & 0.970 & \\
\hline HAD depression & -0.507 & $<0.001$ & $-0.030(-0.060,0.00)$ & -0.372 & 0.049 & \\
\hline PCS & -0.238 & 0.090 & $0.002(-0.006,0.009)$ & 0.064 & 0.651 & \\
\hline RLM2 & & & & & & $42.2 \%$ \\
\hline BPI intensity & & & $-0.052(-0.097,-0.008)$ & -0.353 & 0.022 & \\
\hline HAD anxiety & & & $0.008(-0.019,0.033)$ & 0.115 & 0.553 & \\
\hline HAD depression & & & $-0.032(-0.066,-0.005)$ & -0.397 & 0.050 & \\
\hline PCS & & & $6.208 \mathrm{E}-5(-0.007,0.008)$ & 0.003 & 0.987 & \\
\hline
\end{tabular}

Notes: $r$, Pearson correlation coefficient; $R^{2}$, multiple correlation coefficient squared.

Abbreviations: EQ-5D, Euro QoL-5 dimension questionnaire; BPI, Brief Pain Inventory; HAD, Hospital Anxiety and Depression Scale; PCS, Pain Catastrophizing Scale; Cl, Confidence Interval; RLM1, Regression Linear Model for unadjusted model; RLM2, Regression Linear Model adjusted for age, gender, living situation, education, smoking habits, and weeks from diagnosis to participation. 
Table 8. Bivariate correlations and unadjusted and adjusted linear regression models of EQ VAS

\begin{tabular}{|c|c|c|c|c|c|c|}
\hline \multirow[b]{2}{*}{ Variables } & \multirow{2}{*}{$\begin{array}{l}\text { Correlations } \\
\text { with EQ VAS (r) }\end{array}$} & \multirow{2}{*}{$p$-value } & \multicolumn{2}{|l|}{ Regression coefficients } & \multirow{2}{*}{ p-value } & \multirow{2}{*}{$\mathbf{R}^{2}$} \\
\hline & & & Unstandardized $(95 \% \mathrm{Cl})$ & Standardized & & \\
\hline RLM1* & & & & & & $62.6 \%$ \\
\hline BPI intensity & -0.623 & $<0.001$ & $-3.910(-6.261,-1.559)$ & -0.370 & 0.002 & \\
\hline HAD anxiety & -0.434 & 0.001 & $0.418(-0.940,1.777)$ & 0.084 & 0.538 & \\
\hline HAD depression & -0.714 & $<0.001$ & $-3.287(-4.944,-1.630)$ & -0.567 & $<0.001$ & \\
\hline PCS & -0.408 & 0.003 & $-0.093(-0.491,0.305)$ & -0.053 & 0.640 & \\
\hline RLM2* & & & & & & $69.5 \%$ \\
\hline BPI intensity & & & $-3.711(-6.479,-1.380)$ & -0.351 & 0.003 & \\
\hline HAD anxiety & & & $0.768(-1.112,1.915)$ & 0.155 & 0.287 & \\
\hline HAD depression & & & $-3.933(-5.234,-1.682)$ & -0.678 & $<0.001$ & \\
\hline PCS & & & $-0.251(-0.527,0.038)$ & -0.142 & 0.233 & \\
\hline
\end{tabular}

Notes: $r$, Pearson correlation coefficient; $R^{2}$, multiple correlation coefficient squared.

Abbreviations: EQ VAS, the European Quality of Life Visual Analog Scale; Brief Pain Inventory; HAD, Hospital Anxiety and Depression Scale; PCS, Pain Catastrophizing Scale; Cl, Confidence Interval; RLM1, Regression Linear Model for unadjusted model; RLM2, Regression Linear Model adjusted for age, gender, living situation, education, smoking habits, and weeks from diagnosis to participation.

\section{Paper IV}

Paper IV, evaluate whether patient education and individually tailored SC reduces pain intensity and improves HR-QoL, mood, and sleep during and after RT for patients with HNC.

\section{DESCRIPTION OF THE PATIENTS}

Of the 64 included participants (54 also were included in Paper III), 54 were diagnosed with HNC and informed about the curative intent of RT (in mean 7.7 weeks before inclusion in the study) labelled as "newly diagnosed". Ten patients out of 64 patients were diagnosed with HNC and informed (in mean 150 weeks before inclusion in the study) on the curative intent. Of these ten patients, one patient had undergone surgery once in 2015; the other nine patients participated in Paper III and labelled as non-newly diagnosed patients (above). 
Sociodemographics of the participants at BL are listed in Table 9.

Table 9. Participant characteristics and comparison between the groups at BL

\begin{tabular}{|c|c|c|c|c|}
\hline $\begin{array}{l}\text { Characteristic; } n(\%) \text {, } \\
\text { unless otherwise } \\
\text { stated }\end{array}$ & $\begin{array}{l}\text { Total } \\
(n=64)\end{array}$ & $\begin{array}{l}\text { Intervention } \\
\text { group }(n=34)\end{array}$ & $\begin{array}{l}\text { Control } \\
\text { group } \\
(n=30)\end{array}$ & p-value ${ }^{a}$ \\
\hline Age (years) (mean, SD) & $65.05( \pm 10.47)$ & $64.0( \pm 10.42)$ & $66.3( \pm 10.57)$ & 0.38 \\
\hline Women & $25(39.1)$ & $12(35.3)$ & $13(43.3)$ & 0.51 \\
\hline Living situation & & & & 0.86 \\
\hline Not living alone & $42(65.6)$ & $22(64.7)$ & $20(66.7)$ & \\
\hline Living alone & $22(34.4)$ & $12(35.3)$ & $10(33.3)$ & \\
\hline Education & & & & 0.25 \\
\hline Primary & $10(15.6)$ & $4(11.8)$ & $6(20.0)$ & \\
\hline $\begin{array}{l}\text { Second upper } \\
\text { school/vocational }\end{array}$ & $28(43.8)$ & $13(38.2)$ & $15(50.0)$ & \\
\hline College/University & $26(40.6)$ & $17(50.0)$ & $9(30.0)$ & \\
\hline Smoking habits & & & & 0.83 \\
\hline Non-smokers & $26(40.6)$ & $15(44.1)$ & $11(36.7)$ & \\
\hline Smokers & $10(15.6)$ & $5(14.7)$ & $5(16.7)$ & \\
\hline Ex-smokers & $28(43.8)$ & $14(41.2)$ & $14(46.7)$ & \\
\hline
\end{tabular}

Notes: SD, Standard Deviation; a, Students t-test for continuous variables or Chi-Square test for categorical variables.

\section{PRIMARY OUTCOMES}

We evaluated the effects of the intervention with tailored education and tailored $\mathrm{SC}$ on pain intensity and pain interference based on the text message answers by performing repeated measures GEE model, Figures 8 and 9 (and appendix V). Missing values were $2 \%-3 \%$ from week 7 to week 10 with respect to all primary outcomes. The results showed no overall significant differences between the control and intervention groups over time.

As expected, time was associated with the primary outcomes (Appendix V) in both groups. Compared to BL pain intensity, pain interference on mood and enjoyment of life were higher for weeks 2 - 7, pain interference on general activities was higher for weeks $3-7$, and pain interference on relations with other people and on sleep was higher weeks 2 - 9. Student t- tests (not in Table or Figure) showed results identical to the GEE analyses. 

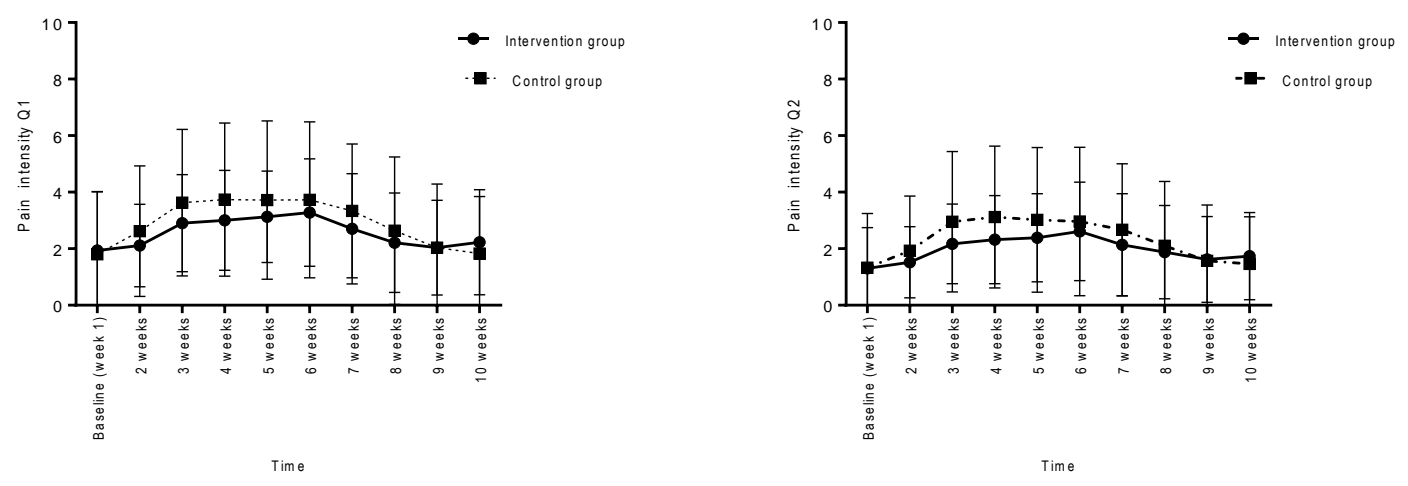

Figure 8. Scores of primary pain intensity outcomes by text message answers and standard deviation (vertical bars), for intervention group $(n=34)$ and control group $(n=30)$. 


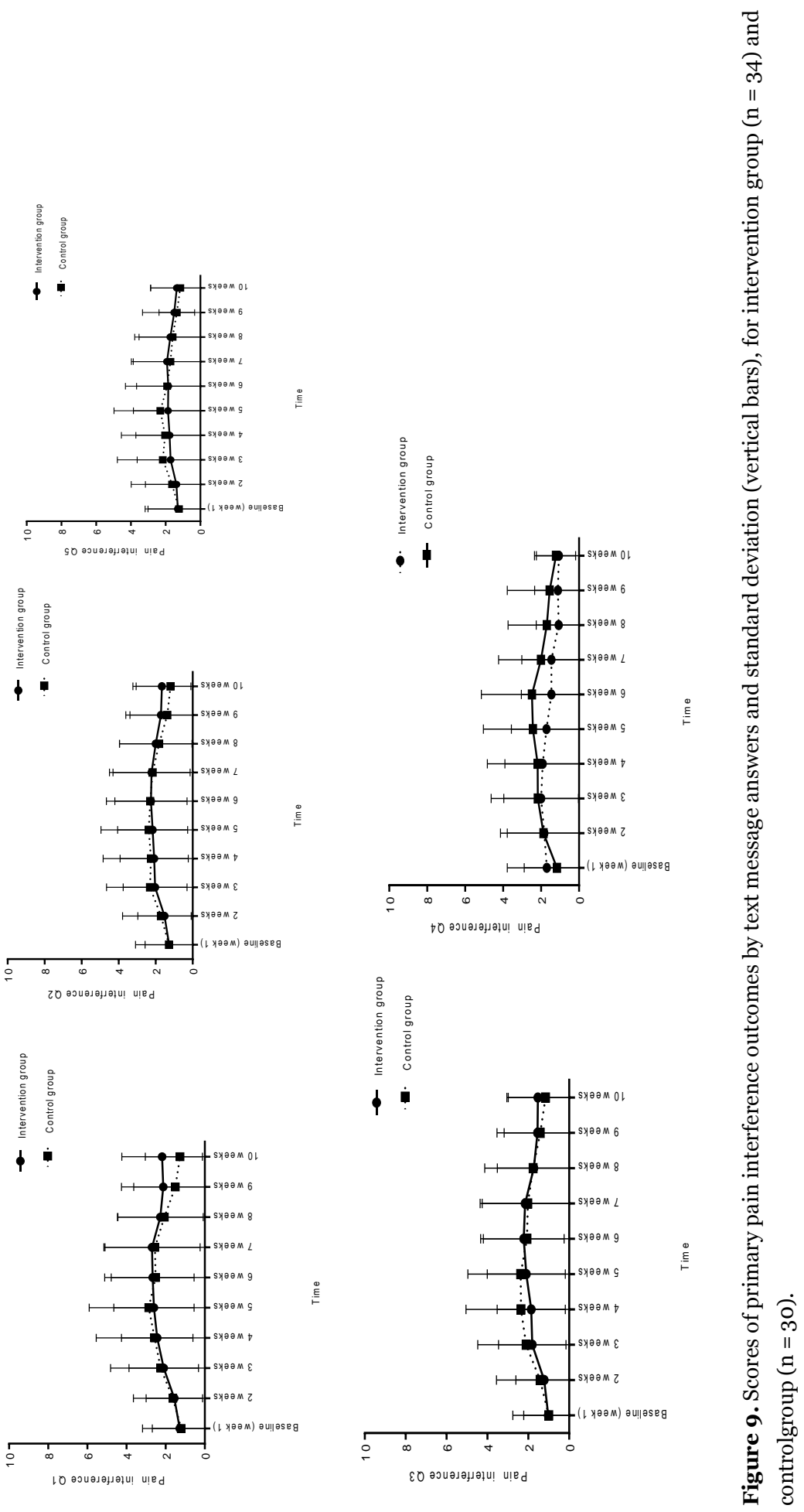




\section{SECONDARY OUTCOMES}

The effects of intervention with education and SC on the secondary outcomes were examined using mixed repeated measures ANOVA. The between-subjects factor consisted of the two groups (intervention and control) and the within-subjects factor was three time points (BL, 4 weeks, and 10 weeks). No statistically significant differences existed between the two groups except for higher EQ-VAS at BL and sleep satisfaction at 10 weeks in the intervention group, Figures 10 and 11 and Appendix VI.

For both groups, time was associated with the secondary outcomes (Appendix VI). Pain intensity and interference were significantly lower at BL compared to 4 weeks and decreased significantly between 4 weeks and 10 weeks. HR-QoL (EQ VAS) was statistically significantly higher at BL compared to 4 weeks and 10 weeks. Depressive symptoms (HAD-depression) were statistically significantly lower at BL compared to 4 weeks. Barriers to pain management (BQ-II) were significantly lower at 4 weeks and 10 weeks compared to BL. Student t-tests (not in Table or Figure) showed results identical to the mixed repeated measures ANOVA analyses. 

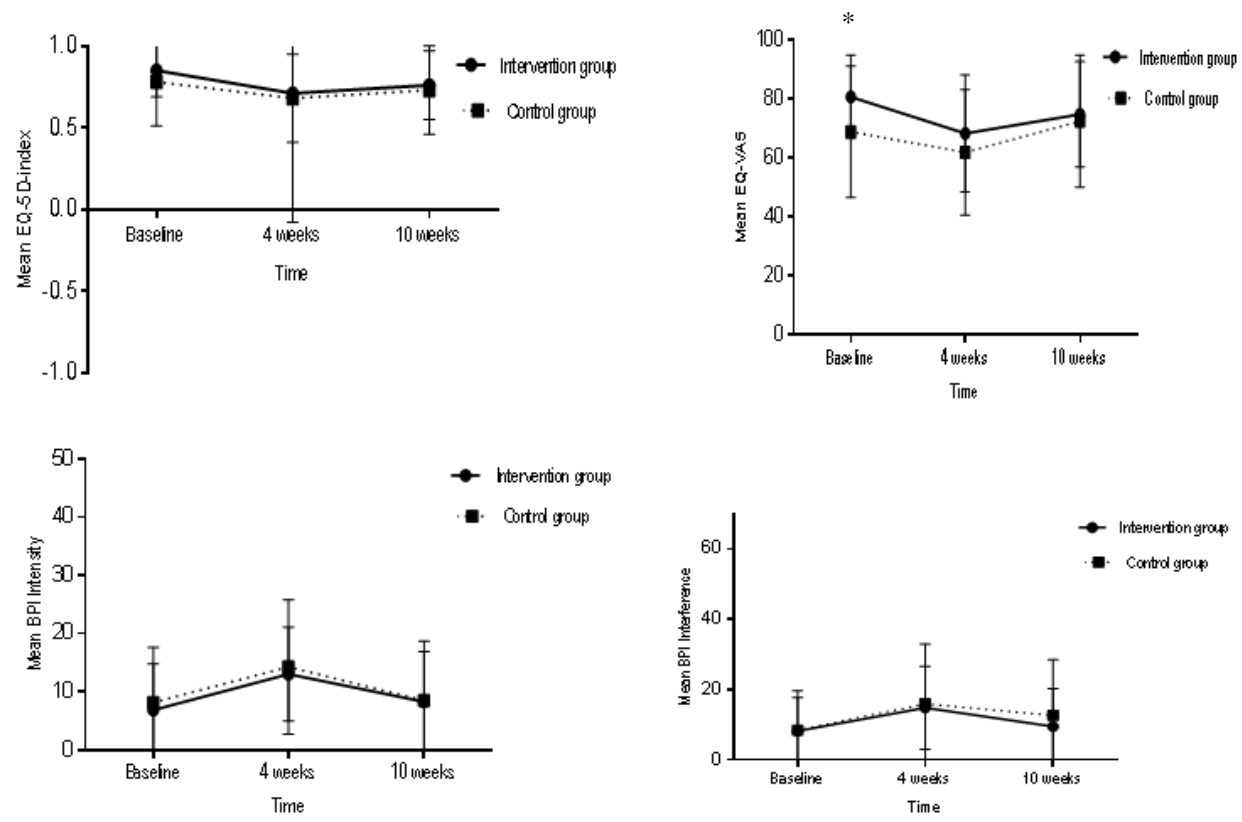

Itenertion goup

- Cortrol goup
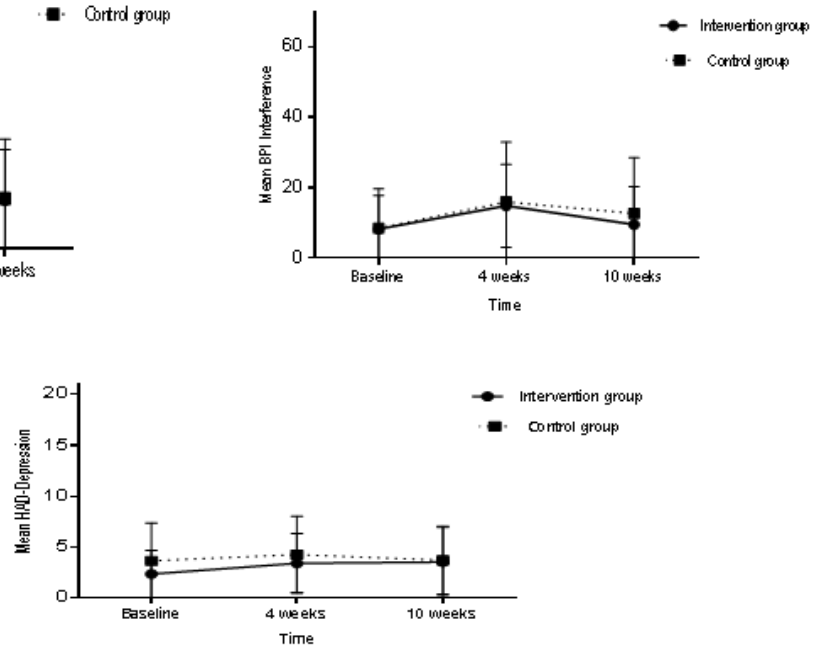

Figure 10. Scores of secondary outcomes and standard deviation (vertical bars), for intervention group $(\mathrm{n}=34)$ and control group $(\mathrm{n}=30),\left({ }^{*}=\mathrm{p}<0.05\right)$ 

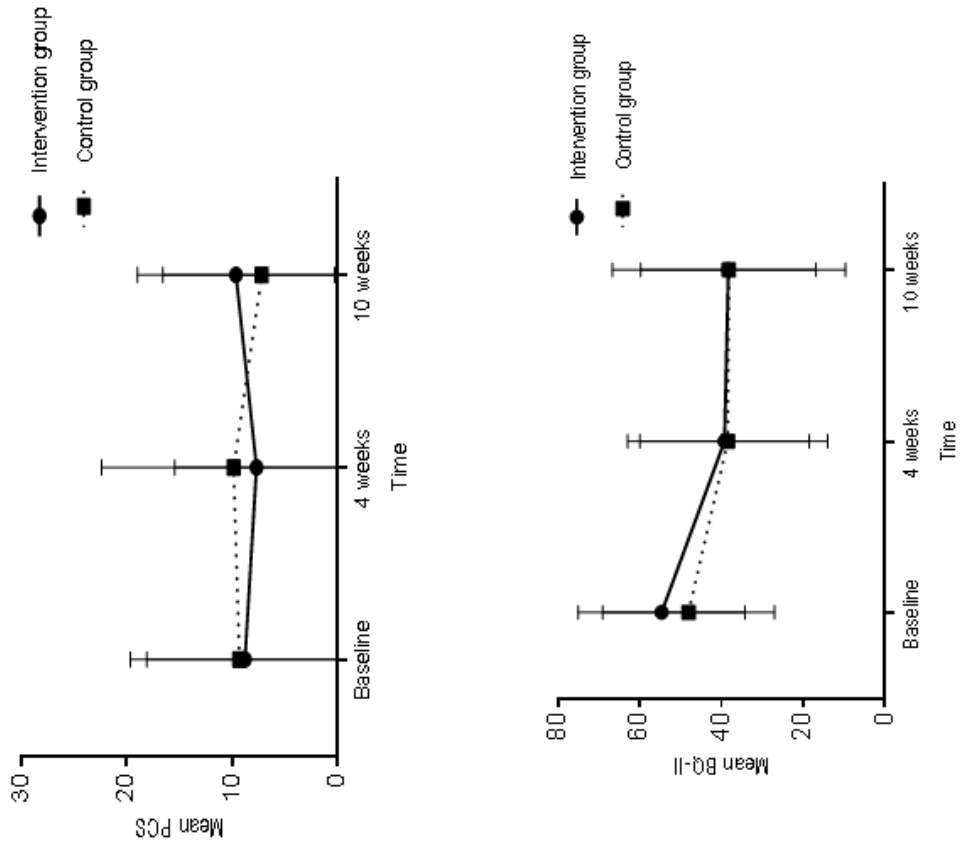

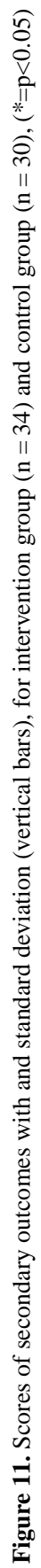
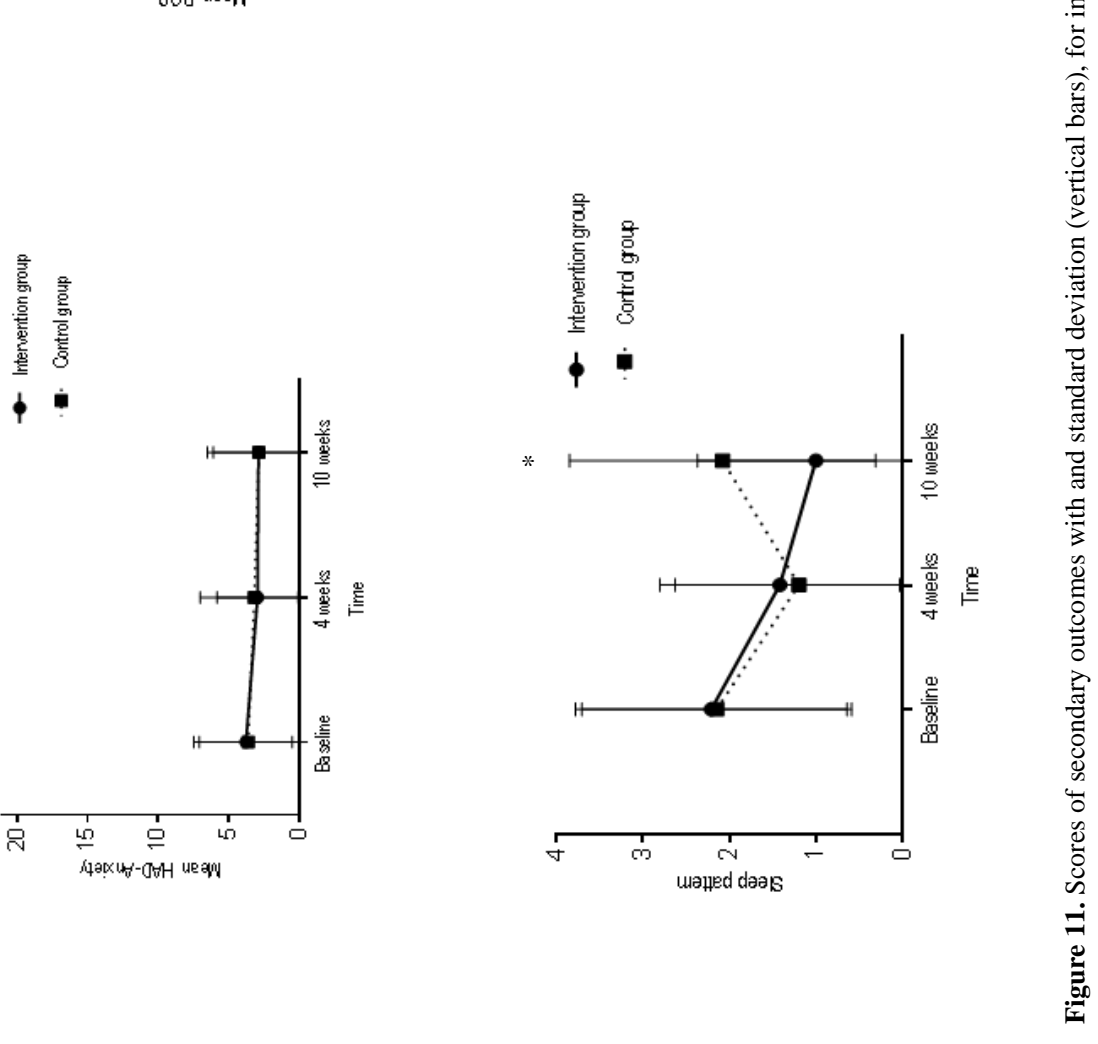



\section{DISCUSSION}

\section{Major Findings}

The overall aim of this thesis was to describe experiences and perceptions of pain and HR-QoL in patients with HNC treated with RT, to develop pain management strategies, and to maintain HR-QoL and daily functions in patients with HNC.

The main findings result in a deeper understanding of how patients with $\mathrm{HNC}$ and their relatives perceived disease-related pain. In addition to physical and social pain, extensive existential and psychological pain were reported. Remarkably, patients conveyed no clear relationship or interaction between pain and psychological load, a finding that may imply a biomedical view of pain or may reflect the difficult situation patients were in. Relatives described the stressful situation of supporting their relatives who suffered from physical, psychological and social pain. A gloomy picture described psychological distress, lack of support from the healthcare system, inadequate knowledge of the situation, and frustration at not being able to participate in the care process.

Additional important findings related to how pain intensity and depressive symptoms negatively influenced HR-QoL during early RT. Systematic customised education and SC interventions as a complement to pharmacological treatment revealed a tendency toward reduced pain intensity during a portion of RT, although no significant group differences were found.

Figure 12. The principal areas to be discussed in relation to the aim of this thesis.

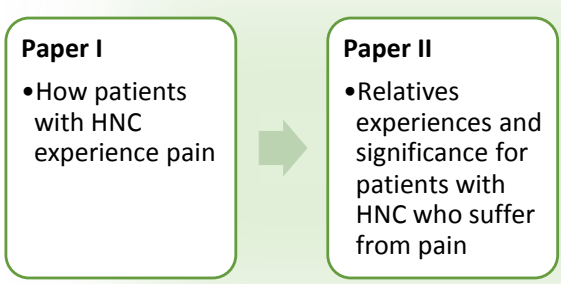

Paper III
-Factors
affecting HR-
QoL during
early RT in
patients with
HNC

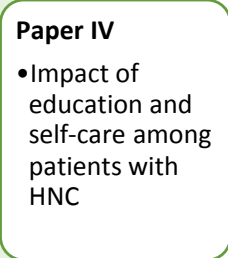




\section{Meaning and Importance of Findings}

Paper I describes patients with HNC who were invited to participate in two interviews. The first interview was conducted within one month of RT and the second interview four to six months later. Paper II addresses the relatives of the patients described in Paper I who still required pain management. The timing of interviews with relatives was a median of 3.5 months (min 0.25 - max 9.75) after the patient had completed RT (Paper II, Table 1).

\section{VARIOUS DIMENSIONS OF PAIN}

The findings in Paper I showed that already during and shortly after RT patients with HNC described existential pain expressed as fear of death, meaninglessness and guilt. These patients experienced physical pain that may have triggered thoughts of life and death, which are elements of the concept of existential pain. Existential pain can be described as an experience with components of loneliness, meaninglessness, guilt, and thoughts of death [49, 144-148]. Moreover, existential pain may amplify physical pain, or even become its primary cause and, left untreated, may trigger doubts about inadequate treatment efficacy and disease progression [49]. Thoughts of death and the meaning of life can intensify the suffering, regardless of whether or not physical pain is present [49]. Collectively, this situation may help explain why the patients in Paper I communicated feelings of distress and that their lives were threatened, which we interpreted as existential pain and which may have been influenced by their physical pain.

Almost all patients in Paper I discussed the meaning of life, the importance of family and that they no longer took life for granted. The meaning of these findings in Paper I corresponds with Yalom's description of existential pain that includes anxiety regarding fear of death, which is in line with the concept of existential struggle [148]. The existential struggle entails ultimate problems like the tension between the inevitability of death and the desire to continue to live. Given the insight that death is inevitable and that ultimately we are alone, thoughts may arise about the meaning of life [148].

Several of the patients stressed how important it was to have optimistic faith that their cancer treatment would undoubtedly conquer their disease (Paper I). This may be in line with Yalom's description of the rapid establishment of protection that conceals anxiety and fear. In difficult situations there is an ability to think that it does not concern me (specialness) and there is always something that can rescue me (the ultimate rescuer) [148], a perception also reported by the patients in Paper I.

Living with doubt and uncertainty was experienced as stressful (Paper I). Four to six months after completion of RT patients continued to be worried about treatment results despite receiving information about curative treatment (Paper I). This reaction could also be viewed as part of the existential pain interwoven with physical pain, suggesting that these patients were considering alternatives other 
than curative outcomes and even death. Patients remained concerned and worried that perhaps the tumor might not be decreasing in size as expected and considered the threat of recurrence.

"You're afraid that it's not...that they haven't removed everything at the surgery...it will not be a success...that I will die..." quoted from a woman with HNC (Paper I, p. 340).

These patients (Paper I) were predominantly male (73\%) and older $(64 \pm 10)$ and may not have felt confident about the information they received about curative treatment. One study that included 529 cancer patients, 112 of whom had HNC, addressed patient-physician communication and found that males and older patients belonged to the group that had the least confidence in their doctor [149].

In addition to existential and physical pain, psychological distress and social withdrawal were also prominent among the patients in Paper I. They did not express any clear association between physical pain and psychological symptoms, a result that may reflect a biomedical view of pain and perhaps the difficult situation of the patients (Paper I). This finding became clear during the interviews when the majority of patients insightfully and spontaneously described their physical experiences of pain. Most provided vivid descriptions of how they experienced the physical pain, and in several cases, where possible, showed their ulcers and vesicles in the oral cavity. Affliction with a demanding, and presumably potentially life-threatening, cancer may have affected the ability of patients with $\mathrm{HNC}$ to reflect on the interaction between various dimensions of pain, despite information about curative treatment (Paper I). However, the patients' perception of existential, psychological and social pain, including their innermost thoughts, were more tentatively and cautiously communicated.

Relatives confirmed the difficulties patients experienced communicating negative emotions such as fear, anger and anxiety. Moreover, relatives described patients perceived emotions as difficult to differentiate from physical pain (Paper II). Even if no correlation ultimately helps to identify the various dimensions of pain, pain may still have made it hard to manage the difficult situation. Interventions aimed at teaching patients how to internalise the BPS model for pain management may prove useful and should be further evaluated [150]. Providing patients with more knowledge gives them insight into how the various dimensions of pain can affect their life situation. This tool may make it easier for patients with $\mathrm{HNC}$ to communicate negative thoughts and emotions that may originate in existential or psychological ill health.

Both the physical and existential experience of pain may lead to have psychological and social consequences [36]. Social pain can be defined as a painful experience resulting from social exclusion or loss, loneliness and moral wounds and may be related to physical pain. Research on social pain shows that the same neural regions of some brain structures are activated as during the experience of 
physical pain [51, 151]. As care providers we should try to gain a complete picture of the patient's pain, for example TP and the BPS approach to pain. Patients who experience continuity and security in the healthcare encounter may possibly be better able to communicate their pain and anxiety, and thereby perhaps have a more positive experience, such as reduced social pain.

The results from Papers I and II suggest that an extensive assessment of pain is a necessary component in the management of cancer pain. Cancer-related pain should be considered as a multidimensional phenomenon, a complex interaction between the physical, psychological, social and existential dimensions of pain [36, 152]. Consequently it is important to identify the meaningful aspects of pain so that individual needs can be addressed to successfully assess the symptoms of patients with HNC [153].

Our results show that both TP and the BPS model can be applied to understand and help patients with $\mathrm{HNC}$ who have undergone RT. Modern pain research, such as the BPS model, has opened new pathways to treat pain by incorporating biological, psychological and social aspects into the assessment and treatment process. Existential pain, which was common among patients in Paper I, is part of TP and in a disease situation such as cancer, which can pose a threat to life, existential pain should be considered and treated by the healthcare system. However, existential pain is not part of the BPS model. Consequently, the BPS model and TP complement each other and through the use of TP, existential pain may also be addressed and treated. The BPS model may be viewed as the foundation from which we assess and treat pain, while TP describes the total suffering experienced as the end of life approaches or when patients perceive their lives to be threatened, as in Paper I.

\section{INFORMATION AND BREAKING NEWS}

The patients who participated in the studies (Papers I, III and IV) were drawn from clinical practice at the Head and Neck and the Oncology clinics at University Hospital in Linköping, Sweden. All patients received curative treatment according to their medical records. When dialogue with the attending physicians shortly after the conclusion of the study, they confirmed what we had learned when reviewing the medical records prior to inclusion, which was that these patients had received information about curative treatment. It became apparent when speaking with the doctors that the patients rarely posed questions concerning disease prognosis. When questions did arise, patients could not be given a full guarantee of being cured. Communication between patients (Papers I, III and IV) and doctors is of course in part unknown since personal interaction is involved. The healthcare system strives to achieve individualised patient-centered medical care and this also applies to information provided to patients and relatives at various stages. 
Relatives who were often present with the patient found the situation to be difficult and traumatic when informed of the diagnosis. The entire situation, especially the period between diagnosis and treatment start, was experienced with fear, vulnerability and uncertainty for the future by both relatives and the patient (Paper II).

Breaking bad news is a healthcare concept that refers to information that changes a person's perception of the future in a negative direction [154]. There is no question that patients and relatives have all experienced breaking bad news (Papers I and II). In general, breaking bad news entails informing the patient about a diagnosis that communicates new information about disease progression [154]. How bad news is received is highly individual and dependent on context, which makes it difficult to anticipate the consequences for the individual patient and the patient's family [155].

In many cases, the patients and their relatives in our study reported dissatisfaction with the way in which medical personnel handled breaking bad news and experienced a lack of tact, understanding and compassion (Papers I and II). Such problems likely contributed to the fear, vulnerability and uncertainty mentioned above. The wait for both treatment start and assessment of treatment effect may have further aggravated such feelings. Prior studies have shown that patients feel more confident and hopeful when conversations focus on patient needs and involve discussions where both patient and relatives are present [149, 155, 156]. The patients in Paper I who reported that they did receive adequate information felt reassured, a finding which is also in line with earlier studies [157-159]. Reassurance may entail individual medical information and improved understanding of the condition [157].

Delivering bad news is stressful, as is supporting and helping patients to understand so that they can cope with the disease and its consequences [160, 161]. Moreover, such information should be trustworthy, based on scientific evidence and proven experience, and instill hope [156]. While doctors usually communicate bad news to patients, doctors and nurses should work together to prepare to provide continued support and information [162]. In general, bad news is not an isolated event, and medical personnel must work together with patients and relatives to help process and clarify the information as needed [163].

The ability to communicate information to patients and relatives in a manner that inspires trust should be considered a necessary skill for healthcare providers. Skilful communication of bad news is essential, since the results of such actions may influence patients and relatives regarding their experience of and satisfaction with both their treatment and the healthcare system. Satisfactory communication benefits both patients and their relatives by helping them to better cope with the consequences of the disease. Guidance and communication tools to help healthcare personnel to develop their communication skills may improve their ability to communicate bad news. Evidence-based communication tools have 
been developed and adapted for use in clinical practice to help nurses and physicians to effectively and productively deliver bad news (breaking bad news). One communication tool often mentioned in the literature is SPIKES (Setting, Perception, Invitation / Information, Knowledge, Empathy and Summarise/Strategise) $[154,164]$. SPIKES is a specific training programme for nurses and doctors to help them communicate with patients and provides an important foundation for teaching effective communication. SPIKES along with support and assistance from colleagues can improve the skills and attitudes required in encounters with patients and their relatives.

\section{RELATIVES' EXPERIENCES}

Relative appeared to be a key component for providing support to patients during and after treatment, which is in line with previous research $[165,166]$. A few relatives described how relationships with family members improved as they grew closer and spending more time together (Paper II).

Relatives also reported finding themselves in a demanding situation in which they were required to support patients who were often affected by various dimensions of pain, accompany them to medical treatments and meetings, assume responsibility for administration of medicines, and help them with personal hygiene and wound care (Paper II). Relatives described a gloomy situation, referring to psychological stress, lack of transparency and participation in health care and lack of personal support and care from care providers. Just as among the relatives in our study, other studies have also reported mental health issues among relatives of patients with HNC [78, 167]. Furthermore, relatives perceived that the patients with HNC had severe physical pain, which is consistent with prior studies in which relatives often felt that the pain was worse than was self-reported by patients $[168,169]$.

The interviews with relatives usually coincided with the patient's second interview (Paper II, Table 1). At the point when the relatives were interviewed, patients were usually feeling somewhat better, with less pain and other symptoms (Papers I and II).

Relatives provided support for patient care and carried out many practical tasks with increasing responsibilities (Paper II), which may have contributed to their stressful situation, also in line with earlier research [78, 79, 167, 170]. Some relatives experienced negative feelings such as inadequacy and loneliness, which were combined with a sense of not knowing how to deal with the situation. In addition, there was fear and concern that the cancer treatment may not have been effective and those family members could also be negatively impacted by recurrent disease (Paper II). Our results are in line with a prior review, which concluded that the point in time when we studied relatives, about six months after diagnosis, proved to be stressful [78]. 
Relatives expressed their insecurity regarding their insufficient knowledge and skills to cope with the patient's pain and pain management (Paper II). Based on the above results concerning the experiences of relatives, the healthcare system should consider providing patients and willing relatives an opportunity to participate in individualised training to address disease-related patient needs. Relatives who are most often involved in the patient's situation have a better overview and can, along with the patient, convey a good foundation to the healthcare system for appropriate interventions.

Those patients with severe symptoms and high care needs, like the relatives in our studies, experienced a difficult situation and required support and assistance, as reported in prior studies [171-173]. This casts light on how care requirements could possibly be reduced if the healthcare system expands care and support for patients and relatives.

Temporary friction was reported in some relationships, although they were still described as open, sincere and intimate. One addition to the results in Paper II: temporary friction arose between a relative and a family member, who sometimes chose to travel during the most intense weeks of RT.

\section{PAPER III}

The qualitative interviews reflected a difficult life situation, for which reason we wish to quantify pain and HR-QoL, as well as to identify factors that may affect HR-QoL among patients with HNC.

Therefore, we investigated factors that affect HR-QoL using a quantitative crosssectional study with questionnaires concerning pain, psychological symptoms and HR-QoL during early RT (Paper III). The hypothesis was that pain intensity, pain interference, mood disturbance and pain catastrophising could affect HRQoL during early RT.

\section{HEALTH-RELATED QUALITY OF LIFE}

Health related quality of life among patients (Paper III) was good during early RT. Among the participants in our study, HR-QoL was found to be comparable to that of the Swedish population at large when measured using EQ-5D, although HR-QoL was somewhat lower when measured using EQ-VAS [174, 175]. This difference may be because EQ-5D covers physical and psychological symptoms that are not affected during an early phase of illness, while EQ-VAS measures the general experien of health. Several studies have shown that HR-QoL among patients with HNC, measured using disease-specific questionnaires, is good at the start of RT, decreases during and immediately after RT, and returns to BL approximately one year after RT [14, 35, 176-178]. Other studies, however, are not in line with the results of Paper III. Low HR-QoL due to conditions such as pain and difficulties eating were reported by patients with HNC one week prior to start of RT [90]. Similarly, one study of 133 patients with HNC found lower QoL compared with 
the general population, both prior to start of RT and one month later [71]. To date, general HR-QoL and health among patients with HNC has been sparsely studied [179] for which reason they were investigated in Paper III. The points at which time measurements were taken, along with differences in the HR-QoL questionnaires used in the studies above, make comparisons difficult.

The advantages of using general instruments such as the EQ-5D and EQ-VAS are that they measure key health areas and that they can be used to make comparisons between groups, as well as with the general population [83]. Another advantage of the EQ-5D is its simplicity; there are few questions to answer compared with disease-specific questionnaires, which are often comprehensive and thus contain many questions. Since the purpose of Paper III was to identify factors that could affect HR-QoL in patients with HNC, more questionnaires were required (BPI, HADS, PCS). We felt that the number of questions in these questionnaires, along with those in the EQ-5D and EQ-VAS, was reasonable. We had a high response rate in both Papers III and IV. The disadvantages of general HRQoL questionnaires such as the EQ-5D and EQ-VAS are that they do not specifically measure those health aspects that may be of importance for the disease under study (Fayers and Machin, 2013). These disadvantages may have affected the results in Paper III; one might speculate that had the battery also included disease-specific questions, HR-QoL may possibly have been worse. One earlier study, however, showed that both general and disease-specific instruments contribute important information about HR-QoL [180].

The most commonly used HR-QoL questionnaire to date in studies of patients with HNC [181] is the disease-specific European Organization for Research and Treatment of Cancer Quality of Life Questionnaire-head and neck 35 [182, 183], the University of Washington Quality of Life Questionnaire [184], and the Functional Assessment of Cancer Therapy Head and Neck Cancer Questionnaire [185]. These questionnaires address emotional, social, and physical well-being, in addition to disease-specific symptoms such as pain, difficulty swallowing, nausea and fatigue. The advantages of disease-specific instruments are that they usually have good content validity, which is to say they cover health aspects that are of relevance to the patient and usually have high sensitivity to identify differences between groups and changes over time. The disadvantages are that the results cannot be compared with groups of patients having other diagnoses, or with the general population. Studies of patients with $\mathrm{HNC}$ have used different disease-specific questionnaires, which renders comparisons difficult [83].

\section{PAIN AND PSYCHOLOGICAL SYMPTOMS}

The patients in Paper III experienced low pain intensity and low pain interference during early RT, which is in line with earlier studies $[35,186]$. The importance of being pain-free was demonstrated in one study of patients with newly diagnosed $\mathrm{HNC}$ who were asked to rank their treatment priories. Their top priorities were to cure the cancer, to live as long as possible and to be free of pain [187]. It is 
paramount to understand when pain becomes clinically problematic for the patient. The clinical impression of patients with $\mathrm{HNC}$ is that physical function may be affected already after a 1-2 step-increment on a pain scale of zero to ten. One such example is pain on swallowing, which may result in worsening of nutritional status. Earlier studies show that patients with cancer experience a significant change in pain intensity corresponding to about a two-point difference on a tenpoint scale [188]. Cancer-related pain can be graded on a scale corresponding to mild (0-4), moderate (5-6) and severe (7-10) [189-191]. Average pain intensity among the patients in Paper III was mild.

One possible explanation for why patients reported relatively good HR-QoL and low pain intensity (Paper III) may be that they were still in an early phase of RT and had not yet been affected by the usual radiation-related side effects. An alternative explanation may be denial of the cancer disease as a protective behavior [192, 193].

The reporting of low pain intensity by patients (Papers III and IV) could possibly be out of respect for the care provider, especially since they were participating in a research study involving pain. The healthcare information that patients receive regarding the possibility of upcoming severe pain associated with RT could mean that patients remain expectant and judge their pain to be relatively mild, since they may envisage and anticipate an even more severe situation.

The majority of participants in Papers I, III and IV are male. A more severe pain situation appeared to be reported during the interviews (Paper I) compared with that in the self-reported questionnaires in Paper III and IV. This is in contrast to previous research and difficult to explain. Thus, male patients with chronic pain have been shown to report lower pain intensity during interviews than in questionnaires [194]. This finding may be due to lower anonymity during interviews and may be associated with over-reporting of desirable behaviours and underreporting of undesirable behaviours [195].

The regression models in Paper III showed that pain intensity had a negative impact on HR-QoL in early RT, which is consistent with an earlier study in which pain was negatively associated with HR-QoL prior to start of cancer treatment in patients with HNC [196]. An association between pain and HR- QoL has been shown to occur both during and after treatment for cancer $[197,198]$ and patients with cancer experienced a lower QoL when pain was inadequately controlled [199].

The patients in Paper III reported few signs of depression during early RT. These results differ from previous studies, which found that a large proportion of patients with HNC had symptoms of depression before starting treatment [200, 201]. The regression models in Paper III showed that depressive symptoms were negatively associated with EQ-5D and EQ VAS, which is consistent with previous 
studies [202, 203]. Depressive symptoms prior to cancer treatment were predictive of a significantly lower HR-QoL over time among patients with HNC [204]. Moreover, we found low mean values for anxiety and pain catastrophising; these symptoms where not associated with HR-QoL (Paper III). Earlier papers have described how patients who are highly impacted by their disease also suffer from anxiety [54, 57]. The patients in Paper III, however, had few symptoms and possibly therefore also low disease impact, which may have entailed relatively low anxiety.

\section{WHAT WE ADD}

The results in Paper III emphasise the importance of early screening for pain and depression in order to prevent a general worsening and decline in HR-QoL in patients with HNC undergoing RT. A systematic review [205] found that good HRQoL was an indicator of better survival and one study [179] showed that pain prior to treatment had a significant association with lower survival.

One suggested method to discover and deal with symptoms in individuals diagnosed with cancer who are undergoing treatment is prehabilitation. This concept entails structured assessments and interventions in the time interval between diagnosis and initiation of cancer treatment [206, 207]. Prehabilitation should be tailored to the individual needs of cancer patients and address many facets, including pain, sleep and fatigue [207].

Our results support the significance of individual prehabilitation programmes for pain and depression during early RT, suggesting that such interventions support and maintain good HR-QoL among patients. Prehabilitation for patients with HNC should be carried out prior to upcoming treatment such as RT or surgery, which are often associated with pain in the aftermath. The use of prehabilitation among patients with HNC appears to be an unexplored field. Only one intervention study has focused on a prehabilitation program, which was aimed at preventing lymphedema caused by accumulation of interstitial fluid in conjunction with RT, a common problem among patients with HNC. The findings showed that such intervention was helpful and resulted in early identification and treatment of lymphedema [208].

\section{PAPER IV}

The findings in Paper IV suggest a tendency for lower pain intensity within the group that received individual patient education and individualised SC, although the differences between the groups was not significant. Barriers to pain management (as measured by BQ-II) were significantly lower after four and ten weeks compared with BL. Surprisingly, the patients in both groups reported low pain intensity during the entire ten-week study. As expected, pain and depressive symptoms increased over time, while HR-QoL declined in both the intervention and control groups. 


\section{EDUCATION}

Our findings are partly in line with earlier randomised controlled trials on individualised patient education concerning pain and SC of patients undergoing treatment for various types of cancer [104, 209]. In other words, no differences in pain intensity were found following education and SC. One systematic review of education and SC [97] found no improvement in pain among patients with cancer who received outpatient treatment, which is consistent with our results where the participants were provided with outpatient RT, education and SC instruction.

Several systematic reviews, however, note a beneficial effect on pain intensity in patients with various types of cancer who received patient education and SC instruction [92, 98-101, 103, 210]. Despite the substantial number of educational intervention studies on cancer-related pain, it remains unclear what type of education and SC instruction has an effect on pain and symptom, because of the heterogeneity of the studies.

\section{SELF-CARE}

Earlier intervention studies on patients with cancer support our findings that SC had no significant impact on cancer pain $[104,105,211]$ while other studies have shown that SC does reduce pain [212, 213]. It is possible that hetero/homogeneity (participants and interventions) in the studies referred to above may have contributed to the different conclusions.

The "Theory of nursing systems" describes the interaction between nurses and patients from the perspective of three different nursing systems in an effort to preserve or create SC balance. The three nursing systems are the supportive-educative system, partly compensatory system and wholly compensatory system [1]. In accordance with this theory, TRN chose one of the above-mentioned nursing systems to meet the needs of the patient for SC. The patients in Paper IV were usually part of the supportive-educative system at the beginning of the study (=beginning of RT), which means that following individualised instruction, the patients carried out SC with the support of TRN. If patients were affected by various symptoms, their needs changed and the nursing role transitioned to ambulatory care where a partly compensatory nursing system took shape. Consequently, patients and TRN collaborated to meet needs which patients were unable to manage themselves. Patients regularly and systematically monitored their symptoms and managed their SC needs with support, feedback and where necessary modified instructions regarding SC provided by the TRN, including advice on changes in pharmacological treatment (prescribed by the attending physician and communicated by the TRN).

Such participation in assessment and reporting of pain and other symptoms, as well as feedback from the TRN as described in the study design in Paper IV, is supported by the middle-range theory of Riegel et al. [120]. According to this theory, patients monitor and respond to their symptoms based on goal-focused 
knowledge provided by healthcare personnel, or knowledge that they have obtained on their own. The role of the care provider is to identify what knowledge patients need and to help them apply this knowledge to SC.

\section{SPARSE IMPACT OF EDUCATION AND SELF-CARE AND POTENTIAL FOR IMPROVEMENT}

The interventions in Paper IV had little effect, which may be due to several reasons. Patients with little knowledge and/or motivation who experience difficulties with SC therefore may require further education and advice $[1,120]$. If the patients in Paper IV had little knowledge and/or motivation to practice SC, the study educational intervention would have had an impact on their ability to practice SC. However, an analysis of patient motivation to practice SC was not part of the study.

Past experience of SC may possibly have an influence on patient motivation to carry out SC. For example, one might speculate that it would have been easier to motivate patients to practice self-care if from the time of inclusion in the study they had already begun to take care of themselves through activities such as exercise. A lifestyle that includes smoking and alcohol might conceivably influence motivation to practice SC. Under some circumstances, socioeconomic factors such as the capacity to afford a healthy lifestyle and to achieve financial balance may affect the ability to practice SC [124]. However, our study did not take into account previous experience with SC, lifestyle or a basic assessment of socioeconomic conditions.

Patients experienced only mild pain and symptoms, which also may have contributed to low motivation among some. Motivation to practice SC is driven by individual need and when patients see clear advantages to $\mathrm{SC}$, they become motivated [116]. Both internal and external motivation have proven to be of significance for $\mathrm{SC}$ behaviours. However, internal motivation appears to be more important than external [124, 214]. In order to increase motivation to practice SC among patients with $\mathrm{HNC}$, a prehabilitation group targeting SC could be introduced even before RT begins. Group participation can be beneficial to patients because it provides an opportunity to discuss with other patients how SC works, as well as to share advice and support.

The nurse plays a major role in implementation of the program and thereby also in the success of SC. Through patient instruction, education, explanation and dedication, the nurse can encourage patients to increase participation and accept responsibility for practicing SC [215]. In our study the TRN was instructed about the importance of this procedure. In an effort to improve outcome, the points below could be structured to be applied when customising similar patient interventions in future studies [99, 103].

1) Preconstructed standardised educational material

2) Focus on knowledge, skills and attitudes regarding pain and treatment

3) Standardised approach to intervention 
4) Repeated educational sessions

5) Frequent monitoring of the educational intervention

6) Support from a supervisor specially trained in the field

7) Encouragement of patient's self-efficacy to cope with the disease and related symptoms

8) Encourage patient understanding and self-efficacy to cope with care and treatment

9) Collaboration between interdisciplinary team of experts.

In Paper IV, interventions were carried out in accordance with points 1-6 above, but with only modest effect on pain and other symptoms. Specifically, during the ten weeks covered by the study, both manual-based education (points 1, 2 above) and individually structured supervision (points 3, 6 above) of SC were covered during weekly meetings (points 4,5 above) between the TRN and the patient, where skills were also monitored and further instruction provided as needed (point 2 above). The nurses were specially trained (point 6 above) in the field of pain management and there is reason to believe that the TRN was well qualified to provide patient education and SC instruction.

Differences in self-efficacy were not considered, nor were patients instructed to encourage self-efficacy (points 7-8 above), which may have contributed to the modest effects of the interventions. Self-efficacy focuses on the patient's belief in their own ability regarding knowledge and attitudes to carry out SC and the confidence to perform a specific intervention and to continue to actively carry out the intervention [120, 216]. Self-efficacy may make the patient feel in control, which in turn may have a beneficial effect on pain, anxiety, and functional impairment [217]. Patients who possess high self-efficacy prior to SC have been shown to be more capable of practicing SC than patients with low self-efficacy [113]. In future studies, self-efficacy should be assessed prior to SC for patients with HNC and pain, and increased as needed.

Because they were undergoing RT, patients met with a number of health professionals over the course of the study (Paper IV). However, these health professionals did not act as a cohesive team of experts (point 9 above). Teamwork for assessment and implementation of rehabilitation interventions, however, is considered to be important for patients with varying needs associated with the course of their malignant disease [218], for which reason future studies should address this shortcoming. Relatives did not systematically participate in the education and SC interventions. One systematic review concludes that education could improve knowledge among relatives about pain and self-efficacy for pain medicine management and change misconceptions regarding cancer-related pain and medications [219]. 


\section{LOW BARRIERS FOR TREATMENT OF PAIN AND LOW PAIN INTENSITY}

The patients in Paper IV consistently reported low barriers for pain management (as measured by BQ-II). The highest barriers occurred at BL (appendix VI). Four weeks following BL the barriers had decreased. No significant differences were seen between groups in any of the measurements over the course of the study. One contributing factor to the low reported barriers may have been participation in the study, which may have favourably affected the attitude among participants regarding pain management; in other words, participation may have lowered the barriers. This effect may have been quite favourable for both groups, while the educational intervention may have played a less important role.

Pain intensity among patients with cancer was considered to be mild when rated 0-4, moderate at 5-6, and severe at 7-10 on a ten-point scale [189-191]. The patients in Paper IV reported mild pain throughout the study. Mean pain intensity reached a maximum of 3.28 (SD 1.90) in the intervention group, compared with a maximum of 3.74 (SD 2.71) in the control group.

The possibility that the interventions in Paper IV may have contributed to the numerical mean differences in pain intensity between the groups cannot be ruled out (Figure 8 and Appendix V). However, the difference was neither clinically nor statistically significant. The low pain assessment ratings may have contributed to the lack of significant differences between the groups, since it may be easier to reduce strong pain than to reduce pain, which is already at low intensity [220]. An earlier study also reported mild pain among patients with HNC [186], though in other studies, patients with HNC have reported moderate to severe pain during RT $[33,134,221]$. Another possible contributing reason for the relatively low pain intensity may be that the patients systematically monitored their pain (particularly via text message three times a week), which may have given them a certain sense of control. Both groups also received pharmacological treatment as needed, based on the same principles used for high-potency analgesics. The patients in Paper IV reported increased pain intensity between weeks two and seven compared with BL. As in previous studies in which patients with HNC were treated with RT [26, 33, 42, 186] treatment time and associated accumulated radiation dose were likely related to pain intensity.

Compared with conventional RT, intensity-modulated RT resulted in fewer radiotherapy-related effects (such as painful damage to the oral mucosa and salivary glands) among patients with HNC [222-224]. Of the patients in Paper IV, 49 received intensity-modulated RT and 15 conventional RT. The large percentage (77\%) of patients who received intensity-modulated RT may help explain the consistently low reported pain intensity and low occurrence of other symptoms in Paper IV. 


\section{DEPRESSION, ANXIETY, CATASTROPHISING AND QUALITY OF LIFE}

The study patients self-reported low scores in the scales measuring depressive symptoms, anxiety and pain catastrophising at BL, four and ten weeks. No significant differences were found between the groups.

Consistent with our results, systematic reviews found that patient education among patients with cancer had no effect on HR-QoL [101, 210]. No statistically significant differences in anxiety and depression were reported among patients with cancer treated on an outpatient basis who received patient education [220]. However, systematic reviews have reported positive trends resulting from patient education concerning anxiety, depression and QoL among patients with cancer [99, 108]. In line with earlier research, [13, 14, 98, 101] patients in Paper IV reported good HR-QoL when RT began. Quality of life significantly declined by week four compared with BL, and again approached BL after ten weeks. No significant differences were found between the groups. Regarding patient age, older patients usually have lower HR-QoL, and when compared with an international population [225], HR-QoL was good in Paper IV. One contributing factor for the consistently good HR-QoL may be that the other symptoms considered by the study were mild $[221,226]$.

\section{Rehabilitation}

Rehabilitation is a complex process that focuses on patient needs and is characterised by collaboration among professionals from several different disciplines. Rehabilitation can be viewed as an overarching concept based on integration of an array of knowledge [227]. Rehabilitation encompasses medical, psychological, educational and social interventions, aimed at assisting ill or injured patients to regain their best potential functional capability and set the stage for a normal life [227].

\section{PREHABILITATION, SELF-CARE AND REHABILITATION FOR PATIENTS WITH HEAD AND NECK CANCER}

More and more cancer patients are surviving their disease, but their symptoms and disabilities may persist. Cancer prehabilitation, $\mathrm{SC}$ and cancer rehabilitation appear to be increasingly important in preventing and reducing the consequences that may lead to disability and early retirement.

Prehabilitation entails making assessments, managing symptoms and carrying out interventions in patients with cancer from the time of diagnosis to the start of treatment [206, 207]. Cancer prehabilitation must be tailored to the individual needs of the patient and encompass many facets, including pain, anxiety, sleep and fatigue [207]. Neither of our two study populations included patients who had received prehabilitation, nor are there any published studies on prehabilitation for patients with HNC that address pain. The patients and their relatives in 
our studies reported that their needs for information and support were inadequately met and that pain intensity and depressive symptoms affected HR-QoL. Prehabilitation may potentially have prepared patients and relatives for the implications of the cancer disease.

Self-care prepares patients and provides support for the various needs that arise during and after the treatment period $[127,228]$. To the best of our knowledge there is only one earlier published study on SC for patients with HNC [134]. Early efforts to develop patient resources (i.e., SC, as seen in Paper IV) to monitor symptoms during treatment, to take decisions and to treat symptoms should result in improved self-monitoring and provide a foundation for well-being and good HR-QoL. To effect the desired results, there is no doubt that patients with HNC need SC.

The purpose of cancer rehabilitation is to provide individuals with knowledge and support so they can proceed with their lives as well as possible, considering the limitations imposed by their disease [218]. Rehabilitation for patients with cancer is a challenge for the healthcare system since these patients pass through various phases of disease. Patient needs vary over time, which requires a specialised multidisciplinary team, compliance and the ability to rapidly intervene [229]. This certainly applies to the patients in Paper I, for whom no structured cancer rehabilitation had been provided. Specific rehabilitation initiatives for patients with HNC have been sparsely studied. Only one observational study has been published concerning a rehabilitation program that reported a clinically significant reduction of severity of symptoms following completed oncology treatment [230]. Meanwhile, cancer rehabilitation including exercise therapy has been proven to be effective for reducing pain and fatigue following cancer treatment [95, 231].

Nurses play an important role in the rehabilitation of patients with cancer throughout the entire care process. Rehabilitation may include symptom relief, education, advice and coordination [232]. Rehabilitative efforts should be temporally coordinated to meet patient needs and should be aimed at providing both patients and relatives with support and the basis to live life as well as possible despite the disease [218]. To meet this challenge, more knowledge is needed among healthcare professionals to identify individual needs and to support patients in coping with daily life, with the ultimate aim of pursuing an active social life and returning to work. Cancer rehabilitation has made forward strides, but further progress is needed regarding the return-to-work process [233]. 


\section{Methodological Considerations}

\section{PAPERS | AND ||}

To achieve a representative selection, consecutive sampling was applied, which is suitable to minimise bias when patients are sequentially referred and invited to participate over long periods of time.

In all, 26 (57\%) of the 46 patients who were invited to participate agreed to do so in Paper I, while 21 (81\%) of 26 relatives agreed to participate in Paper II. A comparison between the participants in Paper I and those who refused to participate shows no significant gender or age differences. It may be that the patients who agreed to participate in our studies were healthier, which could potentially create a selection bias. Relevant information about the most seriously ill patients with HNC may therefore have been excluded, which might affect external validity.

The sample sizes used in Papers I and II may be considered large for qualitative studies. However, the relatively short interview process justifies large sample sizes. One strength of this study is that interviews were conducted with each patient on two separate occasions over a 6-month period, which provided the opportunity to describe findings over time (Paper I). Moreover, because the interviews in Paper II were conducted only once, increasing the sample size was considered to be worthwhile. This approach may also strengthen the validity of the results, and enable them to be transferred to other settings [115].

To increase the reliability and validity of our results, several measures were taken. The quality of the interviews was strengthened because one person, the first author, conducted all of them, which guaranteed a similar approach with regard to interview questions. The interviews were semi-structured and conducted with the help of an interview guide to ensure that important areas were discussed and that a standard opening question was used to begin each interview. A validation of the dialogue was carried out by asking confirmatory questions during the interviews, which clarified and corrected potential misunderstandings [234]. The interviewer was not involved in patient care and treatment, for which reason the participants were not dependent on the interviewer. In regard to credibility, to lend validity to the results, each author read, thoroughly discussed and reflected on the entire analytical process of producing categories and subcategories. The category system was finally tested by all authors for consistency within categories and for categories comprising the overall picture [235]. To further strengthen credibility in regard to categories and subcategories, quotations were used which helped the reader to evaluate the results [234].

Pre-understanding on the part of the first author was an important aspect to be addressed. The first author's personal knowledge of the topic, as well as many years of experience dealing with patients with $\mathrm{HNC}$ and pain may have influenced 
the research process. However, such knowledge and experience may also have been an advantage that had a positive impact on the results. According to Kvale and Patton [234, 236], the interviewer decides how questions should be posed and what is important for follow-up; this process may be aided by a pre-understanding of the field. Previous experience in the field may have contributed to the appropriateness of the interpretations. Circumstances related to the illness of the participants places demands on the sensitivity of the interviewer, where pre-understanding may prove useful.

The results from qualitative studies (Papers I and II) usually cannot be generalised, but may potentially be transferrable to similar situations or groups. However, the purpose of these studies was not to generalise, but rather to explore the experiences of patients with HNC undergoing RT. Additionally, because these studies included participants from only one clinic, the ability to transfer these findings to other units may be limited.

\section{PAPERS III AND IV}

Papers III and IV are limited by small sample size. One might possibly view the estimated average difference on the NRS four-step scale used in the power analysis to be too liberal and thereby the sample size as underpowered. The small sample size in Papers III and IV might therefore be insufficiently representative for populations of patients with HNC and thereby increase the risk for type II error. Gender and age in Papers III and IV are generally representative of patients with HNC, which suggests good population validity.

The cross-sectional design used in Paper III posed a limitation to the establishment of causal relationships. The main limitations in Paper IV include the simplicity of the randomisation process, which may have led to reduced allocation concealment and lack of blindness, and thereby a significant risk of confounding. However, due to the nature of the disease and the small group of patients in this study, blinding the investigator was not possible.

As in Papers I and II, it is likely that the patients who agreed to participate were those who were least ill, which entails a risk of selection bias. Relevant information about the most seriously ill patients with HNC may therefore have been excluded, which might affect external validity.

Earlier studies have shown that both EQ-5D and EQ VAS have good content validity and reliability in cancer patients [237], and this also applies to BPI, HAD and PCS, which were used in Papers III and IV [139-141, 238, 239].

The barriers questionnaire II is one of the most commonly used questionnaires to assess patient barriers to pain management and is a validated self-reporting instrument [240, 241]. One limitation was that a few patients (Paper IV) needed help answering the questions in BQ-II, which may have contributed to interviewer bias [115]. The barrier questionnaire was translated to Swedish according to the test-retest method with good internal consistency reliability (Cronbach's 
alpha coefficient 0.90), but probably needs to be tested in relation to psychometric properties in the Swedish language.

Three times weekly over the ten-week study period, the patients in Paper IV answered seven questions about pain intensity and pain interference by text message. Despite the high number of response occasions (30), the response rate was good with a total of only 2-3\% missing values. When a questionnaires with identical questions is to be answered many times, there is a risk of inadequate reflection about the response. In order to minimise possible recall bias with respect to pain intensity and interference, the average score per week was calculated.

Internal validity may have been compromised since treatment fidelity was not assessed (Paper IV). Concerns may be entertained regarding the extent to which implementation of the intervention remained faithful to the plan [115].

Generalisability may be limited because of the small sample size in Papers III and IV, the lack of blinded randomisation and because of treatment fidelity limitations. A few patients could not be included because of their difficulties understanding Swedish, which may possibly have implications for the generalisability of the findings.

\section{Fatigue}

Patients with HNC experience a number of symptoms, including fatigue and pain. One limitation is that this thesis has not taken fatigue into account. Physical activity and exercise to counter fatigue and pain among patients with HNC may be helpful and should be further assessed in conjunction with prehabilitation, SC and cancer rehabilitation. 


\section{Conclusions}

Concerning the specific aims described on page 27, we conclude the following:

I. Existential pain expressed as fear of death, meaninglessness and guilt were already described in the treatment phase. Patients with $\mathrm{HNC}$ who were treated with RT should also proactively be offered treatment for the various dimensions of pain, as well as interventions to combat psychological distress and social withdrawal, which were also found to be important factors.

II. Relatives experienced psychological distress related to the demanding situation in which they were required to support patients suffering from severe illness, while also lacking personal knowledge and failing to receive adequate support from the healthcare system. Preventive initiatives from the healthcare system on behalf of the relatives may be necessary to meet these needs.

III. Customised prehabilitation programs aimed at preventing pain and symptoms of depression could help preserve good HR-QoL among patients with HNC who are scheduled for RT.

IV. Individual patient education and SC were associated with a tendency towards lower pain intensity during a portion of RT. One way to potentially enhance the benefits of education and SC could be to improve patient motivation and self-efficacy, as well as to optimise supportive efforts from the healthcare system. This should be addressed by future studies. 


\section{Clinical Implications}

The results from this thesis point to the importance of early identification of patients with $\mathrm{HNC}$ who suffer from various dimensions of pain in order to prevent and minimise pain and associated symptoms that may have a negative impact on HR-QoL.

Of likely importance:

- Immediately, from the time of diagnosis, assess the overall situation of the patient, including the various dimensions of pain and other symptoms

- Help patients and relatives to understand, embrace and apply the BPS model.

- Increase the knowledge of healthcare professionals about the importance of early identification and management of the various dimensions of pain in patients with $\mathrm{HNC}$, which may improve the potential of effective preventive measures

- During RT, offer patients and relatives pain education and SC instruction.

\section{Future Research}

Patient education and SC for patients suffering from HNC and undergoing RT should be further expanded and evaluated through high-quality randomised controlled studies.

It should be determined whether prehabilitation that includes education and SC can prepare patients with $\mathrm{HNC}$ and their relatives for the varying needs they face during the illness.

Technological advances provide opportunities for the healthcare system to support and monitor patients who are receiving care at home. Patient education, monitoring of symptoms, and SC should be further developed into web-based courses and smartphone applications.

Future research should provide and evaluate specific skills among healthcare personnel in regard to their encounters with patients facing existential problems. Methods for applying specific theoretical skills in encounters with patients and their relatives should be assessed in care providers.

Furthermore, it should be studied whether patients with existential pain and needs may experience symptom relief through support from patients previously treated for $\mathrm{HNC}$ who have experienced existential problems. A systematic evaluation should be carried out to determine whether patients with HNC may benefit from participation in patient groups that offer the opportunity for dialogue and sharing of experiences. 



\section{ACKNOWLEDGEMENTS}

I feel privileged to have had the opportunity to gain insight into the exciting world of science. I would like to express my warmest gratitude to everyone who has contributed to this thesis and supported me in my endeavour.

First, I would like to especially thank all of the patients with HNC and their relatives who shared their thoughts and the stories of their lives with me.

To my main supervisor Britt Larsson, Associate Professor, who introduced me to the world of science - thank you for your support and encouragement throughout this study and during my initial years in the world of academia and science. Special thanks for sharing your wisdom and for helping me to think straight in times of confusion - everything became possible with your support.

To Gunilla Liedberg, Associate Professor and co-supervisor - thank you for teaching me all about qualitative methodology and for all your support. I have truly appreciated your support and our discussions.

To Elena Dragioti, $\mathrm{PhD}$ and co-supervisor - thank you for your vast knowledge of statistics, encouraging support, advice regarding the research process and for giving me your time.

To Björn Gerdle, Professor and former head of the Pain and Rehabilitation Centre - your expertise and knowledge about pain has been invaluable. Thank you for guiding me through my years as a PhD student and for believing in me.

To Mona Lindblad - thank you for your assistance with the first study, and for your time and consideration during the first year of my research.

To Marie Berggården and Anna Peterson - papers III and IV would not have been possible without your invaluable assistance. You did an amazing job meeting all the patients and you are worth your weight in gold. Working with you has always been a pleasure and I look forward to many years of collaboration in the future.

I would like to thank Emmanuel Bäckryd; working with you is always interesting and your support has been greatly appreciated. I hope we will have the opportunity to work together for many years to come.

Head of the Pain and Rehabilitation Centre, Anders Kjellgren - thank you for your positive thinking and your support help me to be optimistic about the future.

Jan Lindquist, I look back on the many years of our struggle with pleasure. Thank you!

To my colleagues at the Department of Pain and Rehabilitation Centre and especially, to the entire staff at the Pain Unit. Thank you everyone! 
I would also like to thank Professor Tiny Jaarsma, for taking the time to give me feedback and discuss my work.

Thank you to all of my PhD colleagues whom I have met over the years, and a special thank you to Britt-Marie Ahlander.

Thank you, my dear friend, Karin Ingbrant, while we walked and exercised, you listened tirelessly and helped me keep my focus.

Helene Amhliden, what would life be like without you, how could I ever manage all this work without your fun comments and your invaluable friendship?

Thank you, Micke and Camilla, my dear former neighbors, who supported me with good advice and breathing exercises during tough presentations.

Finally, I would like to express my gratitude to everyone else, named and unnamed, who played a part in this project and who supported and encouraged me tremendously, my humble thanks to you.

I would like to thank my family, my parents, Birgitta Söderlund and Gunnar Johansson, who always encouraged me to study. My in-laws, Anthony and Beatrice Schaller, for always asking about my work. Thank you to everyone else in my family.

A special thank you to Britt and Bruno. You have unconditionally supported me through thick and thin, dragged me out when I needed fresh air to be able to see things more clearly special - so many ideas have come from our walks.

Finally, my husband Robert Schaller $\bullet$, who has been incredibly understanding and supportive through all the years. Robert, jag kan inte ens gå utan din luft i mina lungor, vad vore jag utan dina andetag? Thank you for always being there for me.

\section{Thank you all!}

Linköping in May 2018

Anne Söderlund Schaller 


\section{REFERENCES}

1. Orem, D.E., S.G. Taylor, and K.M. Renpenning, Nursing : concepts of practice. Sixth Edition ed. 2001, St. Louis: Mosby.

2. Socialstyrelsen. Internationell statistisk klassifikation av sjukdomar och relaterade hälsoproblem - Systematisk förteckning, svensk version ICD-10-SE. 2011 September 20, 2017]; Available from: http://www.socialstyrelsen.se/klassificeringochkoder/.

3. Swedish head and neck cancer register, S., Regionalt Cancercentrum. Swedish head and neck cancer register, SweHNCR. 2016 September 04, 2017]; Available from: http://www.cancercentrum.se/globalassets/cancerdiagnoser/huvud-ochhals/kvalitetsregister/arsrapport-swehncr-2015 161020 slutversion.pdf.

4. $\quad$ Argiris, A., et al., Head and neck cancer. Lancet, 2008. 371(9625): p. 1695-709.

5. Bose, P., N.T. Brockton, and J.C. Dort, Head and neck cancer: from anatomy to biology. Int J Cancer, 2013. 133(9): p. 2013-23.

6. Hashibe, M., et al., Tobacco, alcohol, body mass index, physical activity, and the risk of head and neck cancer in the prostate, lung, colorectal, and ovarian (PLCO) cohort. Head Neck, 2013. 35(7): p. 914-22.

7. Hashibe, M., et al., Alcohol drinking in never users of tobacco, cigarette smoking in never drinkers, and the risk of head and neck cancer: pooled analysis in the International Head and Neck Cancer Epidemiology Consortium. Journal of the National Cancer Institute, 2007. 99(10): p. 777-789.

8. Chaturvedi, A.K., et al., Worldwide trends in incidence rates for oral cavity and oropharyngeal cancers. J Clin Oncol, 2013. 31(36): p. 4550-9.

9. Chaturvedi, A.K., Epidemiology and clinical aspects of HPV in head and neck cancers. Head and neck pathology, 2012. 6(1): p. 16-24.

10. Epstein, J.B., et al., Oral complications of cancer and cancer therapy: from cancer treatment to survivorship. CA Cancer J Clin, 2012. 62(6): p. 400-22.

11. Torre, L.A., et al., Global cancer statistics, 2012. CA Cancer J Clin, 2015. 65(2): p. 87108.

12. Jemal, A., et al., Global cancer statistics. CA Cancer J Clin, 2011. 61(2): p. 69-90.

13. Babin, E., et al., Quality of life in head and neck cancers patients: predictive factors, functional and psychosocial outcome. European archives of oto-rhino-laryngology : official journal of the European Federation of Oto-Rhino-Laryngological Societies, 2008. 265(3): p. 265-70.

14. Klein, J., J. Livergant, and J. Ringash, Health related quality of life in head and neck cancer treated with radiation therapy with or without chemotherapy: a systematic review. Oral Oncol, 2014. 50(4): p. 254-62.

15. Rosenthal, D.I. and A. Trotti, Strategies for managing radiation-induced mucositis in head and neck cancer. Seminars in radiation oncology, 2009. 19(1): p. 29-34. 
16. Rosenthal, D.I., et al., Patterns of symptom burden during radiotherapy or concurrent chemoradiotherapy for head and neck cancer: a prospective analysis using the University of Texas MD Anderson Cancer Center Symptom Inventory-Head and Neck Module. Cancer, 2014. 120(13): p. 1975-84.

17. Loeser, J.D. and R.D. Treede, The Kyoto protocol of IASP Basic Pain Terminology. Pain, 2008. 137(3): p. 473-7.

18. Marchand, S., The physiology of pain mechanisms: from the periphery to the brain. Rheum Dis Clin North Am, 2008. 34(2): p. 285-309.

19. Brodal, P., Pain. In: The Central Nervous System : Structure and Function. 2010, Cary, UNITED STATES: Oxford University Press.

20. D'Mello, R. and A.H. Dickenson, Spinal cord mechanisms of pain. Br J Anaesth, 2008. 101(1): p. 8-16.

21. Brodal, P., Peripheral Parts of the Somatosensory System. In: The Central Nervous System : Structure and Function. 2010, Cary, UNITED STATES: Oxford University Press. 377-430.

22. Brodal, P., Central Parts of the Somatosensory System. In: The Central Nervous System : Structure and Function. 2010, Cary, UNITED STATES: Oxford University Press. 431-461.

23. Sprouse-Blum, A.S., et al., Understanding endorphins and their importance in pain management. Hawaii Med J, 2010. 69(3): p. 70-1.

24. van den Beuken-van Everdingen, M.H.J., et al., Prevalence of pain in patients with cancer: A systematic review of the past 40 years. Annals of Oncology, 2007. 18(9): $p$. 1437-1449.

25. van den Beuken-van Everdingen, M.H., et al., Update on Prevalence of Pain in Patients With Cancer: Systematic Review and Meta-Analysis. J Pain Symptom Manage, 2016. 51(6): p. 1070-1090.e9.

26. Epstein, J.B., et al., A systematic review of orofacial pain in patients receiving cancer therapy. Supportive care in cancer, 2010. 18(8): p. 1023-31.

27. Raja, S.N. and C.L. Sommer, Pain 2014 Refresher Courses : 15th World Congress on Pain. 2015.

28. Lalla, R.V., D.P. Saunders, and D.E. Peterson, Chemotherapy or radiation-induced oral mucositis. Dent Clin North Am, 2014. 58(2): p. 341-9.

29. Raphael, J., et al., Cancer pain: part 1: Pathophysiology; oncological, pharmacological, and psychological treatments: a perspective from the British Pain Society endorsed by the UK Association of Palliative Medicine and the Royal College of General Practitioners. Pain Med, 2010. 11(5): p. 742-64.

30. Goudas, L.C., et al., The epidemiology of cancer pain. Cancer Invest, 2005. 23(2): p. 182-90.

31. Bennett, M.I., et al., Prevalence and aetiology of neuropathic pain in cancer patients: $a$ systematic review. Pain, 2012. 153(2): p. 359-65.

32. Epstein, J.B., et al., Orofacial pain in cancer: part II--clinical perspectives and management. J Dent Res, 2007. 86(6): p. 506-18.

33. Epstein, J.B., et al., Neuropathic and nociceptive pain in head and neck cancer patients receiving radiation therapy. Head \& neck oncology, 2009. 1: p. 26. 
34. Lam, D.K. and B.L. Schmidt, Orofacial pain onset predicts transition to head and neck cancer. Pain, 2011. 152(5): p. 1206-9.

35. van der Molen, L., et al., Pretreatment organ function in patients with advanced head and neck cancer: clinical outcome measures and patients' views. BMC Ear Nose Throat Disord, 2009. 9: p. 10.

36. Portenoy, R.K., Treatment of cancer pain. Lancet, 2011. 377(9784): p. 2236-47.

37. Lalla, R.V., S.T. Sonis, and D.E. Peterson, Management of oral mucositis in patients who have cancer. Dental Clinics of North America, 2008. 52(1): p. 61.

38. Trotti, A., et al., Mucositis incidence, severity and associated outcomes in patients with head and neck cancer receiving radiotherapy with or without chemotherapy: a systematic literature review. Radiotherapy and oncology : journal of the European Society for Therapeutic Radiology and Oncology, 2003. 66(3): p. 253-62.

39. Sonis, S.T., Oral mucositis. Anticancer Drugs, 2011. 22(7): p. 607-12.

40. Mallick, S., R. Benson, and G.K. Rath, Radiation induced oral mucositis: a review of current literature on prevention and management. Eur Arch Otorhinolaryngol, 2015.

41. Elting, L.S., et al., Patient-reported measurements of oral mucositis in head and neck cancer patients treated with radiotherapy with or without chemotherapy: demonstration of increased frequency, severity, resistance to palliation, and impact on quality of life. Cancer, 2008. 113(10): p. 2704-13.

42. Ling, I.S. and B. Larsson, Individualized pharmacological treatment of oral mucositis pain in patients with head and neck cancer receiving radiotherapy. Supportive care in cancer : official journal of the Multinational Association of Supportive Care in Cancer, 2011. 19(9): p. 1343-50.

43. Lalla, R.V., et al., MASCC/ISOO clinical practice guidelines for the management of mucositis secondary to cancer therapy. Cancer, 2014. 120(10): p. 1453-1461.

44. Worthington, H.V., et al., Interventions for preventing oral mucositis for patients with cancer receiving treatment. Cochrane Database Syst Rev, 2011(4): p. Cd000978.

45. Gatchel, R.J., et al., The biopsychosocial approach to chronic pain: scientific advances and future directions. Psychological bulletin, 2007. 133(4): p. 581-624.

46. Lumley, M.A., et al., Pain and emotion: a biopsychosocial review of recent research. J Clin Psychol, 2011. 67(9): p. 942-68.

47. Clark, D., 'Total pain', disciplinary power and the body in the work of Cicely Saunders, 1958-1967. Soc Sci Med, 1999. 49(6): p. 727-36.

48. Saunders, C., Spiritual pain. J Palliat Care, 1988. 4(3): p. 29-32.

49. Strang, P., et al., Existential pain -- an entity, a provocation, or a challenge? Journal of Pain \& Symptom Management, 2004. 27(3): p. 241-250.

50. Browall, M., et al., Health care staff's opinions about existential issues among patients with cancer. Palliative \& Supportive Care, 2010. 8(1): p. 59-68.

51. Eisenberger, N.I., Social pain and the brain: controversies, questions, and where to go from here. Annu Rev Psychol, 2015. 66: p. 601-29.

52. Meyer, M.L., K.D. Williams, and N.I. Eisenberger, Why Social Pain Can Live on: Different Neural Mechanisms Are Associated with Reliving Social and Physical Pain. PLoS One, 2015. 10(6): p. e0128294. 
53. International Association for the Study of Pain, I.I.A.f.t.S.o.P. Global Year Against Cancer Pain; Total Cancer Pain. 2008-2009 [cited 1/4 2016; Available from: http://www.iasppain.org/files/Content/ContentFolders/GlobalYearAgainstPain2/CancerPainFactSheets $\angle$ TotalCancerPain Final.pdf.

54. Chen, S.C., et al., Prevalence and correlates of supportive care needs in oral cancer patients with and without anxiety during the diagnostic period. Cancer Nurs, 2010. 33(4): p. 280-9.

55. Sawada, N.O., et al., Depression, fatigue, and health-related quality of life in head and neck cancer patients: A prospective pilot study. Supportive Care in Cancer, 2012. 20(11): p. 2705-2711.

56. Verdonck-de Leeuw, I.M., et al., Computerized prospective screening for high levels of emotional distress in head and neck cancer patients and referral rate to psychosocial care. Oral Oncology, 2009. 45(10).

57. Fischer, D.J., et al., Anxiety, depression, and pain: differences by primary cancer. Support Care Cancer, 2010. 18(7): p. 801-10.

58. Kroenke, K., et al., The association of depression and pain with health-related quality of life, disability, and health care use in cancer patients. J Pain Symptom Manage, 2010. 40(3): p. 327-41.

59. Haisfield-Wolfe, M.E., et al., Prevalence and correlates of depression among patients with head and neck cancer: a systematic review of implications for research. Oncology nursing forum, 2009. 36(3).

60. Cheng, K.K. and R.M. Yeung, Impact of mood disturbance, sleep disturbance, fatigue and pain among patients receiving cancer therapy. Eur J Cancer Care (Engl), 2013. 22(1): p. 70-8.

61. Shuman, A.G., et al., Predictors of poor sleep quality among head and neck cancer patients. Laryngoscope, 2010. 120(6): p. 1166-72.

62. Quartana, P.J., C.M. Campbell, and R.R. Edwards, Pain catastrophizing: a critical review. Expert Rev Neurother, 2009. 9(5): p. 745-58.

63. Rogers, S.N., et al., Fear of recurrence following head and neck cancer in the outpatient clinic. European archives of oto-rhino-laryngology : official journal of the European Federation of Oto-Rhino-Laryngological Societies, 2010. 267(12): p. 1943-9.

64. Steiner, J.F., et al., Assessing the impact of cancer on work outcomes: what are the research needs? Cancer, 2004. 101(8): p. 1703-11.

65. Cancerfonden. The Swedish Cancer Societ. 201828 January 2018]; Available from: https://www.cancerfonden.se/om-cancer/om-cancer.

66. Ross, L., et al., Factors associated with Danish cancer patients' return to work. A report from the population-based study 'The Cancer Patient's World'. Cancer Epidemiol, 2012. 36(2): p. 222-9.

67. Verdonck-de Leeuw, I.M., et al., Employment and return to work in head and neck cancer survivors. Oral Oncol, 2010. 46(1): p. 56-60.

68. Isaksson, J., et al., Meaning of work and the process of returning after head and neck cancer. Support Care Cancer, 2016. 24(1): p. 205-13. 
69. Cooper, A.F., et al., Distinct work-related, clinical and psychological factors predict return to work following treatment in four different cancer types. Psychooncology, 2013. 22(3): p. 659-67.

70. Meeker, M.A., D. Finnell, and A.K. Othman, Family caregivers and cancer pain management: a review. Journal of family nursing, 2011. 17(1): p. 29-60.

71. Astrup, G.L., et al., Symptom burden and patient characteristics: Association with quality of life in patients with head and neck cancer undergoing radiotherapy. Head Neck, 2017.

72. Fang, F.M., et al., Changes in quality of life of head-and-neck cancer patients following postoperative radiotherapy. Acta oncologica, 2004. 43(6): p. 571-8.

73. Karnell, L.H., et al., Influence of social support on health-related quality of life outcomes in head and neck cancer. Head Neck, 2007. 29(2): p. 143-6.

74. Socialstyrelsen. Termbank. 2017 September 04, 2017]; Available from: http://www.socialstyrelsen.se/psidata/termbanken

75. Northouse, L., Helping families of patients with cancer. Oncology nursing forum, 2005. 32(4): p. 743-50.

76. Northouse, L., et al., Psychosocial care for family caregivers of patients with cancer. Journal of clinical oncology : official journal of the American Society of Clinical Oncology, 2012. 30(11): p. 1227-34.

77. Precious, E., et al., Head and neck cancer patients' perspective of carer burden. The British journal of oral \& maxillofacial surgery, 2012. 50(3): p. 202-7.

78. Longacre, M.L., et al., Psychological functioning of caregivers for head and neck cancer patients. Oral oncology, 2012. 48(1): p. 18-25.

79. Nightingale, C.L., et al., Burden, quality of life, and social support in caregivers of patients undergoing radiotherapy for head and neck cancer: A pilot study. Chronic Illness, 2016. 12(3): p. 236-245.

80. Schaller, A., G.M. Liedberg, and B. Larsson, How relatives of patients with head and neck cancer experience pain, disease progression and treatment: A qualitative interview study. European journal of oncology nursing : the official journal of European Oncology Nursing Society, 2014.

81. Ross, S., et al., Psychosocial adjustment of family caregivers of head and neck cancer survivors. Supportive care in cancer : official journal of the Multinational Association of Supportive Care in Cancer, 2010. 18(2): p. 171-8.

82. World Health Organization, W., WHOQOL: measuring quality of life. 1997.

83. Fayers, P.M. and D. Machin, Quality of life: the assessment, analysis and interpretation of patient-reported outcomes. 2013: John Wiley \& Sons.

84. Berzon, R., R.D. Hays, and S.A. Shumaker, International use, application and performance of health-related quality of life instruments. Qual Life Res, 1993. 2(6): p. 367-8.

85. Guidance for industry: patient-reported outcome measures: use in medical product development to support labeling claims: draft guidance. Health Qual Life Outcomes, 2006. 4: p. 79.

86. World Health Organization, W. Constitution of the world health organization. 2005 September 20, 2017]; Available from: http://www.who.int/about/mission/en/. 
87. Nordenfelt, L., Livskvalitet och hälsa : teori \& kritik. 2004, Linköping: Univ., Institutionen för hälsa och samhälle.

88. Rogers, S.N., et al., Structured review of papers reporting specific functions in patients with cancer of the head and neck: 2006 - 2013. British Journal of Oral and Maxillofacial Surgery, 2016. 54(6): p. e45-e51.

89. Nelke, K.H., et al., Head and neck cancer patients' quality of life. Adv Clin Exp Med, 2014. 23(6): p. 1019-27.

90. Verdonck-de Leeuw, I.M., et al., The course of health-related quality of life in head and neck cancer patients treated with chemoradiation: a prospective cohort study.

Radiother Oncol, 2014. 110(3): p. 422-8.

91. Ward, S.E., et al., Patient-related barriers to management of cancer pain. Pain, 1993. 52(3): p. 319-24.

92. Oldenmenger, W.H., et al., A systematic review on barriers hindering adequate cancer pain management and interventions to reduce them: a critical appraisal. Eur J Cancer, 2009. 45(8): p. 1370-80.

93. Gunnarsdottir, S., et al., Patient-related barriers to pain management: the Barriers Questionnaire II (BQ-II). Pain, 2002. 99(3): p. 385-96.

94. Tomlinson, D., et al., Effect of exercise on cancer-related fatigue: a meta-analysis. Am J Phys Med Rehabil, 2014. 93(8): p. 675-86.

95. Gerritsen, J.K. and A.J. Vincent, Exercise improves quality of life in patients with cancer: a systematic review and meta-analysis of randomised controlled trials. Br J Sports Med, 2016. 50(13): p. 796-803.

96. Marie, N., et al., Optimal patient education for cancer pain: a systematic review and theory-based meta-analysis. Supportive care in cancer : official journal of the Multinational Association of Supportive Care in Cancer, 2013. 21(12): p. 3529-37.

97. Koller, A., et al., A systematic evaluation of content, structure, and efficacy of interventions to improve patients' self-management of cancer pain. Journal of pain and symptom management, 2012. 44(2): p. 264-84.

98. Bennett, M.I., A.M. Bagnall, and S. Jose Closs, How effective are patient-based educational interventions in the management of cancer pain? Systematic review and meta-analysis. Pain, 2009. 143(3): p. 192-9.

99. Howell, D., et al., Self-management education interventions for patients with cancer: $a$ systematic review. Support Care Cancer, 2017.

100. Jho, H.J., et al., Efficacy of pain education in cancer patients: a meta-analysis of randomized controlled trials. Supportive care in cancer : official journal of the Multinational Association of Supportive Care in Cancer, 2013. 21(7): p. 1963-71.

101. Ling, C.C., L.Y. Lui, and W.K. So, Do educational interventions improve cancer patients' quality of life and reduce pain intensity? Quantitative systematic review. J Adv Nurs, 2012. 68(3): p. 511-20.

102. Oldenmenger, W.H., et al., A combined pain consultation and pain education program decreases average and current pain and decreases interference in daily life by pain in oncology outpatients: A randomized controlled trial. Pain, 2011. 152(11): p. 2632-2639.

103. Cummings, G.G., et al., Effectiveness of knowledge translation interventions to improve cancer pain management. J Pain Symptom Manage, 2011. 41(5): p. 915-39. 
104. Rustoen, T., et al., A randomized clinical trial of the efficacy of a self-care intervention to improve cancer pain management. Cancer Nurs, 2014. 37(1): p. 34-43.

105. Koller, A., et al., Results of a randomized controlled pilot study of a self-management intervention for cancer pain. European Journal of Oncology Nursing, 2013. 17(3): p. 284-291.

106. Ferrell, B.R. and L.M. Rivera, Cancer pain education for patients. Semin Oncol Nurs, 1997. 13(1): p. 42-8.

107. Lovell, M.R., et al., Patient education, coaching, and self-management for cancer pain. Journal of clinical oncology : official journal of the American Society of Clinical Oncology, 2014. 32(16): p. 1712-20.

108. Hammer, M.J., et al., Self-management for adult patients with cancer an integrative review: An integrative review. Cancer Nursing, 2015. 38(2): p. E10-E26.

109. Langford, D.J., K. Lee, and C. Miaskowski, Sleep disturbance interventions in oncology patients and family caregivers: a comprehensive review and meta-analysis. Sleep Med Rev, 2012. 16(5): p. 397-414.

110. Schaller, A., et al., Experiences of pain: a longitudinal, qualitative study of patients with head and neck cancer recently treated with radiotherapy. Pain Manag Nurs, 2015. 16(3): p. 336-45.

111. Meuser, T., et al., Symptoms during cancer pain treatment following WHO-guidelines: a longitudinal follow-up study of symptom prevalence, severity and etiology. Pain, 2001. 93(3): p. 247-57.

112. Thomas, V.N., Cancer pain relief, 2nd Edn: WHO, Geneva. . 1997, Pergamon.

113. Richard, A.A. and K. Shea, Delineation of self-care and associated concepts. J Nurs Scholarsh, 2011. 43(3): p. 255-64.

114. Wilkinson, A. and L. Whitehead, Evolution of the concept of self-care and implications for nurses: a literature review. Int J Nurs Stud, 2009. 46(8): p. 1143-7.

115. Polit, D.F. and C.T. Beck, Nursing research : generating and assessing evidence for nursing practice. 2011, Philadelphia, Pa.; London: Lippincott Williams \& Wilkins.

116. Godfrey, C.M., et al., Care of self - care by other - care of other: the meaning of selfcare from research, practice, policy and industry perspectives. Int J Evid Based Healthc, 2011. 9(1): p. 3-24.

117. Levin, L.S., The layperson as the primary health care practitioner. Public Health Rep, 1976. 91(3): p. 206-10.

118. Gantz, S.B., Self-care: perspectives from six disciplines. Holist Nurs Pract, 1990. 4(2): p. 1-12.

119. Chambers, R., The role of the health professional in supporting self care. Quality in Primary Care, 2006.

120. Riegel, B., T. Jaarsma, and A. Stromberg, A middle-range theory of self-care of chronic illness. ANS Adv Nurs Sci, 2012. 35(3): p. 194-204.

121. Riegel, B., et al., Psychometric testing of the self-care of heart failure index. J Card Fail, 2004. 10(4): p. 350-60.

122. Clari, M., et al., Self-Care of People with Chronic Obstructive Pulmonary Disease: A Meta-Synthesis. Patient, 2017. 10(4): p. 407-427. 
123. Gao, J., et al., Effects of self-care, self-efficacy, social support on glycemic control in adults with type 2 diabetes. BMC Fam Pract, 2013. 14: p. 66.

124. Jaarsma, T., et al., Factors Related to Self-Care in Heart Failure Patients According to the Middle-Range Theory of Self-Care of Chronic Illness: a Literature Update. Curr Heart Fail Rep, 2017. 14(2): p. 71-77.

125. Riegel, B., C.S. Lee, and V.V. Dickson, Self care in patients with chronic heart failure. Nat Rev Cardiol, 2011. 8(11): p. 644-54.

126. McCorkle, R., et al., Self-management: Enabling and empowering patients living with cancer as a chronic illness. CA Cancer J Clin, 2011. 61(1): p. 50-62.

127. Hasanpour-Dehkordi, A., Self-care Concept Analysis in Cancer Patients: An Evolutionary Concept Analysis. Indian J Palliat Care, 2016. 22(4): p. 388-394.

128. Qian, H. and C. Yuan, Factors associated with self-care self-efficacy among gastric and colorectal cancer patients. Cancer Nurs, 2012. 35(3): p. E22-31.

129. Cockle-Hearne, J. and S. Faithfull, Self-management for men surviving prostate cancer: a review of behavioural and psychosocial interventions to understand what strategies can work, for whom and in what circumstances. Psychooncology, 2010. 19(9): p. 90922.

130. Du, S., et al., Self-management programs for chronic musculoskeletal pain conditions: a systematic review and meta-analysis. Patient Educ Couns, 2011. 85(3): p. e299-310.

131. Oliveira, V.C., et al., Effectiveness of self-management of low back pain: systematic review with meta-analysis. Arthritis Care Res (Hoboken), 2012. 64(11): p. 1739-48.

132. Du, S., et al., Self-management program for chronic low back pain: A systematic review and meta-analysis. Patient Education and Counseling, 2017. 100(1): p. 37-49.

133. Johnston, B., et al., Self care and end of life care in advanced cancer: literature review. European journal of oncology nursing : the official journal of European Oncology Nursing Society, 2009. 13(5): p. 386-98.

134. Wong, P.C., et al., Mucositis pain induced by radiation therapy: prevalence, severity, and use of self-care behaviors. Journal of pain and symptom management, 2006. 32(1): p. 27-37.

135. Elo, S. and H. Kyngas, The qualitative content analysis process. Journal of advanced nursing, 2008. 62(1): p. 107-15.

136. Krippendorff, K., Content analysis : an introduction to its methodology. 2004, Thousand Oaks, Calif.: Sage.

137. Edhlund, B.M., Nvivo 9 essentials : your guide to the world's most powerful qualitative data analysis software. 2011, Stallarholmen, Sweden: Form \& Kunskap AB.

138. Dolan, P., Modeling valuations for EuroQol health states. Med Care, 1997. 35(11): p. 1095-108.

139. Cleeland, C.S. and K.M. Ryan, Pain assessment: global use of the Brief Pain Inventory. Annals of the Academy of Medicine, Singapore, 1994. 23(2): p. 129-38.

140. Bjelland, I., et al., The validity of the Hospital Anxiety and Depression Scale. An updated literature review. J Psychosom Res, 2002. 52(2): p. 69-77.

141. Sullivan, M.J., S.R. Bishop, and J. Pivik, The pain catastrophizing scale: development and validation. Psychological assessment, 1995. 7(4): p. 524. 
142. Connelly, S.T. and B.L. Schmidt, Evaluation of pain in patients with oral squamous cell carcinoma. Journal of Pain, 2004. 5(9): p. 505-510.

143. Bastien, C.H., A. Vallieres, and C.M. Morin, Validation of the Insomnia Severity Index as an outcome measure for insomnia research. Sleep Med, 2001. 2(4): p. 297-307.

144. Boston, P., A. Bruce, and R. Schreiber, Existential suffering in the palliative care setting: an integrated literature review. Journal of pain and symptom management, 2011. 41(3): p. 604-18.

145. Henoch, I. and E. Danielson, Existential concerns among patients with cancer and interventions to meet them: an integrative literature review. Psycho-oncology, 2009. 18(3): p. 225-36.

146. Okon, T.R., Spiritual, religious, and existential aspects of palliative care. J Palliat Med, 2005. 8(2): p. 392-414.

147. Murata, H. and T. Morita, Conceptualization of psycho-existential suffering by the Japanese Task Force: the first step of a nationwide project. Palliat Support Care, 2006. 4(3): p. 279-85.

148. Yalom, I.D., Existential psychotherapy. 1980, New York: Basic Books.

149. Fujimori, M., T. Akechi, and Y. Uchitomi, Factors associated with patient preferences for communication of bad news. Palliat Support Care, 2017. 15(3): p. 328-335.

150. Novy, D.M. and C.J. Aigner, The biopsychosocial model in cancer pain. Curr Opin Support Palliat Care, 2014. 8(2): p. 117-23.

151. Eisenberger, N.I., The neural bases of social pain: evidence for shared representations with physical pain. Psychosom Med, 2012. 74(2): p. 126-35.

152. Portenoy, R.K. and P. Lesage, Management of cancer pain. Lancet, 1999. 353(9165): p. 1695-700.

153. Mehta, A. and L.S. Chan, Understanding of the concept of "total pain": a prerequisite for pain control. Journal of Hospice \& Palliative Nursing, 2008. 10(1): p. 26-32.

154. Rosenzweig, M.Q., Breaking bad news: a guide for effective and empathetic communication. Nurse Pract, 2012. 37(2): p. 1-4.

155. Ptacek, J.T. and J.J. Ptacek, Patients' perceptions of receiving bad news about cancer. Journal of clinical oncology, 2001. 19(21): p. 4160-4.

156. Brown, V.A., et al., Patient preferences for the delivery of bad news - the experience of a UK Cancer Centre. Eur J Cancer Care (Engl), 2011. 20(1): p. 56-61.

157. Richardson, A.E., R. Morton, and E. Broadbent, Caregivers' Illness Perceptions Contribute to Quality of Life in Head and Neck Cancer Patients at Diagnosis. J Psychosoc Oncol, 2015. 33(4): p. 414-32.

158. Chen, S.C., et al., Support needs of patients with oral cancer and burden to their family caregivers. Cancer nursing, 2009. 32(6): p. 473-81.

159. Hung, H.C., et al., Change and predictors of social support in caregivers of newly diagnosed oral cavity cancer patients during the first 3 months after discharge. Cancer nursing, 2013. 36(6): p. E17-24.

160. Fujimori, M. and Y. Uchitomi, Preferences of cancer patients regarding communication of bad news: a systematic literature review. Japanese journal of clinical oncology, 2009. 39(4): p. 201-16. 
161. Ptacek, J.T., J.J. Ptacek, and N.M. Ellison, "I'm sorry to tell you ..." physicians' reports of breaking bad news. J Behav Med, 2001. 24(2): p. 205-17.

162. Bumb, M., et al., Breaking Bad News: An Evidence-Based Review of Communication Models for Oncology Nurses. Clin J Oncol Nurs, 2017. 21(5): p. 573-580.

163. Warnock, C., Breaking bad news: issues relating to nursing practice. Nurs Stand, 2014. 28(45): p. 51-8.

164. Baile, W.F., et al., SPIKES-A six-step protocol for delivering bad news: application to the patient with cancer. Oncologist, 2000. 5(4): p. 302-11.

165. Patterson, J.M., et al., Head and neck cancer and dysphagia; caring for carers. Psychooncology, 2013. 22(8): p. 1815-20.

166. Pinquart, M. and P.R. Duberstein, Associations of social networks with cancer mortality: a meta-analysis. Critical reviews in oncology/hematology, 2010. 75(2): p. 122-37.

167. Lee, Y., et al., Prevalence and risk factors of depressive disorder in caregivers of patients with head and neck cancer. Psychooncology, 2015. 24(2): p. 155-61.

168. Molassiotis, A., et al., Symptoms experienced by cancer patients during the first year from diagnosis: patient and informal caregiver ratings and agreement. Palliat Support Care, 2010. 8(3): p. 313-24.

169. Akin, S. and Z. Durna, A comparative descriptive study examining the perceptions of cancer patients, family caregivers, and nurses on patient symptom severity in Turkey. Eur J Oncol Nurs, 2013. 17(1): p. 30-7.

170. Badr, H., et al., Psychological distress in patients and caregivers over the course of radiotherapy for head and neck cancer. Oral Oncol, 2014. 50(10): p. 1005-11.

171. Chen, S.C., et al., Unmet supportive care needs and characteristics of family caregivers of patients with oral cancer after surgery. Psychooncology, 2014. 23(5): p. 569-77.

172. Friethriksdottir, N., et al., Family members of cancer patients: Needs, quality of life and symptoms of anxiety and depression. Acta Oncol, 2011. 50(2): p. 252-8.

173. Baghi, M., et al., Demands on caring relatives of head and neck cancer patients. Laryngoscope, 2007. 117(4): p. 712-6.

174. Burstrom, K., M. Johannesson, and F. Diderichsen, Swedish population health-related quality of life results using the EQ-5D. Qual Life Res, 2001. 10(7): p. 621-35.

175. Burstrom, K., et al., Swedish experience-based value sets for EQ-5D health states. Qual Life Res, 2014. 23(2): p. 431-42.

176. Hammerlid, E., et al., A prospective study of quality of life in head and neck cancer patients. Part I: At diagnosis. Laryngoscope, 2001. 111(4 I): p. 669-680.

177. Hammerlid, E., et al., Health-related quality of life three years after diagnosis of head and neck cancer--a longitudinal study. Head Neck, 2001. 23(2): p. 113-25.

178. Loorents, V., et al., Health-related quality of life up to 1 year after radiotherapy in patients with head and neck cancer (HNC). SpringerPlus, 2016. 5(1).

179. Lango, M.N., et al., Baseline health perceptions, dysphagia, and survival in patients with head and neck cancer. Cancer, 2014. 120(6): p. 840-7.

180. Sherman, A.C., et al., Assessing quality of life in patients with head and neck cancer: cross-validation of the European Organization for Research and Treatment of Cancer 
(EORTC) Quality of Life Head and Neck module (QLQ-H\&N35). Arch Otolaryngol Head Neck Surg, 2000. 126(4): p. 459-67.

181. Ojo, B., et al., A systematic review of head and neck cancer quality of life assessment instruments. Oral Oncol, 2012. 48(10): p. 923-37.

182. Aaronson, N.K., et al., The European Organization for Research and Treatment of Cancer QLQ-C30: a quality-of-life instrument for use in international clinical trials in oncology. J Natl Cancer Inst, 1993. 85(5): p. 365-76.

183. Bjordal, K., et al., Quality of life in head and neck cancer patients: validation of the European Organization for Research and Treatment of Cancer Quality of Life Questionnaire-H\&N35. J Clin Oncol, 1999. 17(3): p. 1008-19.

184. Weymuller, E.A., Jr., et al., Analysis of the performance characteristics of the University of Washington Quality of Life instrument and its modification (UW-QOL-R). Arch Otolaryngol Head Neck Surg, 2001. 127(5): p. 489-93.

185. List, M.A., et al., The Performance Status Scale for Head and Neck Cancer Patients and the Functional Assessment of Cancer Therapy-Head and Neck Scale. A study of utility and validity. Cancer, 1996. 77(11): p. 2294-301.

186. Astrup, G.L., et al., Changes in and predictors of pain characteristics in patients with head and neck cancer undergoing radiotherapy. Pain, 2015. 156(5): p. 967-979.

187. List, M.A., et al., Prioritizing treatment outcomes: head and neck cancer patients versus nonpatients. Head \& neck, 2004. 26(2): p. 163-70.

188. Farrar, J.T., et al., Defining the clinically important difference in pain outcome measures. Pain, 2000. 88(3): p. 287-94.

189. Serlin, R.C., et al., When is cancer pain mild, moderate or severe? Grading pain severity by its interference with function. Pain, 1995. 61(2): p. 277-84.

190. Li, K.K., et al., What should be the optimal cut points for mild, moderate, and severe pain? J Palliat Med, 2007. 10(6): p. 1338-46.

191. Fainsinger, R., et al., What is stable pain control? A prospective longitudinal study to assess the clinical value of a personalized pain goal. Palliat Med, 2017. 31(10): p. 913920.

192. Vos, M.S. and J.C.J.M. de Haes, Denial in cancer patients, an explorative review. Psycho-Oncology, 2007. 16(1): p. 12-25.

193. Vos, M.S., et al., Denial and physical outcomes in lung cancer patients, a longitudinal study. Lung Cancer, 2010. 67(2): p. 237-43.

194. Steingrimsdottir, O.A., et al., Defining chronic pain in epidemiological studies: a systematic review and meta-analysis. Pain, 2017. 158(11): p. 2092-2107.

195. Bowling, A., Mode of questionnaire administration can have serious effects on data quality. J Public Health (Oxf), 2005. 27(3): p. 281-91.

196. Oliveira, K.G., et al., Influence of pain severity on the quality of life in patients with head and neck cancer before antineoplastic therapy. BMC Cancer, 2014. 14: p. 39.

197. Funk, G.F., L.H. Karnell, and A.J. Christensen, Long-term health-related quality of life in survivors of head and neck cancer. Archives of otolaryngology--head \& neck surgery, 2012. 138(2): p. 123-33. 
198. Kohda, R., et al., Prospective studies on mental status and quality of life in patients with head and neck cancer treated by radiation. Psycho-oncology, 2005. 14(4): p. 3316.

199. Black, B., et al., The relationships among pain, nonpain symptoms, and quality of life measures in older adults with cancer receiving hospice care. Pain Med, 2011. 12(6): $p$. 880-9.

200. Chen, A.M., et al., Prospective study of psychosocial distress among patients undergoing radiotherapy for head and neck cancer. Int J Radiat Oncol Biol Phys, 2009. 73(1): p. 187-93.

201. Haisfield-Wolfe, M.E., et al., Prevalence and correlates of symptoms and uncertainty in illness among head and neck cancer patients receiving definitive radiation with or without chemotherapy. Supportive Care in Cancer, 2012. 20(8): p. 1885-1893.

202. Chan, J.Y., et al., The relationship between depressive symptoms and initial quality of life and function in head and neck cancer. Laryngoscope, 2011. 121(6): p. 1212-8.

203. Kim, S.A., et al., Pretreatment depression as a prognostic indicator of survival and nutritional status in patients with head and neck cancer. Cancer, 2016. 122(1): p. 131 40.

204. Howren, M.B., et al., Health-related quality of life in head and neck cancer survivors: impact of pretreatment depressive symptoms. Health Psychol, 2010. 29(1): p. 65-71.

205. van Nieuwenhuizen, A.J., et al., The association between health related quality of life and survival in patients with head and neck cancer: a systematic review. Oral Oncol, 2015. 51(1): p. 1-11.

206. Silver, J.K., Cancer prehabilitation and its role in improving health outcomes and reducing health care costs. Semin Oncol Nurs, 2015. 31(1): p. 13-30.

207. Silver, J.K. and J. Baima, Cancer prehabilitation: an opportunity to decrease treatmentrelated morbidity, increase cancer treatment options, and improve physical and psychological health outcomes. Am J Phys Med Rehabil, 2013. 92(8): p. 715-27.

208. Sember, A., et al., Prehabilitation for Lymphedema in head and neck cancer patients at a community cancer center. Journal of Community and Supportive Oncology, 2017. 15(3): p. e127-e134.

209. Kravitz, R.L., et al., Cancer Health Empowerment for Living without Pain (Ca-HELP): effects of a tailored education and coaching intervention on pain and impairment. Pain, 2011. 152(7): p. 1572-82.

210. Zhou, L., et al., Nurse-led educational interventions on cancer pain outcomes for oncology outpatients: a systematic review. Int Nurs Rev, 2015. 62(2): p. 218-30.

211. Rustøen, T., et al., The pro-self@ pain control program improves patients' knowledge of cancer pain management. Journal of Pain and Symptom Management, 2012. 44(3): p. 321-330.

212. Jahn, P., et al., Improvement of pain-related self-management for cancer patients through a modular transitional nursing intervention: A cluster-randomized multicenter trial. Pain, 2014. 155(4): p. 746-54.

213. Miaskowski, C., et al., Randomized clinical trial of the effectiveness of a self-care intervention to improve cancer pain management. J Clin Oncol, 2004. 22(9): p. 171320. 
214. Jowsey, T., et al., What motivates Australian health service users with chronic illness to engage in self-management behaviour? Health Expect, 2014. 17(2): p. 267-77.

215. Jaarsma, T., M. Nikolova-Simons, and M.H. van der Wal, Nurses' strategies to address self-care aspects related to medication adherence and symptom recognition in heart failure patients: an in-depth look. Heart Lung, 2012. 41(6): p. 583-93.

216. White, L.L., et al., Perceived Self-Efficacy: A Concept Analysis for Symptom Management in Patients With Cancer. Clin J Oncol Nurs, 2017. 21(6): p. E272-e279.

217. Oliver, J.W., et al., Individualized patient education and coaching to improve pain control among cancer outpatients. J Clin Oncol, 2001. 19(8): p. 2206-12.

218. Cancercentrum. Cancerrehabilitering Nationellt vårdprogram. 2018 16/1/18];

Available from: https://www.cancercentrum.se/samverkan/varauppdrag/cancerrehabilitering/vardprogram/.

219. Latter, S., et al., How can we help family carers manage pain medicines for patients with advanced cancer? A systematic review of intervention studies. BMJ Support Palliat Care, 2016. 6(3): p. 263-75.

220. van der Peet, E.H., et al., Randomized clinical trial of an intensive nursing-based pain education program for cancer outpatients suffering from pain. Support Care Cancer, 2009. 17(8): p. 1089-99.

221. Lewis, S., et al., Distress screening using distress thermometer in head and neck cancer patients undergoing radiotherapy and evaluation of causal factors predicting occurrence of distress. Indian J Palliat Care, 2013. 19(2): p. 88-92.

222. Kouloulias, V., et al., The treatment outcome and radiation-induced toxicity for patients with head and neck carcinoma in the IMRT era: a systematic review with dosimetric and clinical parameters. Biomed Res Int, 2013. 2013: p. 401261.

223. Marta, G.N., et al., Intensity-modulated radiation therapy for head and neck cancer: systematic review and meta-analysis. Radiother Oncol, 2014. 110(1): p. 9-15.

224. Tribius, S. and C. Bergelt, Intensity-modulated radiotherapy versus conventional and $3 D$ conformal radiotherapy in patients with head and neck cancer: is there a worthwhile quality of life gain? Cancer Treat Rev, 2011. 37(7): p. 511-9.

225. Szende, A., B. Janssen, and J. Cabases, Self-reported population health: an international perspective based on EQ-5D. 2014: Springer.

226. Sullivan, M.J., et al., Theoretical perspectives on the relation between catastrophizing and pain. Clin J Pain, 2001. 17(1): p. 52-64.

227. Borg, J., Rehabiliteringsmedicin : [teori och praktik]. 2015, Lund: Studentlitteratur.

228. Bjorklund, M., A. Sarvimaki, and A. Berg, Health promotion and empowerment from the perspective of individuals living with head and neck cancer. Eur J Oncol Nurs, 2008. 12(1): p. 26-34.

229. Hellbom, M. and B. Thomé, Rehabilitering vid cancersjukdom : att möta framtiden. 2013, Stockholm: Natur \& Kultur.

230. Eades, M., et al., Effect of an interdisciplinary rehabilitation program on quality of life in patients with head and neck cancer: review of clinical experience. Head Neck, 2013. 35(3): p. 343-9.

231. Egan, M.Y., et al., Rehabilitation following cancer treatment. Disabil Rehabil, 2013. 35(26): p. 2245-58. 
232. Camicia, M., et al., The essential role of the rehabilitation nurse in facilitating care transitions: a white paper by the association of rehabilitation nurses. Rehabil Nurs, 2014. 39(1): p. 3-15.

233. Mehnert, A., Employment and work-related issues in cancer survivors. Crit Rev Oncol Hematol, 2011. 77(2): p. 109-30.

234. Kvale, S., Doing interviews. 2008: Sage.

235. Malterud, K., The art and science of clinical knowledge: evidence beyond measures and numbers. Lancet, 2001. 358(9279): p. 397-400.

236. Patton, M.Q., Qualitative research and evaluation methods. 2002, Thousand Oaks, Calif.: Sage Publications.

237. Pickard, A.S., et al., Health utilities using the EQ-5D in studies of cancer. Pharmacoeconomics, 2007. 25(5): p. 365-84.

238. Osman, A., et al., Factor structure, reliability, and validity of the Pain Catastrophizing Scale. J Behav Med, 1997. 20(6): p. 589-605.

239. Vodermaier, A., W. Linden, and C. Siu, Screening for emotional distress in cancer patients: a systematic review of assessment instruments. J Natl Cancer Inst, 2009. 101(21): p. 1464-88.

240. Gunnarsdottir, S., R.C. Serlin, and S. Ward, Patient-related barriers to pain management: the Icelandic Barriers Questionnaire II. J Pain Symptom Manage, 2005. 29(3): p. 273-85.

241. Valeberg, B.T., et al., Cancer patients' barriers to pain management and psychometric properties of the Norwegian version of the Barriers Questionnaire II. Scand I Caring Sci, 2009. 23(3): p. 518-28. 


\section{APPENDIX}

\section{Appendix I}

\section{Text 1: Translation procedure of the questionnaire BQ-II}

The BQ-II was translated into Swedish using an iterative forward-backward process. Two public translators - both authorized by the Swedish Legal, Financial, and Administrative Services Agency - translated the BQ-II: a native Swedish speaker translated the English to Swedish and a native English speaker translated the Swedish back into English without access to the original. The two translators did not communicate with each other during the process.

After reviewing the English to Swedish translation, two members of the project decided the participants would have no trouble understanding the Swedish, so no further revisions were necessary.

The Swedish version of the BQ-II has not yet been checked for either reliability or validity. Since reliability, content, structural validity, and hypothesis testing regarding the BQ-II were quite consistently good across three investigated languages and cultures (Norway, Germany, and Denmark), there is good reason to believe the same is true for the Swedish version.

\section{Text 2: Policies of pharmacological treatment}

Patients with mild (NRS o-4) and moderate pain (NRS 5-6) were prescribed nonsteroidal anti-inflammatory drug treatment in combination with acetaminophen and with the intention to inhibit the production of substances resulting damage and inflammation.

If the pain intensity was moderate or severe (NRS 7-10) and assessed as nociceptive and derived from the oral cavity or pharynx, for example, wounds and/or blisters, a strong long-acting opioid was administered directly.

If breakthrough pain occurred, short-acting morphine was prescribed.

In case of poor response after optimization with opioids and if the pain was evaluated as neuropathic, pregabalin was prescribed

Local anesthetics such as oral lidocaine solution was prescribed against pain in the oral mucosa. 


\section{Appendix II}

Items of the Barriers Questionnaire II and corresponding education area.

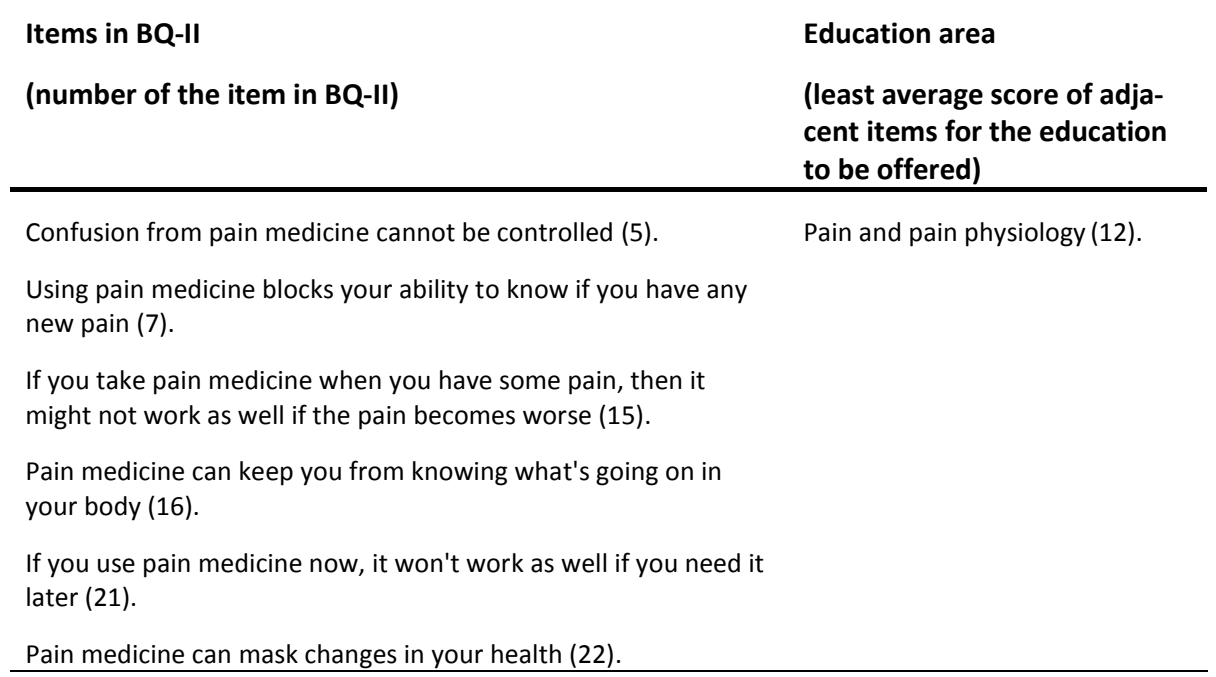

When you use pain medicine, your body becomes used to its ef- Pain medication (14). fects and soon it won't work anymore (6).

Using pain medicine blocks your ability to know if you have any new pain (7).

Pain medicine makes you say or do embarrassing things (14).

If you take pain medicine when you have some pain, then it might not work as well if the pain becomes worse (15).

Pain medicine can keep you from knowing what's going on in your body (16).

If you use pain medicine now, it won't work as well if you need it later (21).

Pain medicine can mask changes in your health (22).

Drowsiness from pain medicine is difficult to control (3).

Nausea from pain medicine can not be relieved (10).

Using pain medicine can harm your immune system (13).

Pain medicine makes you say or do embarrassing things (14).

Constipation from pain medicine cannot be relieved (17).

Pain medicine can hurt your immune system (19).

It is easier to put up with pain than with the side effects that come from pain medicine (20).
Side effects of medications and prevention of side effects (14). 
There is a danger of becoming addicted to pain medicine (2).

Abuse about medications (6).

Many people with cancer get addicted to pain medicine (9).

Pain medicine is very addictive (23).

Cancer pain can be relieved (1).

Pain medicine can effectively control cancer pain (8).

Advice on anxiety (reverse score: items 1, 8, $24(<9))$.

Medicine can relieve cancer pain (24).

Pain medicine weakens the immune system (4).

Advice on anxiety (16).

It is important to be strong by not talking about pain (11).

It is important for the doctor to focus on curing illness and not waste time controlling pain (12).

If doctors have to deal with pain, they won't concentrate on curing the disease (18).

Pain medicine can mask changes in your health (22).

Doctors might find it annoying to be told about pain (25).

Reports of pain could distract a doctor from curing the cancer (26).

If I talk about pain, people will think I'm a complainer (27). 


\section{Appendix III}

\section{Written information on SC measures for the intervention group.}

\section{To maintain flexibility and well-being, you can do the following (1-8)}

\section{Walks or other activity}

It is good to continue with physical activity that you previously used to do. If this is not possible, take daily walks at a comfortable pace, about 20 minutes a day.

\section{Flexibility and head, throat and shoulders}

To maintain head, throat and neck flexibility, you can do the three following exercises 5-10 times a day.

- Rotate your arms in a large circle forward-upward-backward.

- Put your hands on your thighs, inhale and raise your chest toward the ceiling. Breathe out and roll your shoulders forward without leaning forward.

- Pull in your chin so that your neck is extended, nod your head a few times. Then turn the head to the side, roll your head down over your chest; lift up on the other side, repeat. Keep your chin pulled in.

\section{Open mouth wide to prevent stiffness in your jaw}

To prevent tightness and stiffness in your jaw, it is good to open your mouth wide for a maximum of 20 seconds. Do this ten times in the morning and ten times in the evening.

\section{Swallowing and tongue exercises}

If you have a probe inserted to your stomach, it is important that you try to maintain your ability to swallow. Do this by drinking small sips of water often.

\section{Rest during the day}

It is common to be more tired when receiving radiation therapy. You may need to lay down to rest or sleep once or more a day. Try to limit your rest to 20 min each time to avoid disturbing your night sleeping pattern.

\section{Raise the head of your bed}

Raising the head of your bed or using several pillows is recommended as being horizontal often increases pain since radiated tissue can swell.

\section{In case of sleep problems}

In the evening it is good to lay down for the night when you are tired and do not try to stay awake. Try to get up about the same time each day, even if it took time to fall asleep the night before. If you are having trouble falling asleep in the evening and feel tired during the day, rest in bed (as above) but try to avoid falling asleep. Minimise drinking liquids before bedtime; avoid caffeine and alcohol. If you do not fall asleep after 20 minutes, it is better to get up again.

\section{In case of anxiety}

If you feel anxious, you may want to speak to someone you feel comfortable confiding in. This could be a family member, a friend or someone else. Writing down what you experience and feel can help you determine what is causing the anxiety. You are welcome to contact us at the Pain 
Relief Clinic. We are here for you and can also help arrange contact with another person to speak to when needed.

In addition to your prescriptions and advice about pain medications you receive due to mouth and throat pain, try doing some of the following (9-11)

\section{Dry Mouth}

It is important to keep your mouth moist and have water close at hand.

If you sleep with your mouth open and wake up several times a night because of dryness and secretions, have water by your bed so you can easily moisten your mouth and clean away the secretions.

If needed, the saliva substitute recommended by your dentist may be used for dry mouth.

Recipe for saliva substitute:

1 litre of water

1 teaspoon of table salt

1 teaspoon of vegetable oil (rapeseed oil or corn oil)

Boil the water with the salt. Can be stored in the refrigerator up to a week. Mix $1 \mathrm{dl}$ salt solution and 1 teaspoon of oil. Beat with a fork to mix the oil with the salt solution. Rinse your mouth for at least one minute and spit out the solution. This can be repeated every half hour if necessary.

\section{Mouthwash with honey}

Dissolve a teaspoon of honey (not liquid honey) in a cup of lukewarm water. Rinse your mouth for at least one minute and spit out the solution. Alternatively, let a teaspoon of honey melt in your mouth. At most 3-4 times a day

\section{Mouthwash with cream or oil}

Rinse your mouth for one minute with a tablespoon of cream or vegetable oil.

\section{The following relieve mouth and throat pain (12-14)}

\section{Non-prescription mouth rinse}

Aftex Aloclair $囚$ mouth rinse (contains aloe vera) is available at the chemist. Rinse your mouth for at least one minute and spit out the solution. Use 3-4 times a day, or as often as needed.

\section{Cooling}

Sucking on crushed ice or ice cream relieves mouth soreness and pain. Can be done as often as needed.

\section{Mouthwash with morphine}

This treatment is done the first time in consultation with the Pain Relief Clinic. A morphine tablet, $20 \mathrm{mg}$, is dissolved in 1 teaspoon of water +1 tablespoon cream. Rinse your mouth for at least one minute and spit out the solution. 


\section{Appendix IV}

Self-care measurements recommended at weekly follow-up when NRS score $\geq 3$ on any item ( $\geq$ 1 on the item pain interferences on general activities) of the text message scores.

\begin{tabular}{ll}
\hline $\begin{array}{l}\text { Items on pain three times weekly by text } \\
\text { message }\end{array}$ & $\begin{array}{l}\text { Self-care instruction } \\
\text { recommended* }\end{array}$ \\
\hline $\begin{array}{l}\text { Pain intensity } \\
\text { When talking, eating, and drinking } \\
\text { When not talking, eating, or drinking }\end{array}$ & $3-4,9-11$ \\
& \\
Pain interference & \\
General activities & $1-4$ \\
Mood & $1-2,8$ \\
Relations with other people & 8 \\
Sleep & $5-7$ \\
Enjoyment of life & $1-2,8$ \\
\hline
\end{tabular}

* Number of self-care refers to numbers in Appendix III. 


\section{Appendix V}

Mean scores (SD) and regression coefficients for primary outcomes by text message answers.

\begin{tabular}{|c|c|c|c|c|}
\hline Variables & $\begin{array}{l}\text { Intervention group } \\
(n=34)\end{array}$ & $\begin{array}{l}\text { Control group } \\
(n=30)\end{array}$ & $\begin{array}{l}\text { Regression coeffi- } \\
\text { cients } \\
(95 \% \mathrm{Cl}) \mathrm{B}\end{array}$ & p-value \\
\hline \multicolumn{5}{|c|}{ Pain intensity Q1 $(0-10)(M, S D)$} \\
\hline \multicolumn{5}{|c|}{ Overall effect: $p=0.50$} \\
\hline 1 week (baseline) & $1.94(2.09)$ & $1.80(2.22)$ & - & - \\
\hline 2 weeks & $2.11(1.46)$ & $2.62(2.31)$ & $0.82(0.36$ to 1.28$)$ & 0.001 \\
\hline 3 weeks & $2.90(1.72)$ & $3.63(2.59)$ & 1.83 (1.11 to 2.56$)$ & 0.000 \\
\hline 4 weeks & $3.00(1.77)$ & $3.74(2.71)$ & 1.99 (1.13 to 2.84$)$ & 0.000 \\
\hline 5 weeks & $3.13(1.62)$ & $3.72(2.80)$ & 1.94 (0.98 to 2.89$)$ & 0.000 \\
\hline 6 weeks & $3.28(1.90)$ & $3.73(2.76)$ & $1.90(0.95$ to 2.84$)$ & 0.000 \\
\hline 7 weeks & $2.70(1.95)$ & $3.34(2.37)$ & 1.38 (0.35 to 2.40$)$ & 0.009 \\
\hline 8 weeks & $2.21(1.76)$ & $2.64(2.61)$ & $0.71(-0.48$ to 1.90$)$ & 0.240 \\
\hline 9 weeks & $2.04(1.68)$ & $2.04(2.26)$ & $0.34(-0.74$ to 1.44$)$ & 0.530 \\
\hline 10 weeks & $2.23(1.86)$ & $1.83(2.03)$ & $\begin{array}{l}-0.19(-1.32 \text { to } \\
0.95)\end{array}$ & 0.743 \\
\hline \multicolumn{5}{|c|}{ Pain intensity Q2 $(0-10)(M, S D)$} \\
\hline \multicolumn{5}{|c|}{ Overall effect: $p=0.36$} \\
\hline 1 week (baseline) & $1.30(1.45)$ & $1.33(1.93)$ & - & - \\
\hline 2 weeks & $1.52(1.26)$ & $1.93(1.94)$ & $0.60(0.25$ to 0.95$)$ & 0.001 \\
\hline 3 weeks & $2.17(1.41)$ & $2.95(2.49)$ & 1.62 (1.06 to 2.19$)$ & 0.000 \\
\hline 4 weeks & $2.32(1.56)$ & $3.12(2.51)$ & 1.87 (1.18 to 2.57 ) & 0.000 \\
\hline 5 weeks & $2.39(1.56)$ & $3.02(2.56)$ & $1.77(1.02$ to 2.52$)$ & 0.000 \\
\hline 6 weeks & $2.61(1.74)$ & $2.96(2.63)$ & 1.71 (0.93 to 2.48 ) & 0.000 \\
\hline 7 weeks & $2.14(1.81)$ & $2.67(2.33)$ & 1.25 (0.36 to 2.14$)$ & 0.006 \\
\hline 8 weeks & $1.88(1.65)$ & $2.10(2.28)$ & 0.84 (-0.13 to 1.80$)$ & 0.090 \\
\hline 9 weeks & $1.62(1.52)$ & $1.57(1.98)$ & $0.44(-0.46$ to 1.35$)$ & 0.338 \\
\hline 10 weeks & $1.74(1.54)$ & $1.46(1.67)$ & $\begin{array}{l}-0.008(-0.95 \text { to } \\
0.93)\end{array}$ & 0.987 \\
\hline \multicolumn{5}{|c|}{$\begin{array}{l}\text { Pain interference } Q 1(0-10) \\
(M, S D)\end{array}$} \\
\hline \multicolumn{5}{|c|}{ Overall effect: $p=0.83$} \\
\hline 1 week (baseline) & $1.29(1.41)$ & $1.21(1.98)$ & - & \\
\hline 2 weeks & $1.56(1.44)$ & $1.64(2.03)$ & $0.43(-0.19$ to 1.05$)$ & 0.176 \\
\hline 3 weeks & $2.10(1.78)$ & $2.26(2.56)$ & 1.05 (0.24 to 1.86$)$ & 0.011 \\
\hline 4 weeks & $2.44(1.83)$ & 2.57 (2.99) & 1.42 (0.43 to 2.41$)$ & 0.005 \\
\hline 5 weeks & $2.60(2.05)$ & $2.87(3.05)$ & $1.73(0.92$ to 2.53$)$ & 0.000 \\
\hline 6 weeks & $2.67(2.12)$ & $2.52(2.61)$ & $1.34(0.50$ to 2.18$)$ & 0.002 \\
\hline 7 weeks & $2.70(2.46)$ & $2.55(2.55)$ & 1.26 (0.39 to 2.12$)$ & 0.004 \\
\hline 8 weeks & $2.28(2.19)$ & $2.07(2.38)$ & $0.93(-0.01$ to 1.87$)$ & 0.052 \\
\hline 9 weeks & $2.13(2.14)$ & $1.51(2.13)$ & $0.48(-0.42$ to 1.38$)$ & 0.297 \\
\hline 10 weeks & $2.19(2.06)$ & $1.27(1.78)$ & $0.03(-0.79$ to 0.84$)$ & 0.948 \\
\hline \multicolumn{5}{|c|}{ Pain interference Q2 (0-10) } \\
\hline \multicolumn{5}{|l|}{$(\mathrm{M}, \mathrm{SD})$} \\
\hline \multicolumn{5}{|c|}{ Overall effect: $p=0.73$} \\
\hline 1 week (baseline) & $1.28(1.31)$ & $1.29(1.82)$ & - & - \\
\hline 2 weeks & $1.53(1.44)$ & $1.72(2.08)$ & $0.43(0.16$ to 0.70$)$ & 0.002 \\
\hline 3 weeks & $2.04(1.73)$ & $2.31(2.36)$ & $1.02(0.56$ to 1.48$)$ & 0.000 \\
\hline 4 weeks & $2.09(1.84)$ & $2.26(2.59)$ & 1.09 (.050 to1.68) & 0.000 \\
\hline 5 weeks & $2.17(1.89)$ & $2.38(2.59)$ & $1.19(0.46$ to 1.91$)$ & 0.001 \\
\hline
\end{tabular}




\begin{tabular}{|c|c|c|c|c|}
\hline 6 weeks & $2.26(1.95)$ & $2.30(2.37)$ & $1.11(0.50$ to 1.72$)$ & 0.000 \\
\hline 7 weeks & $2.23(2.08)$ & $2.17(2.34)$ & $0.95(0.34$ to 1.56$)$ & 0.002 \\
\hline 8 weeks & $2.00(1.96)$ & $1.82(2.15)$ & $0.68(-0.01$ to 1.38$)$ & 0.054 \\
\hline 9 weeks & $1.72(1.91)$ & $1.38(2.03)$ & $0.43(-0.32$ to 1.18$)$ & 0.259 \\
\hline 10 weeks & $1.67(1.57)$ & $1.20(1.86)$ & $0.29(-0.36$ to 0.94$)$ & 0.386 \\
\hline \multicolumn{5}{|c|}{$\begin{array}{l}\text { Pain interference Q3 (0-10) } \\
(\mathrm{M}, \mathrm{SD})\end{array}$} \\
\hline \multicolumn{5}{|c|}{ Overall effect: $p=0.58$} \\
\hline 1 week (baseline) & $1.03(1.21)$ & $1.00(1.76)$ & - & - \\
\hline 2 weeks & $1.23(1.39)$ & $1.43(2.14)$ & $0.44(0.90$ to 0.80$)$ & 0.014 \\
\hline 3 weeks & $1.81(1.65)$ & $2.11(2.37)$ & 1.12 (0.59 to 1.66$)$ & 0.000 \\
\hline 4 weeks & $1.86(1.67)$ & $2.36(2.70)$ & 1.50 (0.75 to 2.24$)$ & 0.000 \\
\hline 5 weeks & $2.10(1.91)$ & $2.38(2.59)$ & $1.50(0.75$ to 2.26$)$ & 0.000 \\
\hline 6 weeks & $2.23(1.98)$ & $2.07(2.27)$ & $1.24(0.59$ to 1.88$)$ & 0.000 \\
\hline 7 weeks & $2.16(2.21)$ & $2.03(2.24)$ & 1.18 (0.60 to 1.77$)$ & 0.000 \\
\hline 8 weeks & $1.74(1.79)$ & $1.77(2.37)$ & $0.95(0.21$ to 1.69$)$ & 0.012 \\
\hline 9 weeks & $1.55(1.64)$ & $1.42(2.12)$ & $0.87(0.03$ to 1.71$)$ & 0.043 \\
\hline 10 weeks & $1.54(1.52)$ & $1.16(1.83)$ & $0.74(-0.02$ to 1.49$)$ & 0.056 \\
\hline \multicolumn{5}{|c|}{ Pain interference Q4 (0-10) } \\
\hline \multicolumn{5}{|l|}{$(\mathrm{M}, \mathrm{SD})$} \\
\hline \multicolumn{5}{|c|}{ Overall effect: $p=0.25$} \\
\hline 1 week (baseline) & $1.70(2.09)$ & $1.17(1.73)$ & - & - \\
\hline 2 weeks & $1.84(1.96)$ & $1.88(2.28)$ & $0.71(0.24$ to 1.18$)$ & 0.003 \\
\hline 3 weeks & $2.00(1.97)$ & $2.18(2.47)$ & $1.01(0.47$ to 1.55$)$ & 0.000 \\
\hline 4 weeks & $1.92(2.00)$ & $2.19(2.66)$ & 1.07 (0.52 to 1.62$)$ & 0.000 \\
\hline 5 weeks & $1.72(1.86)$ & $2.44(2.62)$ & $1.31(0.68$ to 1.94$)$ & 0.000 \\
\hline 6 weeks & $1.46(1.59)$ & $2.49(2.68)$ & $1.44(0.81$ to 2.06$)$ & 0.000 \\
\hline 7 weeks & $1.46(1.56)$ & $2.01(2.24)$ & $0.81(0.36$ to 1.26$)$ & 0.000 \\
\hline 8 weeks & $1.08(1.19)$ & $1.70(2.05)$ & $0.81(0.23$ to 1.40$)$ & 0.007 \\
\hline 9 weeks & $1.12(1.23)$ & $1.55(2.24)$ & $0.84(0.12$ to 1.55$)$ & 0.022 \\
\hline 10 weeks & $1.07(1.29)$ & $1.22(1.03)$ & $0.69(-0.08$ to 1.46$)$ & 0.078 \\
\hline \multicolumn{5}{|c|}{ Pain interference Q5 (0-10) } \\
\hline \multicolumn{5}{|c|}{$(\mathrm{M}, \mathrm{SD})$} \\
\hline \multicolumn{5}{|c|}{ Overall effect: $p=0.52$} \\
\hline 1 week (baseline) & $1.30(1.72)$ & $1.24(1.96)$ & & \\
\hline 2 weeks & 1.39 (1.79) & $1.64(2.36)$ & $0.40(0.07$ to 0.73$)$ & 0.019 \\
\hline 3 weeks & $1.72(1.93)$ & $2.17(2.62)$ & $0.92(0.46$ to 1.39$)$ & 0.000 \\
\hline 4 weeks & $1.78(1.95)$ & $2.04(2.53)$ & $0.95(0.40$ to 1.51 & 0.001 \\
\hline 5 weeks & $1.87(2.00)$ & $2.31(2.67)$ & $1.20(0.43$ to 1.97$)$ & 0.002 \\
\hline 6 weeks & $1.85(1.83)$ & $1.92(2.41)$ & $0.85(0.27$ to 1.44$)$ & 0.004 \\
\hline 7 weeks & $1.93(2.06)$ & $1.73(2.15)$ & $0.60(0.09$ to 1.11$)$ & 0.022 \\
\hline 8 weeks & $1.74(1.81)$ & $1.60(2.19)$ & $0.62(-0.09$ to 1.33$)$ & 0.087 \\
\hline 9 weeks & $1.51(1.83)$ & $1.36(1.03)$ & $0.50(-0.19$ to 1.19$)$ & 0.158 \\
\hline 10 weeks & $1.36(1.51)$ & $1.16(1.72)$ & $0.49(-0.14$ to 1.12$)$ & 0.128 \\
\hline
\end{tabular}

Notes: $\mathrm{M}=$ mean, $\mathrm{SD}=$ Standard deviation. Values presented are model estimates of generalized estimating equations models with a random intercept and adjusted for baseline. Regression coefficients can be interpreted as the time effect for the groups at a certain follow-up moment compared with baseline. Significant differences are bold. The estimated impact (i.e. overall effect) of treatment reflects the "combined" within- and between-subjects effects. 


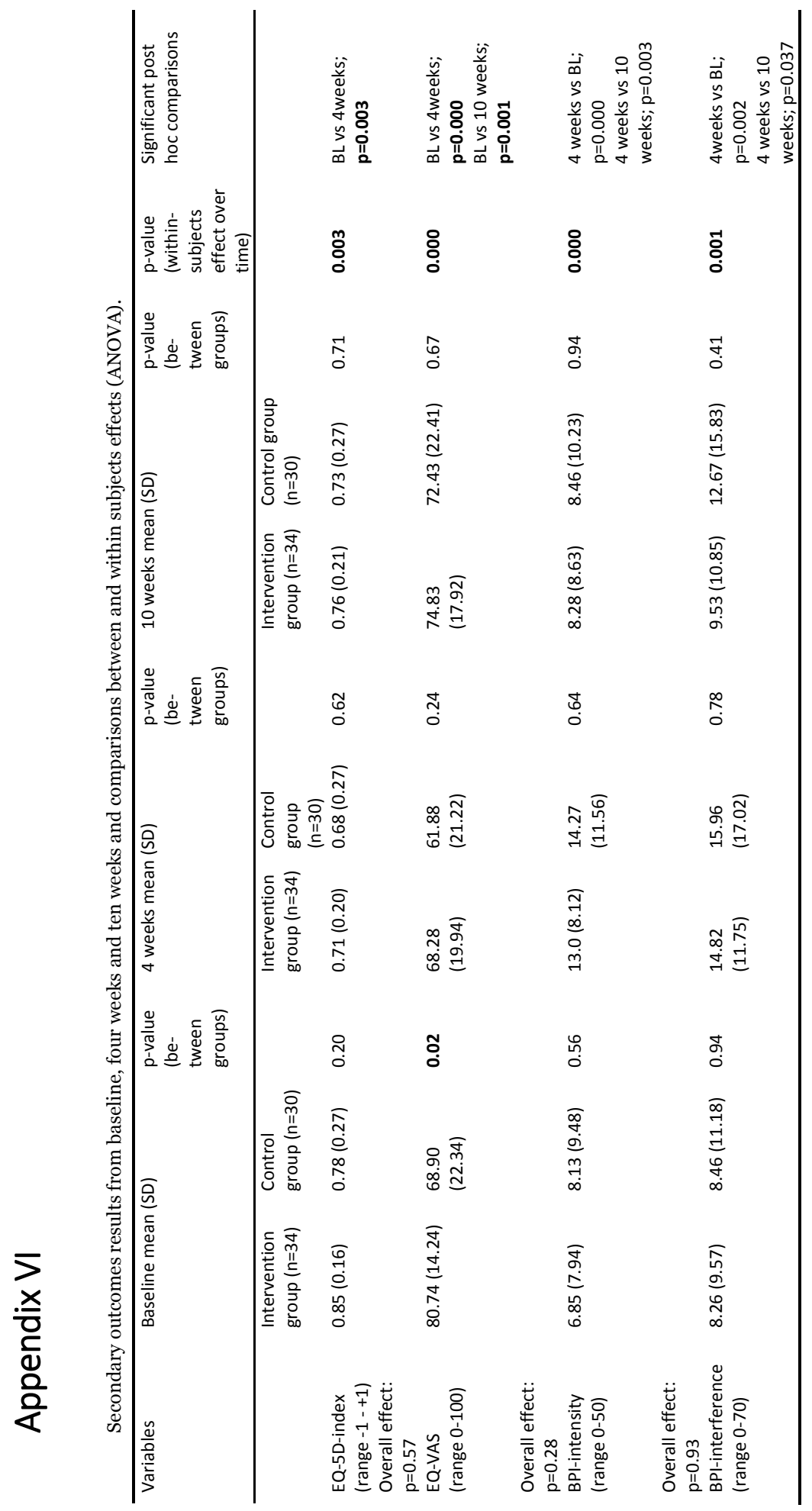




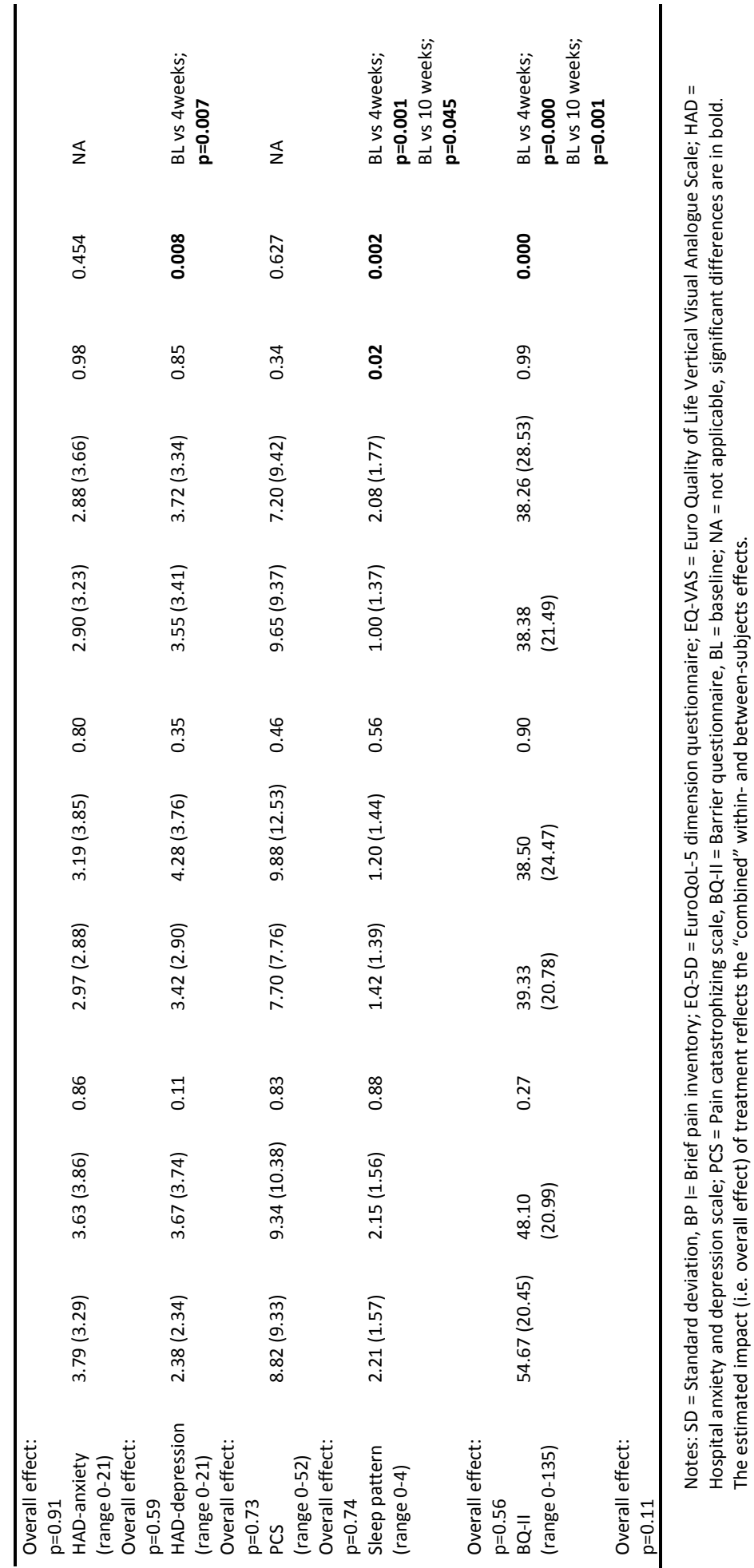


Part II

Appended Papers I-IV 


\section{Papers}

The papers associated with this thesis have been removed for copyright reasons. For more details about these see:

http://urn.kb.se/resolve?urn=urn:nbn:se:liu:diva-147288 